University of Louisville

ThinkIR: The University of Louisville's Institutional Repository

Electronic Theses and Dissertations

8-2013

\title{
Mast cell-T cell interactions in inflammatory chemokine mediated immune surveillance of intestinal cancer.
}

Sobha R. Bodduluri

University of Louisville

Follow this and additional works at: https://ir.library.louisville.edu/etd

\section{Recommended Citation}

Bodduluri, Sobha R., "Mast cell-T cell interactions in inflammatory chemokine mediated immune surveillance of intestinal cancer." (2013). Electronic Theses and Dissertations. Paper 120.

https://doi.org/10.18297/etd/120

This Doctoral Dissertation is brought to you for free and open access by ThinkIR: The University of Louisville's Institutional Repository. It has been accepted for inclusion in Electronic Theses and Dissertations by an authorized administrator of ThinkIR: The University of Louisville's Institutional Repository. This title appears here courtesy of the author, who has retained all other copyrights. For more information, please contact thinkir@louisville.edu. 


\title{
MAST CELL - T CELL INTERACTIONS IN
}

\section{INFLAMMATORY CHEMOKINE MEDIATED IMMUNE SURVEILLANCE OF INTESTINAL CANCER}

\author{
By \\ Sobha R. Bodduluri \\ M.S. University of Louisville, 2011

\begin{abstract}
A Dissertation in Partial Fulfilment of the Requirements

for the Degree of

Doctor of Philosophy

James G. Brown Cancer Center

Department of Microbiology and Immunology

University of Louisville

Louisville, KY 40202
\end{abstract} \\ Submitted to the Faculty of the School of Medicine, University of Louisville
}

August 2013 
Copyright 2013 by Sobha R. Bodduluri

All rights reserved. 



\section{MAST CELL - T CELL INTERACTIONS IN INFLAMMATORY CHEMOKINE MEDIATED IMMUNE SURVEILLANCE OF INTESTINAL CANCER}

\section{By}

\section{Sobha R. Bodduluri}

M.S. University of Louisville, 2011

A Dissertation Approved on

July 11,2013

By the following Dissertation Committee

Venkatakrishna Rao Jala, Ph.D., Assistant Professor, Dept. of Microbiology and Immunology

Thomas C. Mitchell, Ph.D., Professor, Dept. of Microbiology and Immunology

Michele M. Kosiewicz, Ph.D., Associate Professor, Dept. of Microbiology and Immunology

Esma Yolcu, Ph.D., Assistant Professor, Dept. of Microbiology and Immunology

Jun Yan, MD, Ph.D., Professor, Dept. of Medicine 


\title{
DEDICATION
}

\author{
To \\ My Father \\ Shri S.R.K. Rao \\ \& \\ Mother \\ Smt. S.S. Chandrika
}




\section{ACKNOWLEDGEMENTS}

I thank my mentor Dr. Venkatakrishna Rao Jala for laying the ground for this project by noticing mast cells in microarray analysis. I thank him not only for his valuable research skills but willingness and patience in sharing his diverse scientific knowledge and technical expertise. Without his unconditional help with various instruments, at the bench, preparation of figures, this dissertation would not be in its current form. It has been great pleasure working with him from start to the end of this dissertation. I sincerely wish him many important breakthrough discoveries and great future in biomedical research.

I would like to thank my committee members Dr. Michele M. Kosiewicz, Dr. Thomas C. Mitchell, Dr. Esma Yolcu and Dr. Jun Yan for their valuable input and suggestions throughout these five years. Their collective knowledge, guidance and setting the direction for the project are greatly appreciated. I would also like to thank them for their constant encouragement and willingness to help in making this a positive experience. I am grateful to Microbiology and Immunology faculty for giving me this opportunity by selecting me and providing required training with strong curriculum and brilliant teaching. Excellent core facilities and laboratory support provided by The James Graham Brown Cancer Center is greatly appreciated. I would like to thank the Research Resource Center staff for their hard work in taking care of the mouse colony. I am grateful to the members of the Pathology special procedures laboratory and BCC microarray facility for their support. Special appreciation goes to Mr. Robby Jarvis for 
his sincere help in the laboratory, Mrs. Kathy McFarland for her superb administrative help and going the extra mile in getting reagents on time. I thank Mrs. Carolyn Burton for her constant help throughout this program making sure we never fall behind. I would like to thank Dr. Elangovan Krishnan for initiating the work on D6, Dr. Paramahamsa Maturu and Dr. Steven Mathis not only for their contribution into this project but for showing me histological and immunological techniques. I am grateful to Dr. Shuchismita R Satpathy with her excellent background in helping me in immunology techniques and also for her friendship making daily research fun. I thank all the members of the laboratory Ms. Michelle Smith, Dr. Rajesh Sharma, Ms. Zinal Chheda and Ms. Bindu Hegde for their help, discussions and rapport during the course of this work. I would very much want thank my close friend Mrs. Mary Harper for being there to cheer me whenever needed and her unconditional support. I also would like to recall and thank Dr. Robert Dottin at Hunter College for encouraging me to be an independent scientist and providing all the initial training in molecular and cell biology.

I thank my son Neil for being there for me with his love and support when needed and wish him the very best in his future endeavors. I would like to thank my daughter Haritha and her family for the constant joy and support and wish them the very best. I would like to thank my husband Dr. Haribabu Bodduluri for everything; personal and professional help in completing this dissertation research. I respect and value his scientific output and constantly seeking his advice on this project, which ultimately shaped this dissertation. This has been a long time dream and would not have been possible without his support. 


\title{
ABSTRACT \\ MAST CELL - T CELL INTERACTIONS IN INFLAMMATORY CHEMOKINE MEDIATED IMMUNE SURVEILLANCE OF INTESTINAL CANCER
}

\author{
Sobha R. Bodduluri
}

July 11, 2013

Chronic inflammation promotes a variety of cancers but inflammation also plays an important role in immune surveillance of cancer. Chemokine decoy receptor, D6 scavenges large number of inflammatory chemokines without transducing any signals and thus presumably dampens inflammation. Consistent with this notion, the D6 deficient mice displayed enhanced inflammation in variety of disease models. However, our laboratory observed that absence of D6 caused an unexpected decrease in inflammation and reduced tumor burden in the $\mathrm{Apc}^{\mathrm{Min} /+}$ mouse model of intestinal cancer. Intestinal tumors in $\mathrm{D6}^{--} \mathrm{Apc}^{\mathrm{Min} /+}$ mice showed increased mast cell infiltration but their contribution to tumor progression is unknown. Therefore, unravelling the cellular and molecular mechanisms of mast cell mediated regulation of intestinal tumor development is the central theme of this dissertation.

Studies described in three specific aims utilize a combination of genetic, molecular and immunologic approaches to establish the importance of mast cells in the D6 ${ }^{-/}$ $\mathrm{Apc}^{\mathrm{Min} /+}$ model. Chapter III describes generation and characterization of the mast 
cell deficient $\mathrm{D6}^{-/-} \mathrm{SA}^{-/-} \mathrm{Apc}^{\mathrm{Min} /+}$ mice. The results showed that the absence of mast cells led to decreased survival of these mice due to rapid progression of the intestinal adenomas. However, mast cells did not have a significant impact on the rate of tumor initiation in this model. In Chapter IV, we established cultures of bone marrow derived mast cells (BMMCs) from WT and D6 ${ }^{-/-}$mice. Analysis of total RNA from these cells by microarrays, real-time PCR showed that chemokine receptors, CCR2 and CCR5 are highly upregulated in D6-/- BMMCs compared to WT cells. The enhanced mRNA expression also correlated well with the enhanced protein and function of CCR2 and CCR5 in D6-/- BMMCs. Further studies will be required to identify the relevance of CCR2 and CCR5 to enhanced mast cell migration into $\mathrm{D6}^{-1-} \mathrm{Apc} \mathrm{Min}^{\mathrm{M}+}$ tumors.

In Chapter V, immunofluorescence studies on the extent of mast cell and $\mathrm{CD}^{+} \mathrm{T}$-cell infiltration into intestinal adenomas of $\mathrm{Apc}^{\mathrm{Min} /+}, \mathrm{D6}^{-1-} \mathrm{Apc}^{\mathrm{Min} /+}$ and $\mathrm{D6} 6^{-/-}$ $\mathrm{SA}^{--} \mathrm{Apc}^{\mathrm{Min} /+}$ showed that cytotoxic T-cell infiltration is dependent on mast cell presence in the tumors. In contrast, analysis of $\mathrm{D6}^{-/-} \mathrm{Rag}^{-{ }^{--} \mathrm{Apc}} \mathrm{Cin} /+^{-+}$tumors showed T-cell independent mast cell homing into these tumors. Further studies with cultured mast cells and $\mathrm{CD} 8^{+} \mathrm{T}$-cells showed that $\mathrm{D} 6^{-1-}$ mast cells are capable of efficient antigen presentation to induce proliferation and activation of the cytotoxic potential of T-cells. The data suggests that mast cells act upstream of T-cells in mediating effective immune surveillance of intestinal cancers. These results would have important implications in designing immunotherapeutic approaches involving mast cell mediated anti-tumor immunity. 


\section{TABLE OF CONTENTS}

PAGE

DEDICATION.

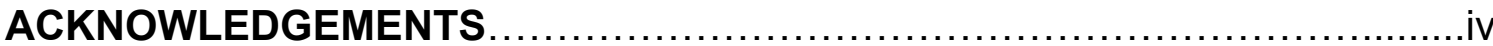

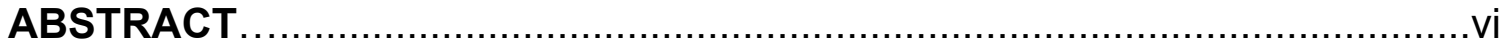

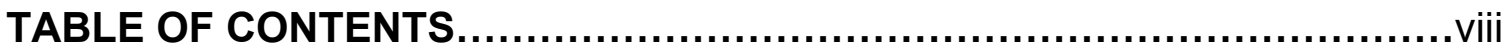

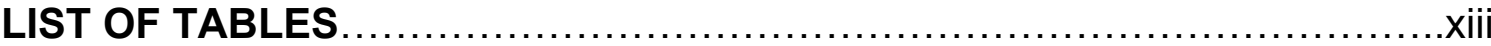

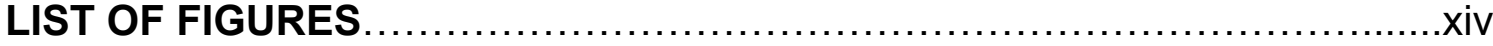

\section{CHAPTER I}

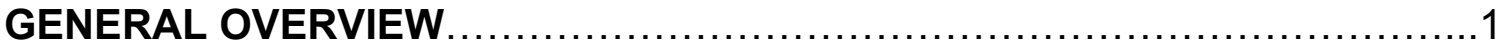

\section{BACKGROUND}

Inflammation and Cancer........................................................

Chemokines signaling and decoy receptors..............................

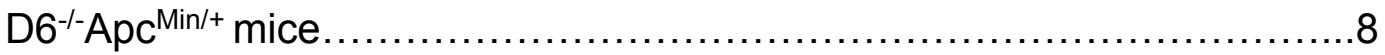

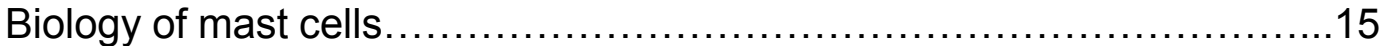


Role of Mast cells in cancer

Pro tumorigenic role of mast cells in human cancer ......................17

Anti-tumor role of mast cells in human cancers..........................18

Role of mast cells in mouse tumor models ...............................22

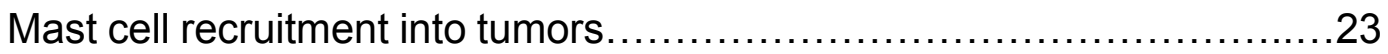

Possible mechanisms for anti-tumor role of mast cells ....................25

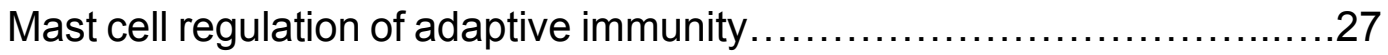

\section{CHAPTER II}

\section{MATERIALS AND METHODS}

Mice

Genotyping .29

Breeding scheme to generate $\mathrm{D6}^{-/-} \mathrm{SA}^{-/-} \mathrm{Apc}^{\mathrm{Min} /+}$ 31

Blood collection for hematocrits and serum. 31

Survival of mice 31

Enumeration of Polyps. 32

Frozen samples for immunohistochemistry (IHC) analysis. 33

Fixing tissues for immunohisotchemistry (IHC) analysis 33 
Bone marrow-derived mast Cell (BMMC) culture.

Chemotaxis.

Calcium flux.

34

Western blot analysis of MCPT1 35

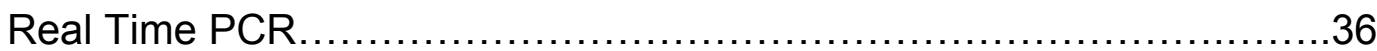

Microarray. .37

Purification of $\mathrm{CD} 8^{+} \mathrm{T}$ Cells. 38

BMMCs and T-cell co-cultures.

Flow Cytometry. 39

Intracellular IFN- $y$ staining.

Purification of immune cells. .40

Immunofluorescence .40

Statistical analysis 41

\section{CHAPTER III}

\section{MAST CELLS ARE TUMOR PROTECTIVE IN D6 ${ }^{-1-} \mathrm{APC}^{\mathrm{MIN} /+}$ MICE INTRODUCTION.} RESULTS

Generating $\mathrm{D6}^{-1-\mathrm{SA}^{-1-} \mathrm{Apc}} \mathrm{Min} /+^{\mathrm{m}}$ mice. .44 
Decreased survival and increased tumor burden in $\mathrm{D6}^{-/-} \mathrm{SA}^{-/-} \mathrm{Apc}^{\mathrm{Min} /+}$ mice relative to $\mathrm{D6}^{-/-} \mathrm{Apc}^{\mathrm{Min} /+}$ mice.................................44 Increased inflammation in $\mathrm{D}^{-/-\mathrm{SA}^{-/-} \mathrm{Apc}} \mathrm{Min} /+^{+}$compared to $\mathrm{D} 6 \% / \mathrm{SA}^{-/-} \mathrm{Apc} \mathrm{Min}^{++}$tumors 46

DISCUSSION .54

\section{CHAPTER IV}

\section{MECHANISMS OF MAST CELL HOMING IN D6--APC ${ }^{\mathrm{MIN} /+}$ MICE}

INTRODUCTION.

\section{RESULTS}

Phenotypic characterization of bone marrow derived mast cells

(BMMCs)

Microarray analysis of BMMCs from wild type (WT) and D6--

mice

Increased expression of CCR2 and CCR5 in D6 ${ }^{-/-}$BMMCs............60

Increased migration of D6 ${ }^{--}$BMMCs towards CCL2 and CCL5 ........61

Functional CCR2 and CCR5 receptors on D6-/- BMMCs...............61

Increased CCR2 and CCR5 expression in D6 ${ }^{-/}$mice is limited to mast cells

Developmental changes in CCR2 and CCR5 expression in D6-BMMCs.

Adoptive transfer of $\mathrm{D6}^{-/-}$mast cells into $\mathrm{D6}^{-/-} \mathrm{SA}^{-/-} \mathrm{Apc}^{\mathrm{Min} /+}$ mice 


\section{CHAPTER V}

\section{MAST CELL MEDIATED T-CELL HOMING AND ACTIVATION REGULATE TUMORIGENESIS IN D6 -1-APC $^{\mathrm{MIN} /+}$ MICE}

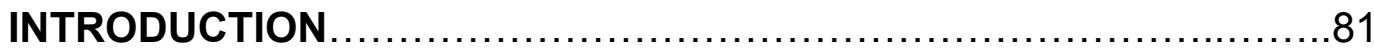

RESULTS

Increased mast cell infiltration into $\mathrm{D6}^{-/-} \mathrm{Apc}^{\mathrm{Min} /+}$ tumors................83

Mast cell mediated infiltration of $\mathrm{CD}^{+} \mathrm{T}$ cells into tumors..............83

T-cell independent mast cell recruitment into $\mathrm{D6}^{-/-} \mathrm{Apc}^{\mathrm{Min} /+}$ tumors......84

Uptake and presentation of exogenous peptide antigens by

BMMCs............................................................. 85

Activation of $\mathrm{CD} 8^{+} \mathrm{T}$ cells proliferation by BMMCs...................86

Mast cell mediated cytotoxic potential of $\mathrm{CD} 8^{+} \mathrm{T}$ cells .................86

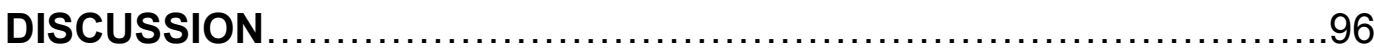

CONCLUSIONS AND SIGNIFICANCE OF THIS STUDY ......................99

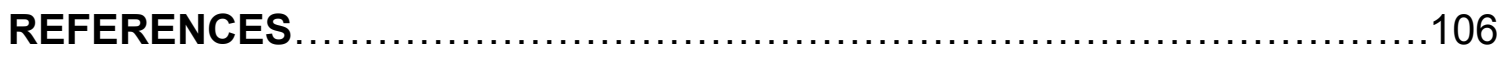

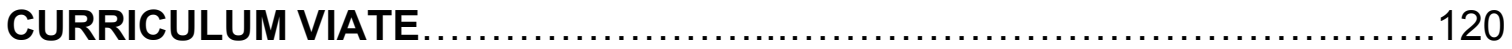




\section{LIST OF TABLES}

\section{TABLE}

PAGE

1. The total number and size of the small intestinal polyps for the indicated

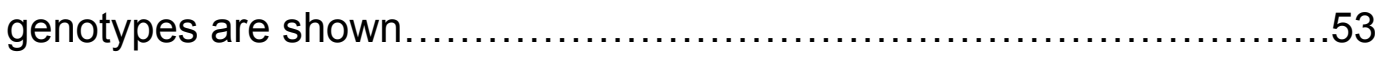




\section{LIST OF FIGURES}

FIGURE

PAGE

1. Leukocyte expression and ligand specificity of chemokine receptors ...........7

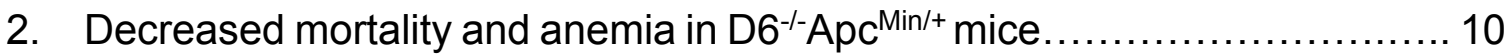

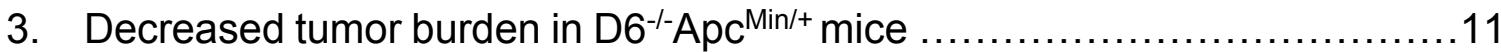

4. Decreased proliferation and increased apoptosis in $\mathrm{D6} 6^{-/-} \mathrm{Apc} \mathrm{Min} /+^{-}$

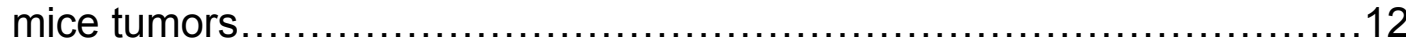

5. Increased expression of Mcpt1 and Mcpt2 in D6 ${ }^{-1-} \mathrm{Apc}^{\mathrm{Min} /+}$ tumors............13

6. Increased chymase activity and MCPT1 protein levels in

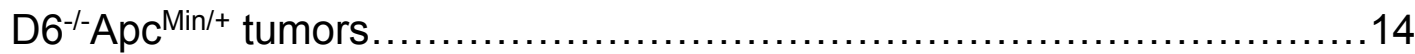

7. Generation of Mast cell deficient mice $K i t^{W-s h / W-s h}\left(\mathrm{SA}^{-/}\right)$in

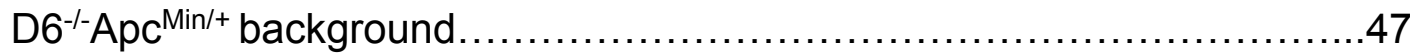

8. Decreased survival of $\mathrm{D6}^{-1-} \mathrm{SA}^{-1-} \mathrm{Apc}^{\mathrm{Min} /+}$ mice relative $\mathrm{D6}^{-1-} \mathrm{Apc} \mathrm{Min} /+^{-}$mice $\ldots \ldots . .48$

9. Small Intestinal polyp development in mast cell deficient Min mice............49

10. The frequency and size of polyps in small intestine .........................50

11. Increased tumor size in mast cell deficient $\mathrm{Apc}^{\mathrm{Min} /+}$ and $\mathrm{D} 6^{-1-} \mathrm{Apc} \mathrm{Min} /+^{+}$mice......51

12. Increased inflammatory markers in the distal intestine tumors of $\mathrm{D6}^{-/-} \mathrm{SA}^{-/-} \mathrm{Apc}^{\mathrm{Min} /+}$ compared to $\mathrm{D6}^{-/-} \mathrm{Apc}^{\mathrm{Min} /+}$

13. Characterization of bone marrow derived mast cells (BMMCs) 
14. Microarray heat map analysis of BMMCs cultured from Wild type (WT) and $\mathrm{D6}^{-{ }^{-}}$mice

15. Expression pattern of chemokines and chemokine receptors in BMMCs....66

16. Increased expression of CCR2 and CCR5 mRNA levels in D6-- BMMCs.....67

17. Expression of chemokine receptors in BMMCs............................68

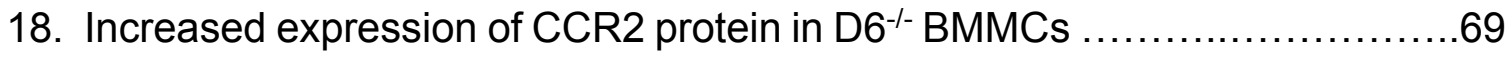

19. Increased migration of D6-/-BMMCs towards CCL2 and CCL5 ...............70

20. Functional CCR2 and CCR5 receptors on D6-/-BMMCs.....................71

21. Functional BMMCs. Dinitrophenyl (DNP) induced calcium release...........72

22. Expression of CCR2 and CCR5 in T and $B$ cells...........................73

23. Expression of CCR2 and CCR5 in bone marrow derived dendritic cells (BMDCs) and bone marrow derived macrophages (BMDMs) ..........74

24. Expression of mRNA levels of CCR2 and CCR5 in BMMCs isolated

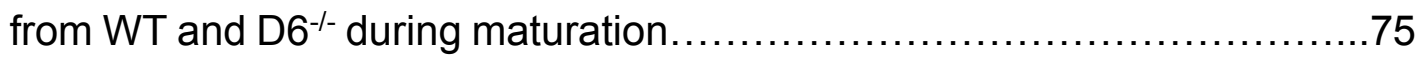

25. Adoptive transfer of BMMCs into $\mathrm{D6}^{-1-\mathrm{SA}^{-1-} \mathrm{Apc}^{\mathrm{Min} /+} \text { mice } \ldots \ldots \ldots \ldots \ldots \ldots \ldots \ldots . . . \ldots \ldots}$

26. Increased mast cell infiltration into $\mathrm{D6}^{-/-} \mathrm{Apc}^{\mathrm{Min} /+}$ tumors $\ldots \ldots \ldots \ldots \ldots \ldots \ldots . \ldots 8$

27. Mast cell mediated enhanced infiltration of $\mathrm{CD}^{+} \mathrm{T}$ cells into tumors.........89

28. T-cell independent Mast cell recruitment into $\mathrm{D6}^{-/-} \mathrm{Apc}^{\mathrm{Min} /+}$ tumors.............90

29. Uptake and presentation of exogenous peptide antigens by BMMCs..........91

30. Induction of $\mathrm{CD}^{+} \mathrm{T}$ cell blasts by peptide pulsed BMMCs..................92

31. Antigen specific activation of $\mathrm{CD} 8^{+} \mathrm{T}$ cells by BMMCs..........................

32. Activation of $\mathrm{CD}^{+} \mathrm{T}$ cells proliferation by BMMCs.........................94

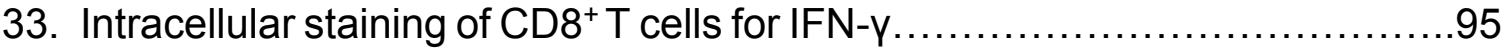


34. A model for reduced tumorigenesis in the $\mathrm{D6}^{-1-} \mathrm{Apc}^{\mathrm{Min} /+}$ mice .................105 


\section{CHAPTER I}

\section{GENERAL OVERVIEW}

The major focus of this research dissertation is to understand the role of inflammatory chemokines in the development and progression of intestinal cancers. This chapter begins with a brief overview of the duality of the immune system functions during carcinogenesis. Many studies have established strong links between chronic inflammation and cancer progression and there are equally compelling arguments about the immune system being an efficient fighter against cancer. What turns a tumor protective inflammation into a promoting response is the major unknown in tumor immunology and an outline of the cellular and molecular mechanisms are emerging. The chapter also provides a brief summary of the chemokines and their role in leukocyte migration with particular emphasis on the chemokine decoy receptor, D6 and the earlier studies from our laboratory that identified the protective phenotype of D6-null mice in the Apc ${ }^{\mathrm{Min} /+}$ background. Since the cellular and molecular mechanisms of mast cell mediated inflammation in cancer is the major focus of this research, the role of mast cells in carcinogenesis is discussed in detail towards the end of the chapter. 


\section{BACKGROUND}

\section{Inflammation and cancer}

The connection between chronic inflammation and cancer has been well established now from clinical studies and animal models, since the initial observation that leucocytes are present in tumor biopsy samples by Virchow in 1863. The reduction in cancer incidence and mortality by non-steroidal antiinflammatory drugs underscores the importance of inflammation in cancer. About $10-15 \%$ of cancers are hereditary and rest of cancers are caused by somatic mutations and environmental factors such as chronic infections, tobacco smoking, particle inhalation and dietary factors [1]. Chronic inflammation triggered by infections, tobacco smoking and obesity increases the risk of developing gastric, colon and pancreatic cancers. Inflammation can also result from activation of oncogenes or inactivation of tumor-suppressor genes at genetic level. Tumors are initiated in this inflammatory environment from mutations produced by reactive oxygen species (ROS) and reactive nitrogen intermediates (RNI) [2]. Dextran sodium sulfate (DSS), the reagent used to induce chronic inflammation causes colonic adenomas through DNA damage also [1]. The hallmark of inflammation is the activation of transcription factors NF-kB, STAT3 and HIF1 $1 \alpha$ in tumors and promoting tumor growth. This will lead to the production of inflammatory cytokines, chemokines and prostaglandins in tumors, which in turn will attract leukocytes. Once tumors are initiated, infiltrating immune cells also activate the same transcription factors and produce more inflammatory mediators generating cancer related environment (Reviewed in Ref [1, 2]). 
In the AOM-DSS induced colon cancer model, inactivation of NF-қB in epithelial cells resulted in reduced tumor number without effecting tumor size, whereas inactivation of NF-қB in myeloid cells reduced tumor size [3]. NF-қB promotes tumor initiation in epithelial cells by suppressing apoptosis and in myeloid cells activating tumor promoting inflammatory mediators COX-2, MMP-9, $\mathrm{KC}$, and MIP-2 production and tumor growth [4]. STAT3 is activated in tumor and immune cells and involved in inhibition of apoptosis and tumorigenesis [5]. Hypoxic conditions in growing tumors will lead to HIF1a activation and production of vascular endothelial growth factor (VEGF). VEGF activates endothelial cell migration and also recruitment of the tumor associated macrophages (TAMS), which in turn promote angiogenesis [6].

Irrespective of the origin of inflammation, the tumor promoting inflammation and tumor inhibiting immunity coexists in tumor environment which consists of cancer cells, surrounding stroma and immune cells [7]. In this environment, if tumor is not rejected the pro tumorigenic conditions persist. Schreiber and colleagues have pioneered the concepts of immune surveillance and proposed that cancer immunoediting is a process by which the immune system controls tumor outgrowth is comprised of three phases: elimination, equilibrium and escape [7-9]. While the mechanisms are still being worked out, studies in implantable models as well as chemical induced spontaneous cancers revealed that effective immune surveillance requires adaptive immune system and cytotoxic T-lymphocytes to keep cancer in an occult state for prolonged periods [10]. Recent cancer exome 
analysis from Schreiber's group revealed a T-cell dependent mechanism of cancer immunoediting [11].

Except for tumor inhibiting Natural Killer (NK) cells, most immune cells can play both tumor promoting and tumor inhibitory functions. Tumor associated macrophages (TAMs) and T cells are most abundant within the tumor. TAMs promote tumor growth and their numbers correlates with poor prognosis [12]. The increase in $\mathrm{CD}^{+}$cytotoxic $\mathrm{T}$ cell and Th1 cell numbers correlate with better prognosis in colon cancer [13]. In this study, colorectal tumors from patients without recurrence had higher $\mathrm{CD}^{+}, \mathrm{CD}^{+}$, memory $\mathrm{T}$ cells supporting the role of T cells in immune surveillance.

\section{Chemokines signaling and decoy receptors}

One of the ways tumor promoting or tumor suppressing inflammation can be controlled is by sequestration of chemokines and cytokines involved in inflammatory cell recruitment in the vicinity of tumor. Over the last two decades about 50 human chemokines have been identified as a family of functionally related small secreted molecules with leukocyte chemoattractant and cytokine-like activities [14-16]. Chemokines exert their biological activities by interacting with a distinct subfamily in the rhodopsin-like seven transmembrane G-Protein coupled receptor (GPCR) super family $[17,18]$. At this time, 18 chemokine receptors have been molecularly defined, 10 for CC chemokines (CCR1 to 10), 6 for CXC chemokines (CXCR1 to 6), and 1 for $\mathrm{C}$ chemokines and CX3C chemokines (XCR1 and CX3CR1, respectively) $[19,20]$. Figure 1 shows the current classification of the known chemokines according to common and official nomenclature [21], their 
receptors, ligand receptor specificity as well as sites of receptor expression. Chemotaxis induced by chemokines plays a crucial role in leukocyte migration, both during resting conditions for control of leukocyte homeostasis (constitutive chemokines) as well as under conditions of infection and/or inflammation induced by proinflammatory mediators (inflammatory chemokines).

The seven transmembrane chemokine receptor D6 binds specifically to inflammatory CC-chemokines without transducing any intracellular signals necessary for chemo attraction [22]. The D6 receptor internalizes its pro inflammatory ligands through a $\beta$-arrestin dependent pathway, targets them to degradation and thus clears inflammatory response [22]. The role of D6 in scavenging inflammatory chemokines is evident from different animal models using D6 null mice. The D6 deficient mice had accumulated higher amount of inflammatory chemokines in skin compared to wild type mice after phorbal ester application [23]. The human D6 receptor is normally expressed on lymphatic endothelial cells within the skin, gut and lung tissues [24]. Later, it was shown by quantitative real time polymerase chain reaction (qPCR ) analysis of human and murine leukocytes, D6 expression was highest in B cells and DCs and lowest in monocytes and T cells [25]. They detected moderate levels of D6 expression in mast cells and neutrophils. They also showed using conditional deletion of GATA1, that D6 expression is GATA1 dependent. In myeloid cells, proinflammatory LPS down regulated the D6 expression and anti-inflammatory TGF- $\beta$ upregulated D6 expression. The D6 expression is negatively correlated with lymph node metastasis in breast cancer patients and positively correlated with their survival 
[26]. The D6 null mice developed by the Sergio Lira's group have been instrumental in working out many biological activities mediated by this receptor. These mice when tested in many models of inflammatory disease models such as chemical-induced cutaneous inflammation [23, 27], ovalbumin or Mycobacteriuminduced lung inflammation [28, 29], lipopolysaccharide (LPS)-induced placental inflammation (abortion model) [30] and methylcholanthrene/phorbol ester (TPA)induced skin cancers [31] showed exaggerated inflammation reinforcing the concept that the natural function of $\mathrm{D} 6$ is to limit inflammation by chemokine scavenging. 


\section{SILENT RECEPTORS CHEMOKINES SIGNALLING RECEPTORS}

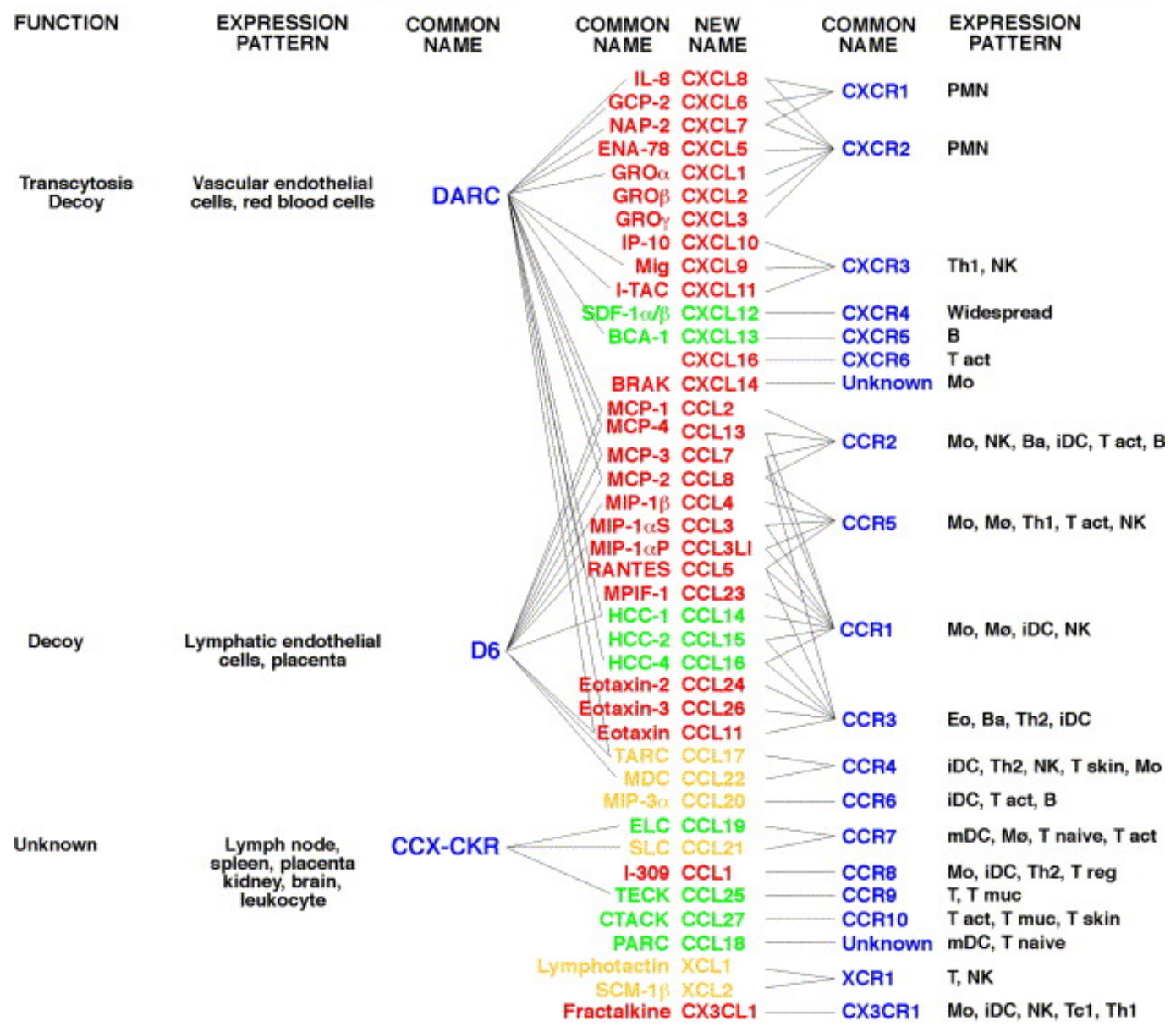

Figure 1: Leukocyte expression and ligand specificity of chemokine receptors.

Candidate decoy receptors and their tissue expression pattern are listed on the left, signaling receptors and their tissue expression pattern on the right. The central columns list chemokines, identified with one old acronym and with the new nomenclature in which the first part of the name identifies the family and $L$ stands for 'ligand' followed by a progressive number (Adopted from [21]). 


\section{D6-/-Apc ${ }^{\mathrm{Min} /+}$ mice}

The $\mathrm{Apc}^{\mathrm{Min} /+}$ mice contains a truncation mutation at codon 850 of the Adenomatous polyposis coli (APC) gene, unable to sequester $\beta$-catenin in cytoplasm leading to accumulation of $\beta$-catenin in nucleus and activation of wnt target genes $[32,33]$. This results in polyp initiation in the small intestine and colon. The $\mathrm{Apc}^{\mathrm{Min} /+}$ mice die at around 150 days of age from anemia and cachexia. In humans, mutations in the Apc gene lead to exclusively colon cancer, whereas the cause of death in $\mathrm{Apc}^{\mathrm{Min} /+}$ mice is related to the severe anemia due to the large number of small intestinal adenomas. The average $\mathrm{D6}^{-/-} \mathrm{Apc}^{\mathrm{Min} /+}$ mice survived for 208 days and showed delayed onset of the disease compared to $\mathrm{Apc}^{\mathrm{Min} /+}$ based on hematocrit values (Fig. 2A). In agreement with the hematocrit data (2B), D6-/$\mathrm{Apc}^{\mathrm{Min} /+}$ mice displayed delayed onset of tumor development in the small intestine and showed significantly reduced tumor burden (Fig. 3). Since it was already known with $\mathrm{Apc}^{\mathrm{Min} /+}$ model, inflammation played a major role in intestinal polyp development, the mRNA from $\mathrm{D6}^{-/-} \mathrm{Apc}^{\mathrm{Min} /+}$ mice tumors were analyzed for proinflammatory markers by qPCR. The CXCL-1, TNF- $\alpha, \mathrm{IL}-1 \beta, \mathrm{COX}-2$ levels decreased in $\mathrm{D6}^{-\mathrm{I}^{-}} \mathrm{Apc} \mathrm{Min}^{\mathrm{M} /+}$ mice compared to $\mathrm{Apc}^{\mathrm{Min} /+} \cdot$ mice. It was further observed that tumors from $\mathrm{D6}^{-/-} \mathrm{Apc} \mathrm{Min} /+^{+}$mice contained less actively proliferating cells and

more apoptotic cells compared to $\mathrm{Apc}^{\mathrm{Min} /+} \cdot$ mice (Fig. 4) We hypothesized the decrease in tumor size in $\mathrm{D6}^{-/-} \mathrm{Apc}^{\mathrm{Min} /+}$ is due to decreased inflammation. However, the puzzle is why the loss of a chemokine scavenging D6 receptor resulted in decreased inflammation? This question was addressed using microarray analysis comparing the gene expression profiles of $\mathrm{D6}^{-/-} \mathrm{Apc}^{\mathrm{Min} /+}$ with $\mathrm{Apc} \mathrm{Min} /+^{\text {intestinal }}$ 
tumors. The microarray data showed that tumors from $\mathrm{D6}^{-1-} \mathrm{Apc} \mathrm{Min}^{\mathrm{H}}$ are highly enriched in mast cell proteases 1, 2 relative to $\mathrm{Apc}^{\mathrm{Min} /+}$ tumors (Fig. 5). This data was confirmed by qPCR analysis as well as histochemical staining (Fig. 6A) and Western blot analysis (Fig. 6B). However, whether this increase in mast cells is directly related to the reduced tumor burden in $\mathrm{D6}^{-/-} \mathrm{Apc}^{\mathrm{Min} /+}$ mice is unknown and therefore is a major focus of our study. 
(A)

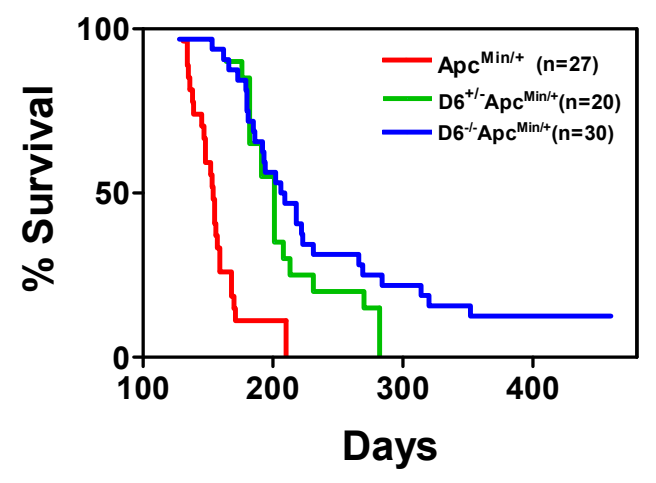

(B)

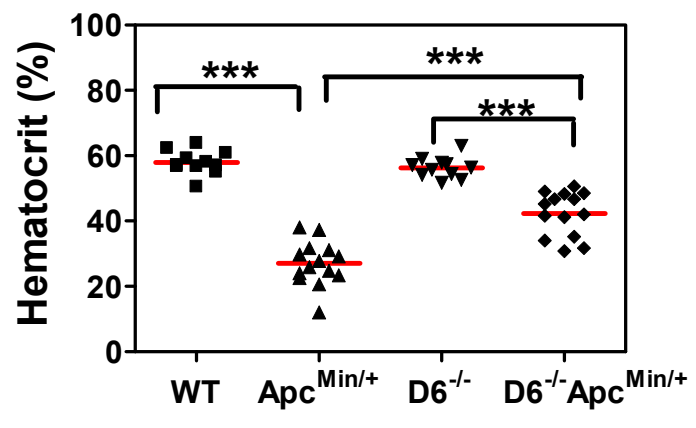

Figure 2: Decreased mortality and anemia in D6--Apc ${ }^{\mathrm{Min} /+}$ mice (A) Kaplan-Meier plot of survival of $D 6$ deficiency on the life expectancy of $\mathrm{Apc}^{\mathrm{Min} /+}$ mice. Survival curves from $\mathrm{Apc}^{\mathrm{Min} /+}(\mathrm{n}=27), \mathrm{D6}^{+/-} \mathrm{Apc}^{\mathrm{Min} /+}(\mathrm{n}=20)$, and D6-/-Apc ${ }^{\mathrm{Min} /+}$ mice $(\mathrm{n}=30)$ are shown. Difference in survival of $\mathrm{Apc}^{\mathrm{Min} /+}$ mice compared to the two other strains was found to be significant by the Mantel-Haenszel/Log-rank test $(\mathrm{P}<0.0001)$. The mean survival for $\mathrm{Apc}^{\mathrm{Min} /+}$ is 154 days, $\mathrm{D6}^{+/-} \mathrm{Apc}^{\mathrm{Min} /+}$ is 201 days, and $\mathrm{D6}^{-{ }^{-}} \mathrm{Apc}^{\mathrm{Min} /+}$ is 208 days. (B) Severe anemia in $\mathrm{Apc}^{\mathrm{Min} / \mathrm{+}}$ mice compared to $\mathrm{D6}^{-/-} \mathrm{Apc}^{\mathrm{Min} /+}$ mice Hematocrit values were determined for the indicated mice at the age of $\sim 110$ days. Statistical analysis was performed using MannWhitney U test. ${ }^{* * *}=p<0.001 ;{ }^{* *}=p<0.01,{ }^{*}=P<0.05$. 
(A)

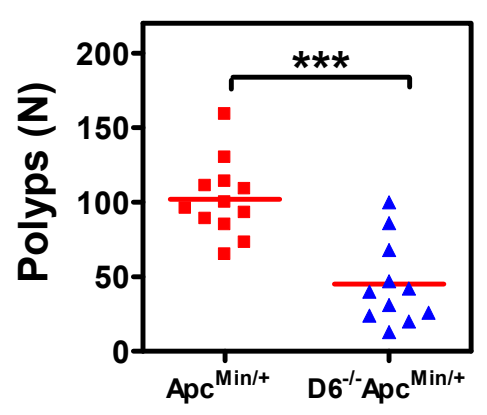

(B)

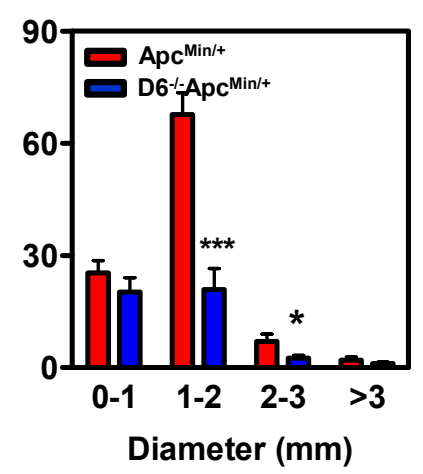

(C)

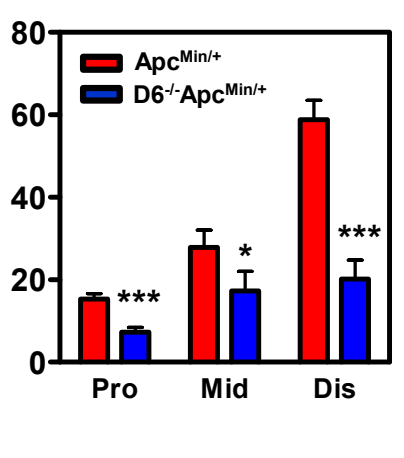

Figure 3: Decreased tumor burden in $\mathrm{D6}^{-1-} \mathrm{Apc} \mathrm{Min} /+^{\text {mice. }}$ (A) The total number of polyps in the small intestine were quantified by stereoscopic microscopy in age-matched (100110 days old) $\mathrm{Apc}^{\mathrm{Min} /+}(\mathrm{n}=12)$ and $\mathrm{D6}^{-/-} \mathrm{Apc}^{\mathrm{Min} /+}(\mathrm{n}=11)$ mice. The frequency $(\mathrm{B})$ and size distribution (Pro: Proximal, Mid: Middle, Dis: Distal regions) (C) of polyps in the small intestine are shown. Statistical analysis was performed using Mann-Whitney $U$ test. ${ }^{* * *}=p<0.001 ;{ }^{* *}=p<0.01,{ }^{*}=P<0.05$. 


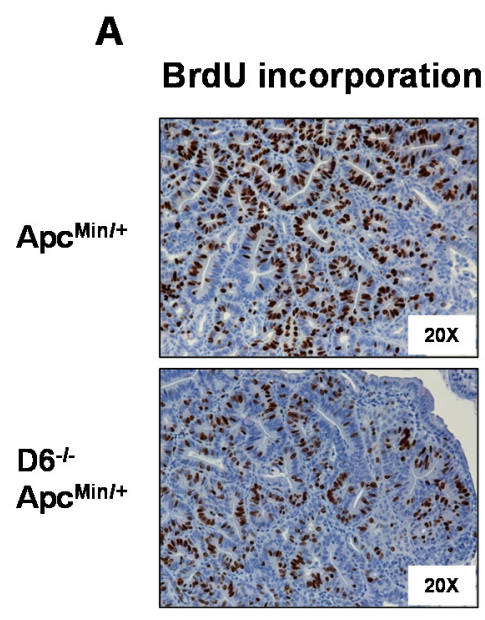

B
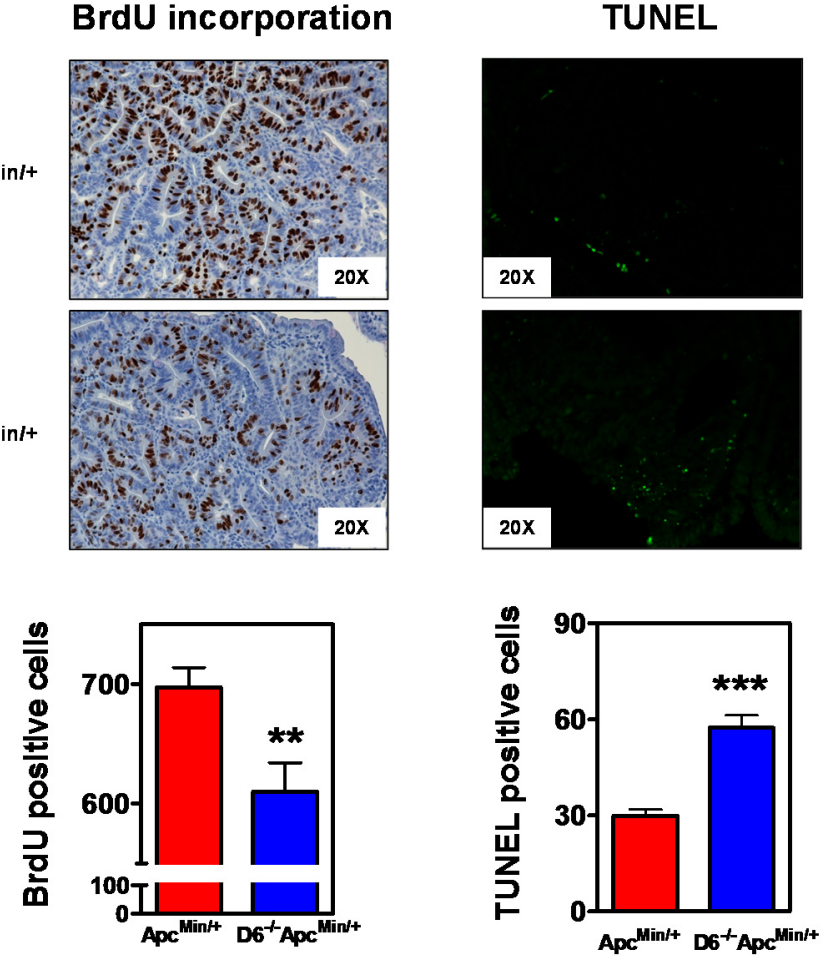

Figure 4: Decreased proliferation and increased apoptosis in $\mathrm{D6}^{-/-} \mathrm{Apc}^{\mathrm{Min} /+}$ mice tumors. (A) 5-Bromodeoxyuridin (5-BrdU) was injected into mice $2 \mathrm{hrs}$ before euthanizing. The cross sections of distal small intestine were stained with anti-BrdU antibody. Immunohistochemical (IHC) analysis of 5-BrdU-incorporation showed a significant decrease in the number of proliferating cells in ileum polyps of $\mathrm{D6}^{-/-} \mathrm{Apc}^{\mathrm{Min} /+}$ mice. BrdU positive cells are counted from $20 \mathrm{X}$ images of 5-6 tumors from 3 mice per genotype. (B) Terminal deoxynucleotidyl Transferase Biotin-dUTP Nick End Labeling (TUNEL) stain performed on distal small intestines of $\mathrm{Apc}^{\mathrm{Min} /+}$ and $\mathrm{D6}^{-{ }^{--} \mathrm{Apc}} \mathrm{Min} /+^{-}$mice. The number of TUNEL positive apoptotic cells are significantly increased in D6 ${ }^{-/-} \mathrm{Apc}^{\mathrm{Min} /+}$ tumors compared to $\mathrm{Apc}^{\mathrm{Min} /+}$ mice. Statistical analysis was performed using Mann-Whitney U test ${ }^{* *}=p<0.01$; $* * *=P<0.001)$. 


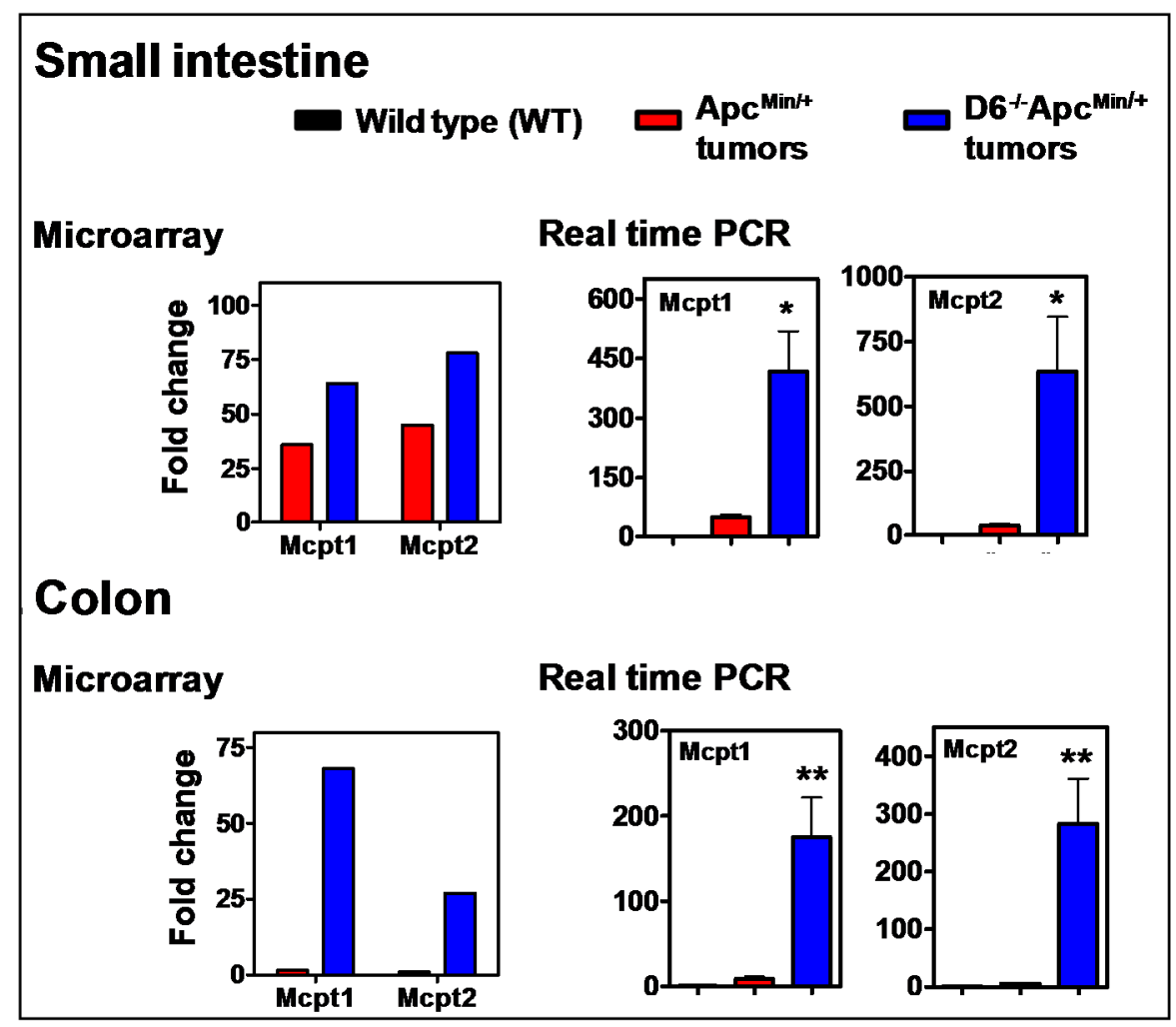

Figure 5: Increased expression of Mcpt1 and Mcpt2 in D6--Apc ${ }^{\mathrm{Min} /+}$ tumors. Small intestine (top panels) and colon (bottom panels) tumors; Left panels Fold change from microarray analysis Mcpt1 and Mcpt2 are shown. These were derived from pair wise comparisons between $\mathrm{D6}^{-1-} \mathrm{Apc}^{\mathrm{Min} /+}, \mathrm{Apc}^{\mathrm{Min} /+}$ mice small intestinal or colon tumors as indicated with wild type normal small intestine or colon tissue levels as baseline. Middle and Right Panels: Validation of microarray data by RT-qPCR. Relative fold change of mRNA levels of Mcpt1 (Middle panel) and Mcpt2 (left panel) RT-qPCR using SyBR method as described in methods. Statistical analysis was performed using unpaired t test $\left({ }^{* *}=p<0.01,{ }^{*}=p<0.05\right)$. 


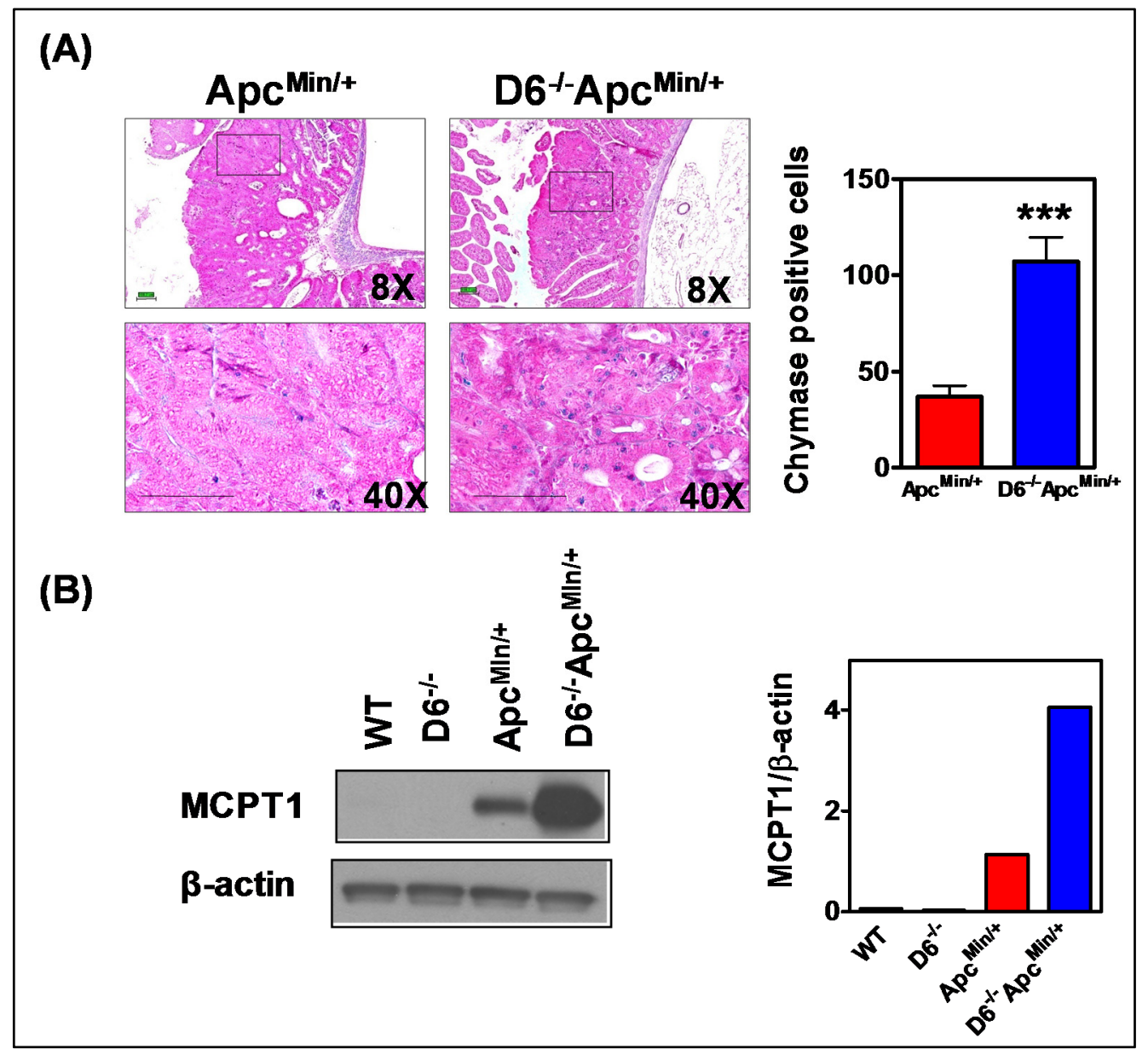

Figure 6: Increased chymase activity and MCPT1 protein levels in in D6 ${ }^{-/-} \mathrm{Apc}^{\mathrm{Min} /+}$ tumors (A) Increased chymase activity in D6 ${ }^{-1-} \mathrm{Apc}^{\mathrm{Min} /+}$ tumors. Histochemical staining for chymase activity was performed using Leder's esterase reaction (blue stain) on distal intestine paraffin-embedded tumor sections of $\mathrm{Apc}^{\mathrm{Min} /+}$ and $\mathrm{D6}^{-\mathrm{I}^{-} \mathrm{Apc}} \mathrm{Min} /+^{\mathrm{H}}$ mice. The scale bar indicates $100 \mu \mathrm{m}$. Chymase positive cells from at least 15 small intestinal tumors (3-4 mice for each genotype) were counted at 40x magnification. (B) Increased Mcpt1 protein in D6--Apc ${ }^{\mathrm{Min} /+}$ tumors. Western blot of the tissue lysates from normal ileums of WT, D6/- and distal small intestinal tumor lysates of $\mathrm{Apc}^{\mathrm{Min} /+}, \mathrm{D6}^{-{ }^{-}-\mathrm{Apc}^{\mathrm{Min} /+}}$ was performed with antimouse Mcpt1 antibody. The same blot was stripped and probed for $\beta$-actin. The quantification of band intensities was determined using Quantity One 4.0.3 software (Biorad) and expressed as a ratio of Mcpt1/ $\beta$-actin. 


\section{Biology of mast cells}

A urochordate contained cells that resembled connective tissue type mast cells. Thus, mast cells evolved long before the evolution of an active adaptive immune system [34]. Mast cells originate in bone marrow from $\mathrm{CD}_{3} 4^{+}$progenitors and enter blood circulation in immature state expressing CD117 and mast cell proteases. Mast cells complete their differentiation in tissue environment expressing lgE receptors. Murine mast cells can be distinguished based on their tissue localization and secretory granule contents. The connective tissue type mast cells (CTMCs) found in the skin, lung, serosa and muscularis propria of intestine express large amounts of heparin and can be distinguished from heparin lacking mucosal mast cells (MCs) found in the mucosa of gut and lung by staining with bereberin or safranin. They interchange their phenotype depending on tissue environment. The stem cell factor (SCF) and its membrane bound receptor CD117 (C-kit) are responsible for mast cell growth and mutations in either of the proteins lead to mast cell deficiency. The mast cell number increases in tissues either by new recruitment of mast cell progenitors or proliferation of local mast cells. The standard procedure of culturing mast cells from bone marrow precursors in vitro is using stem cell factor SCF and IL-3. The mast cell number and phenotype in in vitro

cultures can be influenced by addition of Th2-associated cytokines IL-4, IL-9 and TGF- $\beta 1$ to the medium $[35,36]$.

Mast cells are sentinels of the immune system distributed along the skin, airways and gastrointestinal tract surfaces where pathogens and allergens are encountered continuously. Mast cells in allergic type of a reaction produce 
histamine, leukotrienes, prostaglandins, and TNF- $\alpha$ upon Antigen-IgE activation [37]. They are not only important mediators of allergy, anaphylaxis but also are involved in host defense and are capable of responding to pathogens by rapidly releasing preformed TNF- $\alpha$ rapidly and mediate T-cell recruitment to local lymph

nodes leading to lymph node enlargement [37]. Mast cells can promote T cell migration directly by producing IL-16, CXCL-1, CCL1-5, IL-16, CCL20, CXCL10 and $\mathrm{LTB}_{4}$ [38]. Mast cells activated by IgE cross linking, release leukotrienes including $\mathrm{LTB}_{4}$. $\mathrm{LTB}_{4}$ attracts $\mathrm{BLT1}$ expressing effector $\mathrm{T}$ cells through vascular endothelium [39]. LTB 4 is essential in host defense, arthritis and asthma. The immunomodulatory role of mast cells in no-tumor setting is highlighted in this review [40]. Because the focus of the current research further discussion of mast cell functions in this chapter are limited to cancer.

\section{Role of Mast cells in cancer}

Paul Ehrlich, in his 1893 thesis on the application of aniline dyes described how to stain specifically certain granular cells and called them Mastzellen [41]. He was able to identify mast cells in several tumors using his pioneering histochemical techniques instead of normal histological methods common at that time. Mast cells are recruited to tumors as a host defense mechanism and play a direct or indirect role in reducing the tumor burden. The direct ways of mast cells killing tumor is by releasing cytotoxic granules or engulf and destroy them by phagocytosis. The indirect ways of effecting tumorigenesis is through release of mediators such as heparin, Granzyme B, cathepsin and TNF- $\alpha$ or immune surveillance through cytotoxic T-cells. 
Mast cells play a dual role depending on the stromal environment [42]. They can promote tumorigenesis through secretion of heparin, IL-8 and VEGF mediating vascular growth, growth factors promoting tumor growth and histamine which is immunosuppressive. Mast cells also produce cytokines and proteolytic enzymes that are damaging to tumor cells.

\section{Pro tumorigenic role of mast cells in human cancer}

Since Ehrlich's days there is no dispute in acknowledging the presence of mast cells in tumors, but significance of their presence, good or bad is divided. It is possible whether mast cells play a dual role in tumor progression depends on tumor setting. Mast cells release several factors such as TNFa, TGF, FGF-2, VEGF, PDGF, IL-8, Osteopontin and NGF that are involved in tumor progression and angiogenesis. Mast cell produced cytokines such as IL-1, IL-2 and IFNy can also bring immune response leading to tumor inhibition [42].

The type of mast cells in the tumor can also change the outcome of tumor growth. When breast lesions were double stained for tryptase and chymase, benign tumors have equal number of tryptase and chymase containing cells whereas malignant tumors have three times more tryptase positive cells than chymase positive cells [43]. The tryptase positive cells are more concentrated at the edge and most likely involved in tumor growth.

In hepatocellular carcinoma model, peritumoral infiltration of mast cells are associated with bad prognosis [44]. In this study, 207 patient surgically removed tumor samples were stained with tryptase and the patient survival was followed for 
five years. They found higher number of mast cells in peritumoral region correlated with poor prognosis. Not only mast cells, Foxp3 stained T-regs also increased in these tumors suggesting presence of mast cells combined with T-regs indicated recurrence of the disease.

Bellone et al analyzed mRNA expression and protein levels of SCF and ckit in normal, premalignant adenomas and malignant colon tissues from 126 patients [45]. SCF and c-kit mRNA is expressed in all tissues. C-kit- protein is expressed in $\sim 10 \%$ of adenomas or adenocarcinomas. SCF is expressed in $25 \%$ of adenomas but co expressed in $80 \%$ of adenocarcinomas. The co expression of SCF and C-Kit in malignant tumors indicate there is autocrine loop for SCF expression and negative correlation for this axis in CRC [45].

In a colon cancer study analysis of 325 stage I and III advanced colon cancer patients, Xianrui et al found that high number of tryptase antibody positive cells are associated with poor clinical out come in CRC patients affecting overall survival and also disease free survival [46]. They also noted mast cell infiltration is more in male patients. Mast cells were found to stimulate tumor growth by producing proteases and angiogenesis factors in mouse models of skin [47] and pancreatic cancers [48].

\section{Anti-tumor role of mast cells in human cancers}

In contrast to the few human studies that suggested pro tumor role for mast cells large number of studies clearly outline a protective role for mast cells in variety 
of human cancers including breast, prostate, oral, ovarian, pancreatic, gastric and colon cancers.

Aaaltoma et al. studied 187 women with breast cancer during 1978-1990 for mast cell infiltration into tumor stroma and correlated mast cell number with histological characters and survival [49]. No significant relationship could be drawn with histological features and mast cell density. However, the high mast cell numbers in breast tumor is associated with high survival probability and low mast cell number is associated with low survival probability indicating mast cell density could be used as prognostic factor [49]. Malignant tumors also have reduced histamine content relating with low mast cell number. The CD117 staining of tissue microarrays (TMAs) from 348 invasive breast carcinoma patients in a 20 year follow up study also showed mast cell presence in peritumoral stroma is beneficial and serves as a good independent prognostic indicator [50]. They also studied hormonal status and estrogen and progesterone are positively correlated whereas Her2 is negatively correlated with survival. Macrophage number is negatively correlated with survival and no correlation was seen with B-cells and T-cells. They suggested IL-4 secretion by mast cells can cause apoptosis of cancer cells [50].

Tryptase staining of invasive breast cancer Patient TMAs showed high mast cell number is associated with low tumor grade, even though there is no statistically significant correlation with overall survival [51]. Three other studies in oral squamous cell carcinomas [52] and in B cell Lymphomas [53] and ovarian cancer [54] pointed out that patients with higher mast cell density in tumors had significant survival advantage. 
In a recent study, a large cohort (2300) of prostate cancer patients surgically removed tissue samples were stained for CD117 tissue microarray format and followed their survival for 10 years. Higher intra tumoral mast cell density clearly correlated with better survival in prostate cancer [55]. Johansson group in their study of large pancreatic cancer patients also confirmed the good prognostic value of intra tumoral mast cells [55]. In their study, they showed how mast cells can have different effect in tumor progression depends on their location in the same cancer setting. They noticed mast cells in peritumoral area correlated with poor survival. They used orthotopic rat model and showed peritumoral mast cell cells stimulated tumor growth [56]. They suggested that peritumoral mast cells promote angiogenesis and tumor growth by secreting growth factors like FGF-2.

Mast cell densities in gastric tumor biopsies were determined with toluidine blue staining [57]. Benign tumors are three times more than malignant tumors in 210 samples. Mast cell density is higher in benign tumors than malignant tumors and within malignant tumors mast cells are present only in well differentiated tumors not in poorly differentiated tumors. They postulated mast cell are accumulated in tumors as a host defense mechanism and also have a role in angiogenesis leading to for malignant cell growth. Lack of mast cells in poorly differentiated tumors could be that they are self-sufficient and do not need mast cell factors as demonstrated in prostate tumors

Nielsen et el showed high mast cell number correlated with better patient survival using intra-operative tumor tissue samples from 584 colorectal cancer (CRC) patients and followed their survival for five years [58]. They stained not only 
for lymphocyte infiltration into tumors, but also for other inflammatory immune cell distribution. Both high counts of lymphocytes and individual high counts of mast cells, eosinophils and neutrophils in tumors correlated with better survival. However, prognostic role of mast cells in CRC was defined using small cohort studies in many of previous studies [59]. Further research efforts are needed to define the role of the mast cells in human CRC progression with larger cohorts.

The pathways are often different between tumor initiation and tumor progression [59]. In $\mathrm{Apc}^{\mathrm{Min}}$ tumorigenesis polyp initiation and progression are not effected at same time as the other. Thus, mast cells also may effect either initiation or size of colorectal tumors. TGF- $\beta$ is known for both pro or anti-tumor development depends on the tumor setting. TGF at basal level prevents tumor development and latter promotes tumor development [60].

In a different study, colon cancer patients were followed for five years [61] and tumor samples were carefully chosen for the analysis unlike earlier studies where they combined colon and rectal tumors and also did not differentiate between different TNM stages. This group used only stage III B tumor tissues and stained for mast cell tryptase. They found normal mucosa surrounding the tumor tissue was enriched with more mast cells than the tumor core, but there is no correlation of primary tumor mast cell number with survival. Mast cell number in lymph node metastasis and draining lymph node are also not correlated with 5 year survival. This study clearly shows mast cells are not involved in tumor promotion. 


\section{Role of mast cells in mouse tumor models}

Role of mast cells in mouse models colon cancer has been studied by few groups. Tanaka and Ishikawa [62] looked at mast cell role in AOM/DSS induced colon cancer model using control WBB6F1 and mast cell deficient WBB6F1- kit w/W-v mice. After 20 weeks, the tumor multiplicity of adenoma and adenocarcinomas were significantly higher in control mice than mast cell deficient mice but there is no statistically difference in tumor incidence. They looked at the inflammatory chemokines profile in colons at 12 weeks and found several of them significantly lower in mast cell deficient mice.

Mast cells both connective and mucosal type are recruited into intestinal polyps in two murine models of polyposis, $\beta$-catenin overexpressed mice and APC $^{\triangle 468}$ mice with truncated APC gene [63]. The polyp number was reduced after bone marrow devoid of mast cell progenitors was transferred suggesting mast cell role in tumor development. The anti-tumor role of mast cells also well demonstrated by crossing $\mathrm{Apc}^{\mathrm{Min} /+}$ with mast cell deficient SASH mice [64]. The genetic ablation of mast cells in $\mathrm{Apc}^{\mathrm{Min} /+}$ increased the tumor number and size indicating the mast cells are protective in tumorigenesis. Tumor cell proliferation is not different in mast cell deficient $\mathrm{SASH}^{\mathrm{Min} /+}$ compared to $\mathrm{Apc}^{\mathrm{Min} /+}$ mice. The apoptosis is significantly reduced in $\mathrm{SASH}^{\mathrm{Min} /+}$ mice tumors explaining increase in size of the tumors. They did not see any difference in T cell, neutrophil recruitment

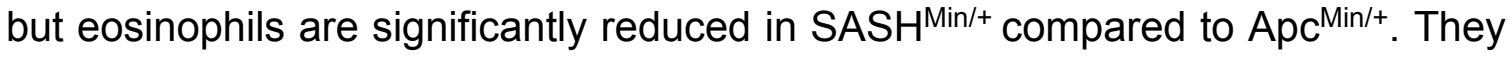
suggested that direct cytotoxic effect of mast cell granules to tumors or eosinophil mediated increase in apoptosis as possible mechanisms in tumor inhibition. The 
results presented in this dissertation agrees well with the latter study on the tumor protective role of mast cells but suggest a clear link to adaptive immunity via T-cell activation mediated pathways.

\section{Mast cell recruitment into tumors}

The mechanisms are not known how mast cells are recruited specifically to the periphery or into the tumor core. Chemoattractants recruit mast cells to the tumor environment. Rat mast cells migrated to the injection site when MCP-1 and RANTES (CCL5) were injected intradermally [65]. In addition to mast cells, monocytes and eosinophils also migrated in this model. MCP-1 (CCL2) is a chemoattractant to monocytes and basophils. CCL5 is a chemoattractant for monocytes, memory $\mathrm{T}$ lymphocytes, $\mathrm{CD} 4^{+} \mathrm{T}$-cells. Nine chemokine receptors and 27 chemokines are expressed by human intestinal mast cells [66]. Chemokine expression is upregulated by antigen stimulation but chemokine receptor expression is independent. Chemokine receptors on mouse mast cells are upregulated by activation of C-kit or FceR1.

SCF and c-Kit plays crucial role in mast cell recruitment to tumors and also restructuring tumor environment. Mast cell migration to tumors was studied in a subcutaneous model using variety of different cancer cell lines [67]. In this study they detected SCF RNA and protein expression in several tumor cell lines as well as corresponding human tumor tissues. Blocking SCF with antibodies inhibited mast cell recruitment to tumors. Low concentration of SCF recruits mast cells to tumors and higher SCF concentrations activates mast cells. SCF-C-Kit signaling facilitates MMP-9 production from mast cells, which will help tumor cells to release 
more soluble SCF. Higher concentrations of SCF activated mast cells to up regulate several proinflammatory cytokines and chemokines (IL-6, TNF- $\alpha$, VEGF, Cox-2, CCL2) and immune suppressive genes (adenosine, IL-10, Foxp3 and SCF, TGF- $\beta$ ) leading to increase in T-reg population and suppression of T-cells and NK cells. Mast cells are capable secreting various mediators without degranulating [68]. This was called piecemeal degranulation. Such type of activation of mast cells might be a central of immune regulation by mast cells without tissue damaging cytotoxicity associated with complete degranulation.

In transgenic adenocarcinoma of the mouse prostate cancer (TRAMP) model, two different kinds of tumors develop the well differentiated and poorly differentiated. Mast cells are recruited to the well differentiated tumors because of their high SCF content but not to poorly differentiated tumors [69]. The cell lines developed from these tumors were injected back into the wild type mice. The tumors developed from well differentiated lines recruited mast cells but not the tumors developed from poorly differentiated cell lines. When these cell lines were injected into mast cell deficient mice, well differentiated cell lines of epithelial origin did not grow and poorly differentiated cell lines of mesenchymal origin grew. The well differentiated cell lines are dependent on mast cell generated MMP9 for their growth and poorly differentiated cell lines produce MMP9 on their own and are not mast cell dependent. It was concluded from these experiments early growth of prostate tumors require mast cells to produce MMP9 to invade nearby tissues and the more advanced tumors after EMT transition produce their own MMP9 without requiring mast cell help [69]. 
Mast cells are recruited to the tumor site when Myc is induced with tamoxifen in pancreatic $\beta$-islets. When mast cells are depleted in this model, either by stabilizing with cromolyn or by crossing with SASH mice, tumors did not grow and apoptosis was increased [48]. Mast cells were responsible for tumor growth in this model. Myc activation rapidly induced several chemokines into tumors including mast cell chemoattractants CCL2 and CCL5 as demonstrated by microarray analysis. These tumors also stained for CCL2 and CCL5 protein expression suggesting that they are involved in the early recruitment of mast cells to tumors.

The activated mast cells in subcutaneous model release multiple proinflammatory factors IL-6, TNF-alpha, Cox-2, iNOS, VEGF, IL-17and CCL2, responsible for immune suppression and promote tumor growth. Most cancer cells do not express c-kit on their membrane [70] and could obtain c-kit from mast cell derived exosomes in membrane exchange. The activated mast cells produce proteases and proangiogenic factors VEGF, PDGF, MMP9 and tryptases promoting metastasis. Thus, mast cells promote tumor growth by increasing angiogenesis, remodeling tumor microenvironment and by recruiting suppressive immune cells [70].

\section{Possible mechanisms for anti-tumor role of mast cells}

Mast cell direct role as anti-tumor effector cells was recognized long time back. Peritoneal mast cells were isolated and purified from chemically induced fibrosarcoma bearing mice or normal mice and tested in vitro cytotoxicity assays for tumor killing capability [71]. Mast cells isolated from normal or tumor bearing 
mice were equally cytotoxic to mouse or rat fibrosarcomas and less effective to mouse fibroblasts suggesting tumor specific cytotoxicity. Mast cells are capable of removing aggressive cancer cells also by phagocytosis as demonstrated in this study of invasive ductal breast carcinomas [72]. Hormone sensitive tumors contained more mast cells than hyporesponsive tumors indicating mast cell presence is associated with good prognosis. After careful microscopic examination of these tumors they identified mast cells phagocytosing cancer cells. They showed one or two mast cells engulfing cancer cells with their pseudopodia and disintegrating slowly inside the mast cell from their toxic granules.

When human mast cell line HMC-1 and human squamous carcinoma cell line SCC-25 were co-cultured in vitro, mast cells inhibited SCC-25 cell proliferation. Microarray analysis was performed to compare mast cell co-cultured SCC-25 gene expression with control SCC-25 gene expression, one of the up regulated gene is apoptosis inducing TRAIL [73] . The mechanism behind mast cells inhibition of tumor growth is by reducing proliferation and increase in apoptosis.

Immunostaining of various human breast, head and neck, ovarian, lung, non Hodgkins and Hodgkins tumors for mast cell tryptase, demonstrated mast cells were recruited mainly to peritumoral fibrous tissue. Addition of heparin reduced the size and number of breast cancer cell colonies, when grown in the presence of fibroblasts but had no effect in the absence of fibroblasts. The mast cell produced heparin role in inhibiting the growth of primary and metastatic tumors was suggested based on the peritumoral location of mast cells and in vitro co culture of tumor cells with fibroblasts [74]. 
The drug Imatinub, a specific bcr-abl tyrosine kinase inhibitor used in the treatment of multiple cancers is also known to inhibit c-kit on mast cell surface effectively and reduce the mast cell numbers and function. Imatinub treatment accelerated mammary adenocarcinoma tumor growth in subcutaneous model and resulted in peritumoral blood clotting [75]. Inhibition of mast cell specific heparin by injecting heparinase into tumors also increased tumor growth in this model. Blood clotting promotes tumor growth. Mast cells are recruited to tumors at the periphery and their heparin mediated anti-clotting property prevents tumor growth.

\section{Mast cell regulation of adaptive immunity}

Mast cells can recruit T-cells directly by secreting chemotactic molecules such as IL-6, XCL-1(lymphotactin), CCL1-5, IL-16, CCL20,CXCL10 and LTB4 [38]. Mast cells activated by lgE cross linking, release leukotrienes including LTB4. LTB4 attracts BLT1 expressing effector T cells through vascular endothelium [39]. Mast cells can also recruit T-cells indirectly by inducing adhesion molecules expression on endothelial cells. Mast cell's physical interaction with different innate and adaptive immune cells and outcome of that interaction is adeptly summarized in a recent review by Gri et al. [76]. Mast cell interactions are bidirectional and they are capable of delivering and receiving co-stimulatory signals from immune cells promoting tumor escape or tumor surveillance. Mast cells interaction especially with cytotoxic T-cells are known for long time in mastocytoma cell line p815 studies [77]. Mast cells express major histocompatibility MHC-I and MHC-II molecules and are able to present antigens to $\mathrm{CD} 8^{+}$and $\mathrm{CD} 4^{+} \mathrm{T}$ cells, respectively. Mast cells can phagocytose bacteria and present OVA containing bacterial antigens to $C D 8^{+}-$ 
OVA T-cell hybridomas through MHC-I as efficiently as peritoneal macrophages [78]. Selekato et al. showed mast cells induced $\mathrm{CD}^{+} \mathrm{T}$ cells activation, proliferation and also $\mathrm{CD} 8^{+} \mathrm{T}$-cell cytotoxicity in antigen specific way [79]. They demonstrated that adoptively transferred antigen pulsed mast cells are capable of activating antigen specific $\mathrm{CD} 8^{+} \mathrm{T}$-cell proliferation in an EAE model. Mast cells are also capable of suppressing T-regs [80] by IL-6 production through OX40/OX40L axis and switching them into IL-17 producing effector cells. The close proximity of human tansillar mast cells and T-cells is known in allergy. Tansillar mast cells increased T-cell proliferation through OX40/OX40L interaction when cocultured in vitro [81]. T-reg cells also inhibit mast cell Fcer1 mediated degranulation involving OX40/OX40L axis in vitro and in vivo [82].

Thus, mast cells have wide ranging activities and biological functions. The experiments described in this dissertation are aimed at developing a better understanding of the mechanisms of their tumor protective functions. 


\section{CHAPTER II}

\section{Materials and Methods}

\section{Mice}

$\mathrm{D6}^{-/-} \mathrm{Apc} \mathrm{Min}^{++}$strain was generated in the laboratory by crossing C57BL/6$\mathrm{Apc}^{\mathrm{Min} /+}$ mice (Jackson Laboratory) and D6-/- mice (Schering-Plough). Animals were housed in barrier facility under specific pathogen free conditions. The ovalbumin specific TCR OT-1 mice, $K i t^{W-s h} /$-sh mice on the C57BL/6 background (SASH mice or $\mathrm{SA}^{-/}$) were purchased from The Jackson Laboratory. Rag2 ${ }^{-/-}$mice were purchased from Taconic Farms Inc. D6 ${ }^{-/-}$Rag2 $^{-/-} \mathrm{Apc} \mathrm{Min}^{++}$mouse was generated by breeding $\mathrm{D6}^{-/-} \mathrm{Apc}^{\mathrm{Min} /+}$ with Rag2/-- mice. All the experiments were conducted according to the protocols approved by the Institutional Animal Care and Use Committee (IACUC) at University of Louisville.

\section{Genotyping}

Genomic DNA from mouse tail $(0.1 \mathrm{~mm})$ was extracted from using a Direct PCR lysis reagent (Viagen Biotech) according to the manufacturer's instructions. The following primers were used for genotyping of indicated strains.

\section{1. $\mathrm{Apc}^{\mathrm{Min} /+}$}

WT:

$\mathrm{Apc}^{\mathrm{Min} /+}(\mathrm{KO})$ :
5' GCCATCCCTTCACGTTAG 3'

5' GCCATCCCTTCACGTTAG 3' 
Common:

5' GCCATCCCTTCACGTTAG 3'

The expected PCR product size for Apc ${ }^{\operatorname{Min} /+}$ mouse: WT 600 bp; Apc ${ }^{\operatorname{Min} /+}: 340$ bp.

2. $\mathrm{D6}^{-1-}$

WT:

5' CAGAGCTGAGATGGTCCCAA 3'

$\mathrm{D6}^{-1-}(\mathrm{KO})$ :

5' AGCCGTCACCTTAATATGCG 3'

Common:

5' AGTAAGGCTCTCGGTGAACAG 3'

The expected PCR product sizes for D6--- mouse: WT 260 bp; KO: 550 bp.

The PCR was performed using Mango Taq polymerase (Bioline) in $30 \mu \mathrm{l}$ reaction containing final concentrations of $1 X$ Mango Taq buffer, $1.5 \mathrm{mM} \mathrm{MgCl}_{2}$, $0.25 \mathrm{mM}$ dNTPs with $0.5 \mathrm{U}$ of enzyme. The primer concentrations for $\mathrm{Apc}^{\mathrm{Min} /+}$ and $\mathrm{D6}^{-/}$was $0.6 \mu \mathrm{M}$. The $\mathrm{D6}^{-/}$genotyping PCR was performed in Effendorf Thermocylcer. The PCR conditions: Initial denaturing at $95{ }^{\circ} \mathrm{C}$ for $2 \mathrm{~min}$, followed by 30 cycles of $95^{\circ} \mathrm{C} \times 30$ seconds, $60^{\circ} \mathrm{C} \times 1 \mathrm{~min}$, and $72{ }^{\circ} \mathrm{C}$ for $1 \mathrm{~min}$. The reaction was terminated after 5 min extension at $72{ }^{\circ} \mathrm{C}$. Similar conditions were used for $\mathrm{Apc}^{\mathrm{Min} /+}$ genotyping except for annealing temperature, which was performed at $56{ }^{\circ} \mathrm{C}$ for $1 \mathrm{~min}$. The PCR products were analyzed on $2 \%$ agarose gel. The SASH mice $\left(\mathrm{SA}^{-/}\right)$are white due to reduced melanocytes and heterozygous mice have black and white color band as name indicates and identified easily by coat color without genotyping. 


\section{Breeding scheme to generate $\mathrm{D6}^{-/-} \mathrm{SA}^{-/-} \mathrm{Apc}^{\mathrm{Min} /+}$}

$\mathrm{D6}^{-1-} \mathrm{Apc} \mathrm{Min}^{\mathrm{M} /+}$ strain is maintained by breeding $\mathrm{D6}^{-1-} \mathrm{Apc}^{\mathrm{Min} /+}$ males with $\mathrm{D6} 6^{-1-}$ females and genotyping for $\mathrm{Apc}^{\mathrm{Min} /+}$. To generate $\mathrm{D6}^{-1-\mathrm{SA}}{ }^{-1-} \mathrm{Apc}^{\mathrm{Min} /+}$ triple knockout, $\mathrm{D6}^{--} \mathrm{Apc}^{\mathrm{Min} /+}$ males were bred with female $\mathrm{SA}^{-/-}$mice and generated heterozygous $\mathrm{D6}^{+/-} \mathrm{SA}^{+/-}$mice with or without $\mathrm{Apc}^{\mathrm{Min} /+}$ allele. The heterozygous $\mathrm{D6}^{+/-} \mathrm{SA}^{+/-} \mathrm{Apc}^{\mathrm{Min} /+}$ male mice were then crossed with $\mathrm{D6}^{+/-} \mathrm{SA}^{+/-}$and $\mathrm{SA}^{-/-}$females for several rounds to obtain $\mathrm{D6}^{-/-} \mathrm{SA}^{-/-} \mathrm{Apc}^{\mathrm{Min} /+}$ and $\mathrm{SA}^{-/-} \mathrm{Apc}^{\mathrm{Min} /+}$ male breeders.

\section{Blood collection for hematocrits and serum}

Mice were euthanized at the age of 110 days by $\mathrm{CO}_{2}$ inhalation, cut open and blood was drawn from heart using a $1 \mathrm{ml}$ syringe with 23 gauge needle. Approximately $200 \mu \mathrm{l}$ of blood was taken into EDTA (heparin) coated tubes (Sarstedt), mixed gently up and down and stored at $4{ }^{\circ} \mathrm{C}$. The blood samples were analyzed at room temperature using the Hemavet-950 Hematology System (Drew Scientific). For serum, blood was collected into Microtainer (BD Microtnr Sst W/gard) allowed to clot for 30 minutes. The blood samples were centrifuged at 10,000 RCF for 2 minutes and top layer (supernatant) was carefully collected and stored at $-80^{\circ} \mathrm{C}$.

\section{Survival of mice}

Mice $\left(\mathrm{Apc}^{\mathrm{Min} /+}, \mathrm{SA}^{--} \mathrm{Apc} \mathrm{Min}^{+}, \mathrm{D6}^{-/-} \mathrm{SA}^{-/-} \mathrm{Apc}^{\mathrm{Min} /+}\right)$ were passively followed for long-term survival as per IACUC regulations. The mice were sacrificed, if they were found morbid and sick. Significance of differences in survival was determined by the Mantel-Haenszel/ Log-rank test. 


\section{Enumeration of Polyps}

The intestinal polyps (tumor burden) were analyzed at 110 days of age. The mice were euthanized by $\mathrm{CO}_{2}$ inhalation. The visceral layer was opened and the pubic bone clipped. The large intestine was removed from the rectal end without excess pressure. The rest of the intestine slowly removed without fat and other attachments and clipped at the pyloric-duodenum junction. The large intestine or colon was cut at illeocecal junction. The remaining small intestine was divided into three equal parts i.e., distal, middle and proximal portions. The intestines were flushed with 1 X PBS using $10 \mathrm{ml}$ syringe and 18 gauge gavage needle to remove any fecal samples. Small intestines and colons were longitudinally opened and spread on the filter paper and placed another filter paper on top (sandwiched). These tissues were fixed in the $10 \%$ formalin for $16 \mathrm{hrs}$ followed by transferring into $70 \%$ alcohol. Tissues are stored in $70 \%$ alcohol until counting. The tumors were counted and sized under stereo microscope containing reticle eye piece. Polyps were categorized as $<1 \mathrm{~mm}, 1-2 \mathrm{~mm}, 2-3 \mathrm{~mm}$ and $>3 \mathrm{~mm}$ size. For each experimental group, the incidence of tumors, defined as the number of mice with tumors/number of mice in the group. The mean number of tumors/mouse $\pm S E M$, and the mean tumor diameter $(\mathrm{mm})$ in the group \pm SEM were calculated for the small intestine and colon separately. Statistical analysis was performed using the Mann-Whitney U test using Graph Pad Prism 4.0 software. 


\section{Frozen samples for immunohistochemistry (IHC) analysis}

The flushed intestines were filled with OCT and prepared swiss-roll in OCT blocks using standard methods. The OCT blocks were used to prepare frozen section slides with Cryostat (Leica CM1900).

\section{Fixing tissues for immunohisotchemistry (IHC) analysis}

The flushed intestines were fixed with $10 \%$ neutral formalin buffer for $16 \mathrm{~h}$ followed by transfer into $70 \%$ alcohol. The fixed tissues were prepared as Swiss rolls and embedded into paraffin. The sections were cut at $5 \mu \mathrm{m}$ thickness and one of the sections used for hematoxylin and eosion (H\&E) and others for immunohistochemical analysis.

\section{Bone Marrow-Derived Mast Cell (BMMC) culture}

Bone marrow derived mast cell cultures were prepared from female mice (4 to 6 weeks old). The mice were euthanized using $\mathrm{CO}_{2}$ inhalation and the rest of the procedure was carried out in laminar hood. Tibia and femur bones were dissected from these mice. The bone marrow was flushed with RPMI from tibia and femur bones gently mushed (pulped) with back of syringe barrel. The cells were separated by filtering through $60 \mu \mathrm{m}$ nylon mesh. The filtrate was centrifuged at $450 \mathrm{~g}$ for $5 \mathrm{~min}$ and the pellet was resuspended in BMMC culture medium (DMEM containing 10\% FCS,100 units $/ \mathrm{ml}$ Penicillin, Streptomycin $100 \mu \mathrm{g} / \mathrm{ml}, 2$ $\mathrm{mM}$ L-Glutamine, $50 \mu \mathrm{M} \beta$-mercaptoethanol) supplemented with $12.5 \mathrm{ng} / \mathrm{ml}$

recombinant Mouse SCF (R\&D \# $455 \mathrm{MC}, 10 \mu \mathrm{g} / \mathrm{ml}$ Stock,) and $10 \mathrm{ng} / \mathrm{ml}$ recombinant Mouse IL-3 (R\&D \#403-ML, $10 \mu \mathrm{g} / \mathrm{ml}$ Stock). The BMMCs were plated 
at $\sim 1 \times 10^{6} / \mathrm{ml}$ density in T-75 $\mathrm{cm}^{2}$ flask containing $15 \mathrm{ml}$ of medium. The nonadherent cells were transferred after 48 hours into fresh flasks without disturbing the adherent (fibroblast) cells. The flasks were changed weekly or as needed to separate the non-adherent mast cells from the contaminating adherent cells. The medium was changed once a week with medium containing SCF, IL-3. The homogenous population of mast cells were visible after 4 weeks of culture and propagated further by dividing once or twice a week to $0.5-1 \times 10^{6} \mathrm{cells} / \mathrm{ml}$ density. The purity of BMMCs confirmed by surface staining with mast cell specific markers c-Kit and FceR1 by FACS analysis.

\section{Chemotaxis}

Chemotaxis of BMMCs (WT and D6-/-) was evaluated using $5-\mu \mathrm{m}$ pore size Transwell filters (Corning Costar, Cambridge, MA). Briefly, cells were resuspended at a density of $0.5 \times 10^{7} / \mathrm{ml}$ in chemotaxis buffer (RPMI-1640, $0.5 \%$ BSA). The lower chamber was loaded with various concentrations of chemokines in a volume

of $600 \mu \mathrm{l}$ and $100 \mu \mathrm{l}\left(0.5 \times 10^{6}\right.$ cells $)$ of cells from above cell suspension was placed onto the upper chamber. After $3 \mathrm{~h}$ of incubation at $37{ }^{\circ} \mathrm{C}$ in $5 \% \mathrm{CO}_{2}$, the upper chamber was removed and cells in the lower chamber were fixed in buffered $2 \%$ formaldehyde. The cells migrated were counted by running for fixed time (fixed volume of cells) and analyzed using buffer as background control.

\section{Calcium flux}

Ligand induced calcium mobilization was monitored in INDO-1 loaded cells stimulated with various concentrations of chemokines as previously described by 
Jala et al $[83,84]$. Briefly, BMMCs were resuspended in $1 \mathrm{X} \mathrm{Ca}^{2+}, \mathrm{Mg}^{2+}$ free HBBS buffer $+1 \%$ BSA and loaded with $1 \mu \mathrm{M}$ Indo-1 in the presence of $1 \mu \mathrm{M}$ pluronic acid and placed in tissue culture chamber at $37^{\circ} \mathrm{C}, 5 \% \mathrm{CO}_{2}$. After 30 min incubation, cells were washed with $1 \mathrm{X}$ HBBS, $0.1 \%$ BSA and resuspended in the same buffer containing $1 \mathrm{mM}$ calcium buffer at $4 \times 10^{6}$ cells per $2 \mathrm{ml}$ density. All the calcium measurements were performed in temperature controlled cuvette chamber with constant gentle stirring. The required concentration of ligand (in $20 \mu$ volume) was added in to the cuvette containing $2 \mathrm{ml}$ of cells $\left(4 \times 10^{6}\right.$ cells $)$ at $37^{\circ} \mathrm{C}$ and the emission fluorescence (405 nM and $490 \mathrm{nM}$ ) were continuously recorded by exciting at $335 \mathrm{nM}$ using F-2500 FL Spectro flurometer (Hitachi). The ratio of emission fluorescence represents relative intracellular calcium release/response upon stimulation.

\section{Western blot analysis of MCPT1}

The intestinal tumors were dissected and snap frozen in liquid nitrogen and stored at $-80^{\circ} \mathrm{C}$. Freshly dissected or thawed tumors/normal tissues were homogenized in Bio-Rad lysis buffer using hand held homogenizer (Omni International). The total proteins from these extracts were quantified using Bradford protein estimation method. The extracts (50 $\mu \mathrm{g}$ of total protein) were separated on SDS-PAGE and transferred onto PVDF (Biorad) membrane. The membrane blot was probed with Rat anti mouse MCPT-1 antibody (R\&D) $1 \mu \mathrm{g} / \mathrm{ml}$ and peroxidase coupled secondary anti rat antibody. The same blot was stripped with stripping buffer (Thermo Scientific) and re-probed for $\beta$-actin-HRP antibody 
(Santa-Cruz Biotechnologies). The blot was developed using Western Blotting Luminol Reagent (Santa-Cruz Biotechnologies).

\section{Real Time PCR}

RNA was prepared from small intestine and colon tissues of WT, D6 ${ }^{--}$as

well as size matched intestinal tumors of $\mathrm{Apc}^{\mathrm{Min} /+}, \mathrm{D6}^{-/-} \mathrm{Apc}^{\mathrm{Min} /+}, \mathrm{SA}^{-/-} \mathrm{Apc}^{\mathrm{Min} /+}$ and $\mathrm{SA}^{-/-} \mathrm{D6}^{-/-} \mathrm{Apc}^{\mathrm{Min} /+}$ mice (105-110 days age old) using Trizol and followed by RNeasy mini kit from Qiagen. Briefly, tissues were homogenized in Trizol reagent using hand held homogenizer with disposable RNAase free homogenizing probes from Omni International Inc. Chloroform (1/5 volume of Trizol) was added to homogenized sample. These samples were centrifuged at $12000 \mathrm{~g}$ for $15 \mathrm{~min}$ and supernatant was collected. Equal volume of $100 \%$ alcohol was added and transferred everything onto RNeasy mini column and followed the manufacture's protocols. The RNA was treated with DNAase using Turbo DNAse kit, Ambion Inc or on column DNAse treatment (Qiagen DNAse kit) to remove traces of genomic DNA contamination. Total RNA from BMMCs, Macrophages, T-cells, B-cells and dendritic cells was isolated by lysing samples with Trizol followed by RNeasy mini purification kit according to manufacturer's protocols. The amount of RNA was estimated using Nanodrop.

For semi quantitative real-time PCR, $1 \mu \mathrm{g}$ of total RNA was reverse transcribed in $50 \mu \mathrm{l}$ reaction using TaqMan reverse transcription reagents (Applied Biosystems) using random hexamer primers. $2 \mu \mathrm{l}$ of cDNA and $1 \mu \mathrm{M}$ real time PCR primers were used in a final $20 \mu \mathrm{l}$ qPCR reaction with 'power SYBR-green master mix' (Applied Biosystems). The PCR conditions as follows: Initially, 1 cycle of 50 
${ }^{\circ} \mathrm{C}$ for 2 min followed by $95^{\circ} \mathrm{C}$ for $10 \mathrm{~min}$. Next, 60 cycles of $95^{\circ} \mathrm{C}$ for $10 \mathrm{sec}$ followed by $58^{\circ} \mathrm{C}$ for $45 \mathrm{sec}$. The SYBR fluorescence (amplification) was recorded at $58{ }^{\circ} \mathrm{C}$. The real time primers were purchased from Real Time Primers, LLC, Elkins Park, PA. Real time qPCR was performed either in ABI-Prism 7900 sequence detect system (Applied Biosytems) or Biorad CFX96 real time PCR machine. Expression of the target genes was normalized to $\beta$-actin and the relative fold changes were calculated using the delta CT method by Livak et al. [85]. The fold changes are displayed relative to the wild type samples. Data are representative of tumors/tissues isolated from at least 5 different mice for each genotype.

\section{Microarray}

Total RNA from WT and D6-/- BMMCs (2week old, 10 weeks old cultures) was isolated using Trizol and followed by RNeasy mini kit from Qiagen as described above. The micro array was performed using Affymetrix GeneChip ${ }^{\circledR}$ Mouse Gene 1.0 ST Array according to manufacturer's protocol at Microarray core facility, University of Louisville. The GeneChip-brand array comprised of over 750,000 unique 25-mer oligonucleotide features constituting over 28,000 gene level probes with an average of 27 probes per gene. Briefly, Total RNA was amplified and labeled following the Affymetrix (Santa Clara, CA) standard protocol for whole transcript expression analysis, followed by hybridization to Affymetrix Mouse Gene $1.0 \mathrm{ST} \circledast$ arrays. The arrays were processed following the manufacturer recommended wash and stain protocol on an Affymetrix FS-450 fluidics station and scanned on an Affymetrix GeneChip® $7 G$ scanner using 
Command Console 3.1. The resulting .cel files were imported into Partek Genomics Suite 6.6 and transcripts were normalized on a gene level using RMA as normalization and background correction method. Contrasts in a 1-way ANOVA were set up to compare the treatments of interest. The fold changes along with Affymetrix IDs, p-values were uploaded Ingenuity pathway analysis (IPA) software. The fold change level (D6-/- vs WT) in chemokines and their receptors were represented in graphs.

\section{Purification of $\mathrm{CD}^{+} \mathrm{T}$ Cells}

$\mathrm{CD}^{+} \mathrm{T}$ cells were isolated from spleen and mesenteric lymph nodes from OT-1 mice using standard protocols. Briefly, spleen or lymph nodes were crushed and passed through $70 \mu \mathrm{m}$ strainer (Corning). The red blood cells were lysed with RBC lysis buffer (Biolegend). After lysis step, cells were resuspended in $1 \mathrm{ml}$ of 1 X PBS containing $0.5 \%$ BSA and $100 \mu$ of $\mathrm{CD}^{+}$a (Ly-2) micro beads (Miltenyi Biotec) and incubated for $45 \mathrm{~min}$. The CD8+ cells were purified on MACS LS columns. The purified $\mathrm{CD} 8^{+} \mathrm{T}$ cells were $>95 \%$ positive for CD8 as analyzed by Flow Cytometer.

CFSE labeling: The CFSE (Invitrogen) stock was freshly prepared at $10 \mu \mathrm{M}$ in DMEM. The purified OT-1 CD8 ${ }^{+}$T Cells were washed with DMEM and labeled with $2.5 \mu \mathrm{M}$ CFSE for 10 minutes at $37^{\circ} \mathrm{C}$ in dark. The reaction was stopped quickly with DMEM containing 2\% FCS, centrifuged, washed and resuspended in $2 \mathrm{ml}$ DMEM containing10\% FBS buffer. The cells were counted and diluted to $1 \mathrm{X}$ $106 / \mathrm{ml}$ density for plating. 


\section{BMMCs and T-cell co-cultures}

The stock of SIINFEKL peptide (Sigma) was prepared in $1 \mathrm{X}$ PBS at 0.5 $\mathrm{mg} / \mathrm{ml}$ concentration and stored at $-20^{\circ} \mathrm{C}$. BMMCs from WT and D6 ${ }^{-/-}\left(2 \times 10^{6}\right)$ were incubated with OVA octapeptide SIINFEKL (257-264) (Sigma) for 3 hours in $4 \mathrm{ml}$ of DMEM containing 10\% FBS medium. Following incubation, BMMCs were washed three times and resuspended in DMEM containing 10\% FBS medium. For co-culture experiments, $1 \times 10^{6} \mathrm{CD}^{+} \mathrm{T}$ Cells or CFSE labeled CD8+ T cells were mixed with different ratios of BMMCs that were prepared in $3 \mathrm{ml}$ DMEM containing $10 \%$ FBS and cultured in 12 well plates for 48 hrs (activation) or $72 \mathrm{hrs}$ (proliferation) respectively. CD8 $+\mathrm{T}$ cell activation was measured by surface expression of CD69, CD44 and CD25 by Flow cytometry. The CD8+ T cell proliferation was determined using CFSE labeled CD8+ T cells by following CFSE dilution.

\section{Flow Cytometry}

Cells were taken into $12 \times 75 \mathrm{~mm}$ round bottom polypropylene tubes, washed with $1 \mathrm{X}$ PBS and centrifuged at $450 \mathrm{~g}$ for $3 \mathrm{~min}$. The cell pellet was resuspended in $50 \mu$ 1XPBS containing 1\% BSA and Fc blocked for 20 minutes on ice with $1 \mu \mathrm{g}$ of Rat anti mouse CD16/CD32 (2.4G2) antibody. After Fc block, specific fluorescence labeled antibodies were added at a concentration recommended by manufacturer or titrated in the laboratory and incubated on ice protecting from light. After 40 minute labeling, cells were washed with cold 1XPBS, centrifuged at $400 \mathrm{~g}$ for 3 minutes and fixed with 1 X PBS containing $2 \%$ 
Paraformaldehyde. The cell viability was measured using $0.5 \mu \mathrm{l}$ of fixable viability Dye eFluor 660 (e-bioscience) in 500ul 1XPBS.

\section{Intracellular IFN-Y staining}

The cells were stimulated for 5 hours with $1 \mathrm{X}$ cell stimulation cocktail containing phorbol 12-myristate 13-acetate (PMA) and ionomycin (e-bioscience), washed, permeabilized and stained with Rat anti mouse IFN- $\gamma$ antibody according to e-Bioscience instructions using their buffers.

\section{Purification of immune cells}

T and $B$ cells were isolated by incubating with their specific rat monoclonal antibodies for 45 minutes, washing and incubating with magnetic anti rat antibodies and purified on MACS MS columns according to manufactures instructions.

\section{Immunofluorescence}

The distal intestine tissue was filled with OCT compound, Swiss rolled and mounted with OCT. The OCT block was rapidly frozen by immersing in cold 2Methybutane chilled with dry ice. The OCT frozen tissue was cut into 6-7 $\mu \mathrm{m}$ size sections using Leica CM1900 Cryostat, placed onto super frost slides and fixed in cold acetone $\left(-20^{\circ} \mathrm{C}\right)$ for 10 minutes. After air drying for one hour, serial sections were washed with $1 \mathrm{X}$ PBS and blocked for 30 minutes with $5 \%$ goat serum followed by incubation with primary Rat-anti mouse antibodies [CD8 $\alpha$ (BD Biosciences, MCPT-1 (e-Bioscience)] or isotype antibodies (at 1/50 dilution) for 60 min at room temperature in humidified chamber. After incubation, the slides were

washed with $1 \mathrm{X}$ TBS and added secondary goat anti-rat IgG AlexaFluor 488 at 
1/500 dilution and incubated for $30 \mathrm{~min}$. Sections were counterstained with DAPI1, mounted using Vectashield mounting medium (Vector labs) and visualized on Nikon A1R confocal Microscope using appropriate filters.

BMMCs double staining: BMMCs $\left(1 \times 10^{6}\right)$ were washed and spread on superfrost slides in $70 \mu \mathrm{l}$ volume using Shandon cytospin centrifuge. Cytospin preparations of BMMCs were stained indirectly using Rat anti CD117 and Biotin labeled antiFcER1 antibodies and visualized by Green Alexa-488 labeled anti rat antibody and Red Alexa-647 Streptavidin. The immunofluorescence images were captured using Nikon A1R confocal microscope using appropriate filters.

\section{Statistical analysis}

The number of animals (n) were calculated using 'Two-sample $t$ test' in Web-based power analysis versions that is available at, http://www.stat.uiowa.edu/ rlenth/Power/index.html. The ' $n$ ' was chosen to give an approximately $80 \%$ chance of detecting the difference with no more than $5 \%$ chance of error. Standard Mann-Whitney $U$ non-parametric two-tailed and twotailed Student's t-test were used for comparisons between two experimental groups, with a $p$ value of $<0.05$ considered as significant using Graph Pad Prism software $\left({ }^{* * *}=p<0.001 ;{ }^{* *}=p<0.01,{ }^{*}=P<0.05\right)$. The significance of survival of animals was calculated using Kaplan-Meier survival curves by the MantelHaenszel/Log-rank test. 


\section{CHAPTER III}

\section{MAST CELLS ARE TUMOR PROTECTIVE IN D6 ${ }^{-1-}$ APC ${ }^{\mathrm{MIN} /+}$ MICE}

\section{INTRODUCTION}

Increase in mast cell numbers correlated well with good prognosis in human colorectal cancer $[58,86]$, breast cancer $[49-51,87]$ and prostate cancer $[55,56]$. In $\mathrm{Apc}^{\triangle 468}$ mice, a different allele of APC gene, intestinal tumors develop very rapidly [88]. In this case, mast cells are more abundant in intestinal adenomas than in normal intestine [88]. In contrast, when mast cells were depleted genetically by crossing $\mathrm{Apc}^{\mathrm{Min} /+}$ mice with $\mathrm{c}-\mathrm{kit}^{\mathrm{W}-\mathrm{sh} / \mathrm{W} \text {-sh }}$ (Sash or SA) mice, intestinal adenomas increased in number and size indicating a protective role for mast cells in tumorigenesis [64]. Studies in our laboratory also suggested that mast cells might play a protective role in the tumor onset in $\mathrm{D6}^{--} \mathrm{Apc}^{\mathrm{Min} /+}$ mice compared to $\mathrm{Apc}^{\mathrm{Min} /+}$ mice. We observed increased number of mast cells and mast cell chymase activity in intestinal tumors of $\mathrm{D6}^{-/-} \mathrm{Apc}^{\mathrm{Min} /+}$ compared to $\mathrm{Apc}^{\mathrm{Min} /+}$ mice. Therefore, we hypothesize that depletion of mast cells in $\mathrm{D6}^{-/} \mathrm{Apc} \mathrm{Min} /+^{-}$will increase the intestinal tumor burden in $\mathrm{D6}^{-/-} \mathrm{Apc}^{\mathrm{Min} /+}$ mice. To address the role of mast cells in the development of intestinal tumor development in $\mathrm{D6}^{-{ }^{-}} \mathrm{Apc} \mathrm{Min}^{\mathrm{H}}$, we have selected genetic methods to deplete mast cells. This approach offers relatively more reliable method, despite some potential for pleotropic effects, to resolve the 
issue, whether increased mast cell numbers in $\mathrm{D6}^{-1-} \mathrm{Apc}^{\mathrm{Min} /+}$ is the cause or consequence of reduced intestinal tumorigenesis in $\mathrm{D6}^{-1-} \mathrm{Apc} \mathrm{Min} /+^{+}$mice. WBB6F1$\mathrm{kit}^{\mathrm{W} / \mathrm{W}-\mathrm{v}}$ and C57BL/6-kit ${ }^{\mathrm{W}-\mathrm{sh} / \mathrm{W}-\mathrm{sh}}$ are the two commonly used strains with mast cell and melanocyte deficiency. The W-sash mutation is an inversion mutation in the transcriptional regulatory elements upstream of the Kit transcription start site that originally arose spontaneously. The adult c-kit ${ }^{\mathrm{W}-\mathrm{sh} / \mathrm{W}-\mathrm{sh}}$ mice lack mast cells in all tissues but exhibited normal B cells, T cells but show some myeloid abnormalities, in particular increased numbers of neutrophils. The c-kit ${ }^{\mathrm{W}-\mathrm{sh} / \mathrm{W}-\mathrm{sh}}\left(\mathrm{SA}^{--/}\right)$mice are neither sterile nor anemic and preferred over other mast cell deficient strain Kit ${ }^{W / K i t W-v}$ mice with these phenotypic abnormalities. 


\section{RESULTS}

\section{Generating D6 ${ }^{-1-\mathrm{SA}^{-1-} \mathrm{Apc}}{ }^{\mathrm{Min} /+}$ mice}

The mast cell deficient $\mathrm{SA}^{-/-}$mice were crossed with $\mathrm{D6}^{-1-} \mathrm{Apc} \mathrm{Min}^{\mathrm{M}}+$ mice to generate $\mathrm{D6}^{-1-} \mathrm{SA}^{-1-} \mathrm{Apc}^{\mathrm{Min} /+}$ along with control $\mathrm{SA}^{-/-} \mathrm{Apc}^{\mathrm{Min} /+}$ mice. The breeding scheme is outlined in detail in Fig. 7A. Briefly, $\mathrm{D6}^{-1-} \mathrm{Apc}^{\mathrm{Min} /+}$ mice were crossed with $\mathrm{SA}^{-/-}$mice to generate heterozygous $\mathrm{D6}^{+/-} \mathrm{SA}^{+/-}$mice with or without $\mathrm{Apc}^{\mathrm{Min} /+}$ allele. The heterozygous male mice with $\mathrm{Apc}^{\mathrm{Min} /+}$ allele were then crossed with $\mathrm{D6}^{+/-} \mathrm{SA}^{+/-}$ and $\mathrm{SA}^{-/-}$females for several rounds to obtain $\mathrm{D6}^{-/-} \mathrm{SA}^{-/-} \mathrm{Apc}^{\mathrm{Min} /+}$ and $\mathrm{SA}^{-/-} \mathrm{Apc}^{\mathrm{Min} /+}$ male breeders as well as $\mathrm{D6}^{--\mathrm{SA}^{-/-}}$and $\mathrm{SA}^{-/-}$female breeders. The representative images of breeding strains depicted in Fig. 7B. To reduce the stress during pregnancy from disease, only male breeders with $\mathrm{Apc}^{\mathrm{Min} /+}$ allele were used. $\mathrm{SA}^{-/-}$ mice are prone to anxiety [89] and due to higher rate of cannibalism, the colony was maintained with several more breeding setups than normal colony.

\section{Decreased survival and increased tumor burden in $\mathrm{D6}^{-/-} \mathrm{SA}^{-/-} \mathrm{Apc}^{\mathrm{Min} /+}$ mice relative to $\mathrm{D6}^{--_{-}} \mathrm{Apc} \mathrm{Min}^{\mathrm{H}}$ mice}

The $\mathrm{D6}^{-/-} \mathrm{SA}^{-/-} \mathrm{Apc}^{\mathrm{Min} /+}$ mice were maintained under the same conditions as $\mathrm{D6}^{--} \mathrm{Apc}^{\mathrm{Min} /+}$ mice and their survival was monitored. The mice were always maintained on breeders chow with autoclaved water in barrier animal facility. The survival advantage observed in $\mathrm{D6}^{-/-} \mathrm{Apc}^{\mathrm{Min} /+}$ mice was lost with the mast cell deficiency. The $\mathrm{D6}^{--} \mathrm{SA}^{--} \mathrm{Apc}^{\mathrm{Min} /+}$ mice lived on average 180 days, close to the $\mathrm{Apc}^{\mathrm{Min} /+}$ mice average lifespan (Fig. 8A). The hematocrit values of $\mathrm{D6}^{-1-} \mathrm{SA}^{-1-} \mathrm{Apc} \mathrm{Min} /+^{-}$ mice at 110 day age are significantly lower than $\mathrm{Apc}^{\mathrm{Min} /+}$ mice indicating faster disease progression in the absence of mast cells (Fig. 8B). The $\mathrm{SA}^{--A} \mathrm{Apc} c^{\mathrm{Min} /+}$ mice 
showed even more severe disease with average HCT values around 15 compared to $\mathrm{D6}^{-1-} \mathrm{Apc} \mathrm{Min}^{\mathrm{I}}$ with an average of 42 . We then studied the intestinal tumor burden in $\mathrm{D6}^{-1-} \mathrm{SA}^{-1-} \mathrm{Apc}^{\mathrm{Min} /+}$ along with the control $\mathrm{SA}^{-1-} \mathrm{Apc}^{\mathrm{Min} /+}$ mice at 110 days age. As described in the methods, small intestine was divided in to three equal parts (distal, middle and proximal sections) and counted under stereomicroscope. Tumors were graded into four size ranges 0.1 to $1 \mathrm{~mm}, 1-2 \mathrm{~mm}, 2-3 \mathrm{~mm}$ and $3 \mathrm{~mm}$ and above using reticles attached to microscope eyepiece. The representative images of distal intestines in Fig. 9A shows $\mathrm{SA}^{---} \mathrm{Apc}^{\mathrm{Min}}$ mice has more tumors than $\mathrm{D6}^{-1-\mathrm{SA}^{-}}$ ${ }^{-} \mathrm{Apc}^{\mathrm{Min} /+}$ and $\mathrm{D6}^{-{ }^{-}} \mathrm{Apc}^{\mathrm{Min} /+}$. The total number of polyps in the small intestine of $\mathrm{D6}^{-}$ ${ }^{\text {I-SA }}{ }^{-1-} \mathrm{Apc}^{\mathrm{Min} /+}$ mice increased slightly but not significantly from $\mathrm{D6}^{-1-} \mathrm{Apc} \mathrm{Min} /+^{+}$mice (Fig. 9B). The $\mathrm{SA}^{--} \mathrm{Apc}^{\mathrm{Min} /+}$ mice has significantly higher number of tumors compared to $\mathrm{D6}^{--} \mathrm{Apc}^{\mathrm{Min} /+}$ and $\mathrm{D6}^{--} \mathrm{SA}^{--} \mathrm{Apc}^{\mathrm{Min} /+}$ but did not show any difference in tumor numbers in comparison with $\mathrm{Apc}^{\mathrm{Min} /+}$. All the polyp numbers are tabulated in Table 1.

There is no significant difference in tumor numbers in different regions of

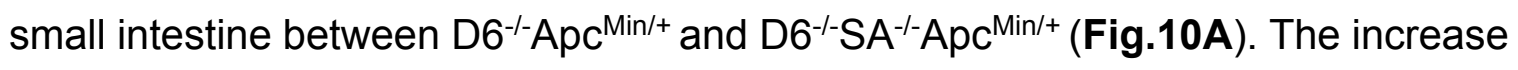

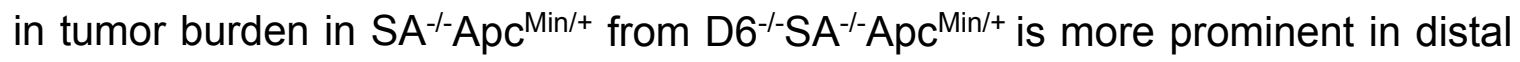
region and slightly less in proximal region and no change in the middle region. It is possible that the regional differences exist in the tumor initiation along the length of the intestine. The complete mechanisms for this phenomenon are unknown. In Fig.10B, total number of polyps were plotted again as a histogram and compared with the size distribution of these polyps in the small intestine. Even though no difference in total number of number of polyps in $\mathrm{D6}^{-1-} \mathrm{SA}^{-1-} \mathrm{Apc}^{\mathrm{Min}}$ from $\mathrm{D6} 6^{-/-} \mathrm{Apc}^{\mathrm{Min} /+}$, 
the tumor sizes increased significantly in $1-2 \mathrm{~mm}, 2-3 \mathrm{~mm}$ and $3 \mathrm{~mm}$ and above range in both in $\mathrm{SA}^{--} \mathrm{Apc}^{\mathrm{Min} /+}$ and $\mathrm{D6}^{-/-} \mathrm{SA}^{-/-} \mathrm{Apc}^{\mathrm{Min} /+}$. The tumor numbers are significantly reduced in the range of $0-0.1 \mathrm{~mm}$ in $\mathrm{D6}^{-1-} \mathrm{SA}^{-1-} \mathrm{Apc}^{\mathrm{Min}}$ and this could be due to enhanced growth rate of tumors in the absence of mast cells. The representative $\mathrm{H}$ \& E staining (Fig.11) of the small intestinal sections also show the presence of large tumors in the distal intestine of $\mathrm{D6}^{-1-} \mathrm{SA}^{-1-} \mathrm{Apc}^{\mathrm{Min}}$ and $\mathrm{SA}^{-/-}$ $\mathrm{Apc}^{\mathrm{Min} /+}$ compared to mice sufficient with mast cells.

Increased inflammation in $\mathrm{D} 6 /-\mathrm{SA}^{---} \mathrm{Apc}^{\mathrm{Min} /+}$ compared to $\mathrm{D} 6 /-\mathrm{SA}^{---} \mathrm{Apc} \mathrm{Min} /+^{-+}$ tumors

As indicated in the background section, expression of markers of inflammation such as COX2 and TNF- $\alpha$, are reduced in the small intestinal tumors from $\mathrm{D6}^{--} \mathrm{Apc}^{\mathrm{Min} /+}$ mice relative to $\mathrm{Apc}^{\mathrm{Min} /+}$ mice. To examine the expression of inflammatory markers in the tumors in mast cell deficient mice total RNA was isolated from distal intestine tumors and control intestines and analyzed for the expression of tumor promoting inflammatory markers COX-2 and TNF- $\alpha$. As shown Fig. 12 both COX2 and TNF- $\alpha$ are up-regulated in tumors of D6-/-SA ${ }^{-/}$ $\mathrm{Apc}^{\mathrm{Min} /+}$ compared to $\mathrm{D6}^{-1-} \mathrm{Apc}^{\mathrm{Min} /+}$ mcie. 


\section{Breeding scheme}

\begin{tabular}{|c|c|c|c|}
\hline \multirow[b]{2}{*}{1.} & Parents (M X F) & \multicolumn{2}{|c|}{ Selected Progeny } \\
\hline & $\mathrm{D} 6^{-/-} \mathrm{Apc} \mathrm{Min} /+^{-}$ & $\mathrm{D}^{+/-} \mathrm{SA}^{+/-} \mathrm{Apc}^{\mathrm{Min} /+}$ & $\mathrm{D}^{+/ /} \mathrm{SA}^{+/-}$ \\
\hline 2. & $\begin{array}{l}\mathrm{D6}^{+/-} \mathrm{SA}^{+/-} \mathrm{Apc}^{\mathrm{Min} /+} \times \mathrm{SA}^{-/-} \\
\text {and }\end{array}$ & $\begin{array}{l}\mathrm{D}^{-1-} \mathrm{SA}^{+/-} \mathrm{Apc}^{\mathrm{Min} /+} \\
\mathrm{D}^{-1-} \mathrm{SA}^{+/-}\end{array}$ & $\begin{array}{l}\mathrm{DG}^{+/-} \mathrm{SA}^{-/-} \mathrm{Apc}^{\mathrm{Min} /+} \\
\mathrm{D6}^{+/-} \mathrm{SA}^{-/-}\end{array}$ \\
\hline & $\mathrm{DG}^{+/-} \mathrm{SA}^{+/-} \mathrm{Apc}^{\mathrm{Min} /+} \mathrm{X} \mathrm{D6}^{+/-} \mathrm{SA}^{+/-}$ & $\mathrm{SA}^{-/-} \operatorname{Min}$ & $S_{A^{-1-}}$ \\
\hline 3. & $\begin{array}{l}\mathrm{D}^{-/-} \mathrm{SA}^{+/-} \mathrm{Apc}^{\mathrm{Min} /+} \times \mathrm{D}^{-/-} \mathrm{SA}^{+/-} \\
\text {and } \\
\mathrm{D} 6^{+/-} \mathrm{SA}^{-/-} \mathrm{Apc}^{\mathrm{Min} /+} \times \mathrm{D}^{+/-} \mathrm{SA}^{-/-}\end{array}$ & $D 6^{-1-} \mathrm{SA}^{-1-} \mathrm{Apc} \mathrm{c}^{\mathrm{M}}$ & $\mathrm{D}^{-1} \mathrm{SA}^{-1-}$ \\
\hline 4. & $\mathrm{D}^{-/-} \mathrm{SA}^{-/-} \mathrm{Apc}^{\mathrm{Min} /+} \times \mathrm{DG}^{-/-} \mathrm{SA}^{-/-}$ & $\mathrm{D} 6^{-/-} \mathrm{SA}^{-/-} \mathrm{Apc} \mathrm{M}^{\mathrm{M}}$ & $\mathrm{D}^{-1 /} \mathrm{SA}^{-1-}$ \\
\hline
\end{tabular}

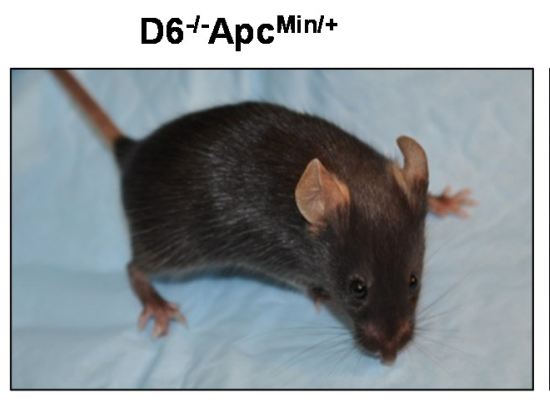

D6-I-SA ${ }^{+1-} \mathrm{Apc}^{\mathrm{Min} /+}$

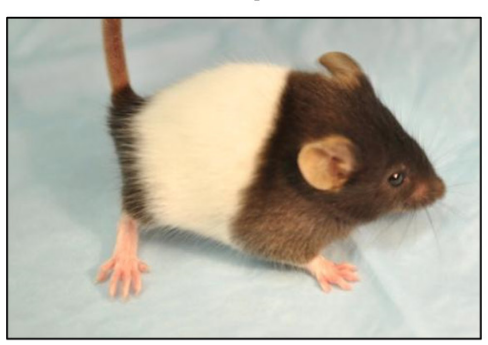

D6--SA ${ }^{-1-} \mathrm{Apc}^{\mathrm{Min} /+}$

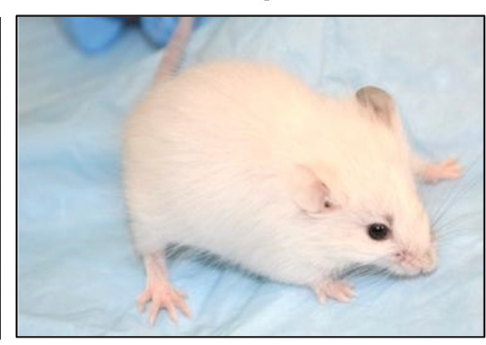

Figure 7: Generation of Mast cell deficient mice $K i t^{W-s h / W-s h}\left(\mathrm{SA}^{-\sigma^{-}}\right)$in $\mathrm{D6}^{-I^{-}} \mathrm{Apc}{ }^{\mathrm{Min} /+}$ background. $\mathrm{D6}^{-/-} \mathrm{Apc}^{\mathrm{Min} /+}$ was crossed with $\mathrm{SA}^{-/-}$mice to generate heterozygous $\mathrm{D6}^{+/-} \mathrm{SA}^{+/-}$ mice with or without $\mathrm{Apc}^{\mathrm{Min} /+}$ allele. The heterozygous male mice with $\mathrm{Apc}^{\mathrm{Min} /+}$ allele were

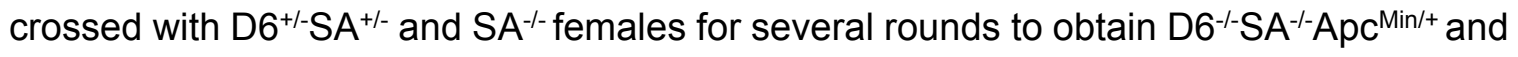
$\mathrm{SA}^{-l-} \mathrm{Apc} \mathrm{Min}^{\mathrm{+}}$ male breeders. The representative images of mice (different genotypes) are shown. 
(A)

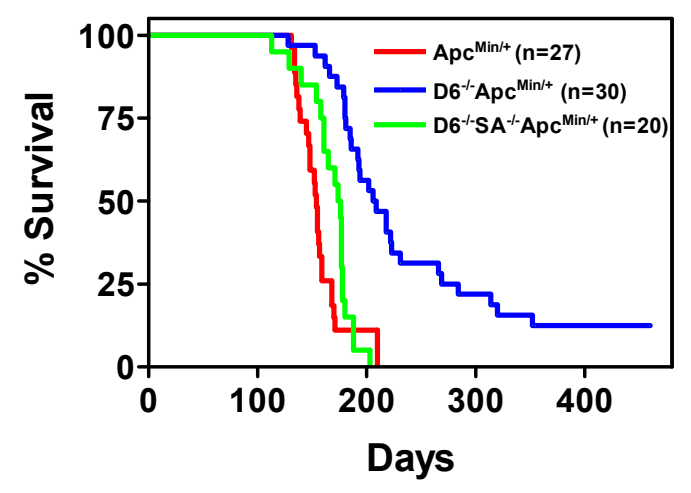

(B)

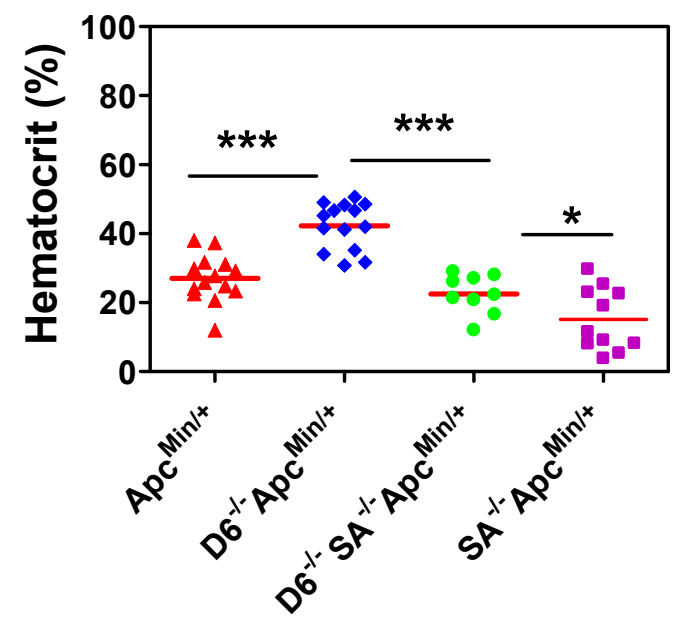

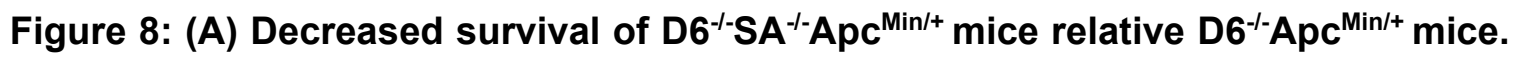
Kaplan-Meier survival curves. Lack of mast cells in $\mathrm{Apc} \mathrm{Min} /+^{-}$back ground $\left(\mathrm{SA}^{-/-} \mathrm{Apc}^{\mathrm{Min} /+}\right)$ decreased the survival of mice compared to $\mathrm{Apc}^{\mathrm{Min} /+}$. The survival advantage observed in $\mathrm{D6}^{-/-} \mathrm{Apc}^{\mathrm{Min} /+}$ mice was lost with mast cell deficiency. The median life span for $\mathrm{D6} 6^{-/-S A^{-/-}}$ $\mathrm{Apc}^{\mathrm{Min} /+}$ mice is 180 days, close to $\mathrm{Apc}^{\mathrm{Min} /+}$ mice median life span. (B). Hematocrit analysis (Anemic status): The $\mathrm{D6}^{-/-} \mathrm{SA}^{-/-} \mathrm{Apc}^{\mathrm{Min} /+}$ mice displayed lower hematocrits relative to $\mathrm{D6}^{--} \mathrm{Apc} \mathrm{Min}^{\mathrm{H}}$ mice at 110 days age indicating rapid disease progression in the absence of mast cells. The $\mathrm{SA}^{--} \mathrm{Apc} \mathrm{Min}^{\mathrm{Min}}$ showed even more severe disease with average HCT values around 15. Statistical analysis was performed using Mann-Whitney U test. ${ }^{* * *}=p<0.001$; ${ }^{* *}=p<0.01,{ }^{*}=P<0.05$ 
(A)

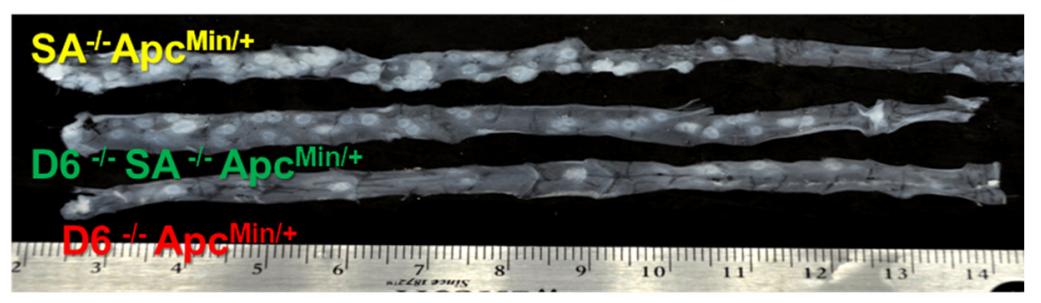

(B)

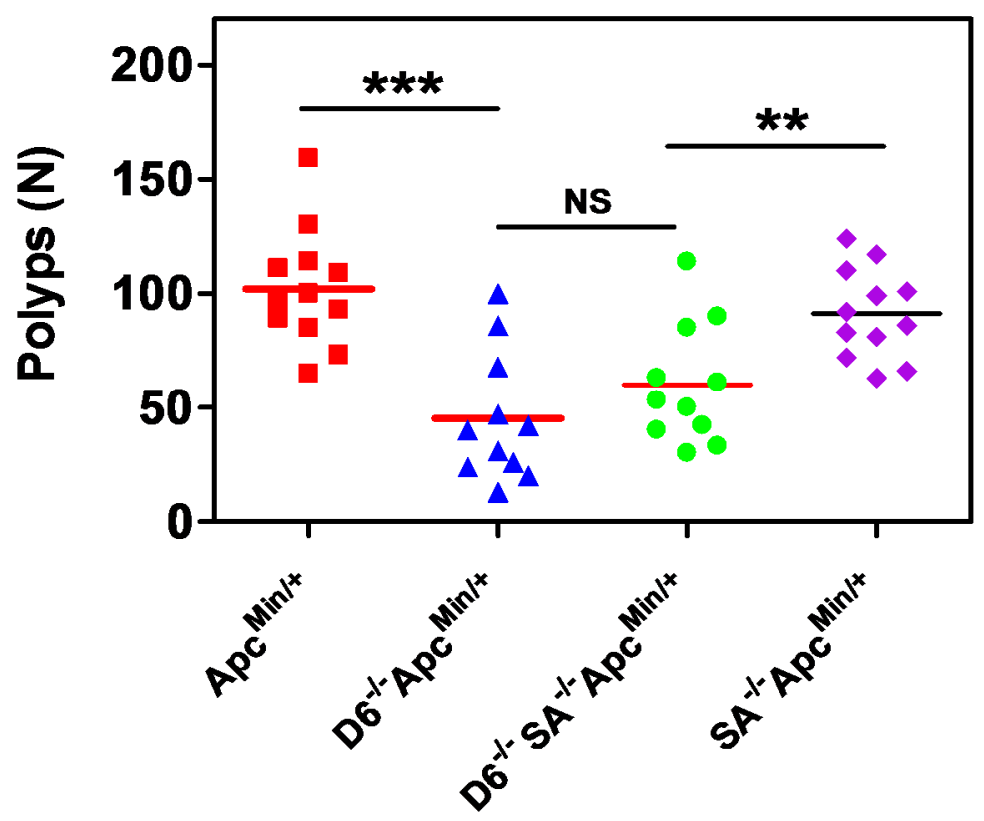

Figure 9: Small Intestinal polyp development in mast cell deficient Min mice A) Representative images of longitudinally opened distal intestine from 110 day old SA ${ }^{-/-}$ Apc ${ }^{\mathrm{Min},} \mathrm{D6}^{-{ }^{-}-\mathrm{SA}^{-/-} \mathrm{Apc}} \mathrm{Min} /+^{-}$and D6-/-Apc ${ }^{\mathrm{Min} /+}$ mice. B) The total number of polyps in the small intestine in $\mathrm{Apc}^{\mathrm{Min} /+}(\mathrm{n}=12), \mathrm{D6}^{-/-} \mathrm{Apc}^{\mathrm{Min} /+}\left(\mathrm{n}=11, \mathrm{D6}^{-/-} \mathrm{SA}^{-/-} \mathrm{Apc}^{\mathrm{Min} /+}(\mathrm{n}=11)\right.$ and $\mathrm{SA}^{-/-} \mathrm{Apc}^{\mathrm{Min} /+}$ mice. After 1 X PBS cleansing, the longitudinally opened small intestine was divided into three equal segments, and the total polyps were counted by stereo microscope at $10 \mathrm{X}$ magnification. 
(A)

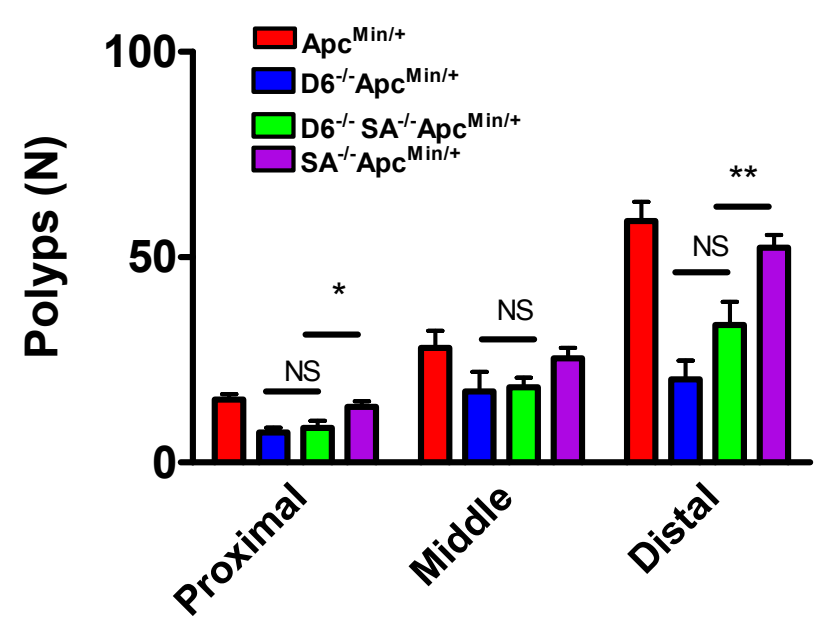

(B)

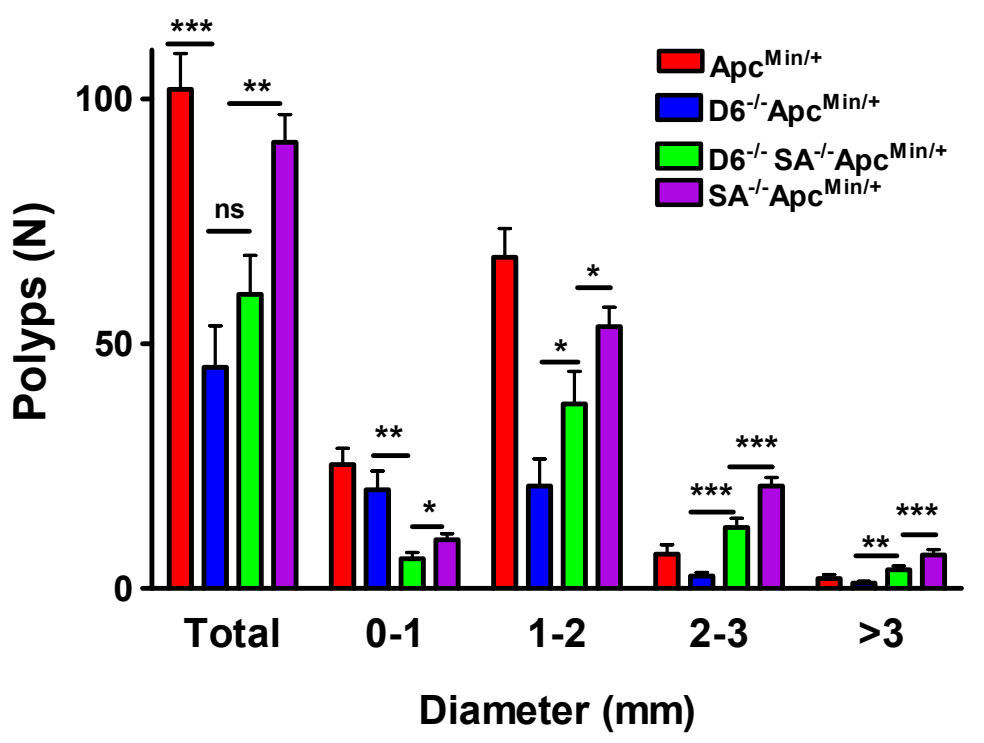

Figure 10: The frequency and size of polyps in small intestine. (A) The small intestine was divided into three parts equally as proximal, middle and distal. The longitudinally opened sections were used to count the polyps as described in methods. Lack of D6 in $\mathrm{SA}^{-1-} \mathrm{Apc}^{\mathrm{Mn} /+}$ background reduced polyp number in proximal and distal intestine compared

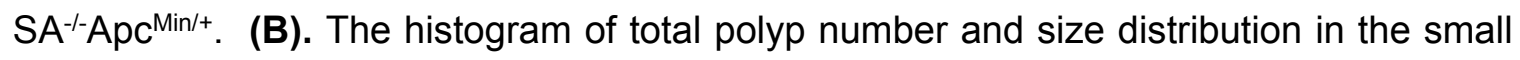

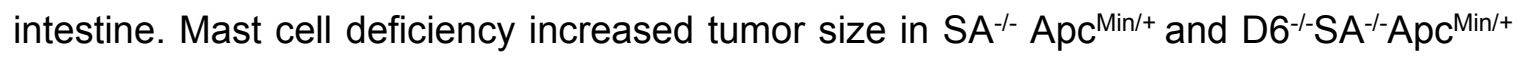
mice. 


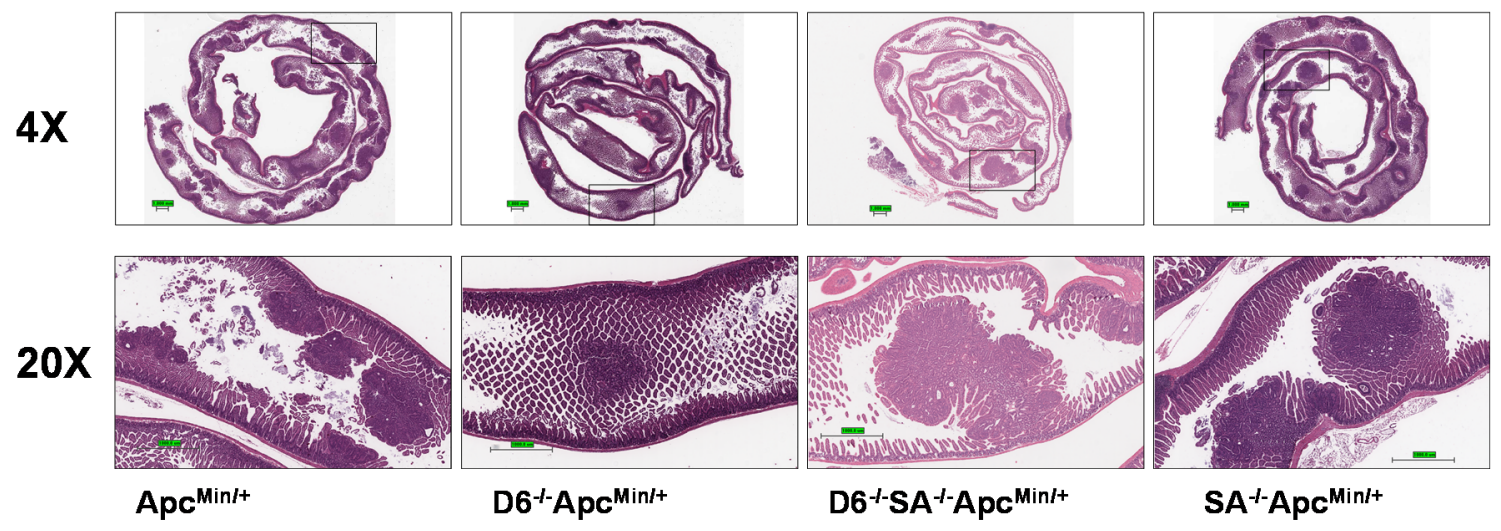

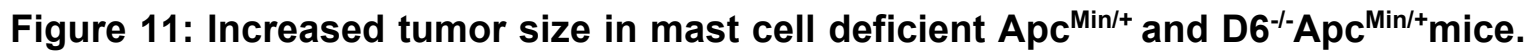
Distal regions of the small intestines of mice (age of 110 days) of the indicated genotype were prepared for histopathological examination as described in the methods. Cross section images stained with Hematoxylin and Eosin (H\&E) shows increased size of tumors

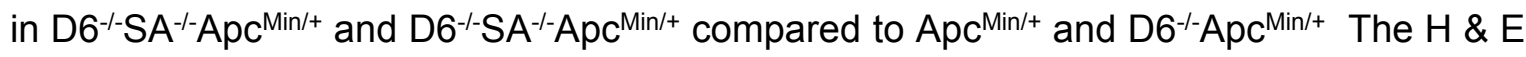
images were captured using an Aperio Image scope at indicated magnification. Scale bar indicates $1 \mathrm{~mm}$. 


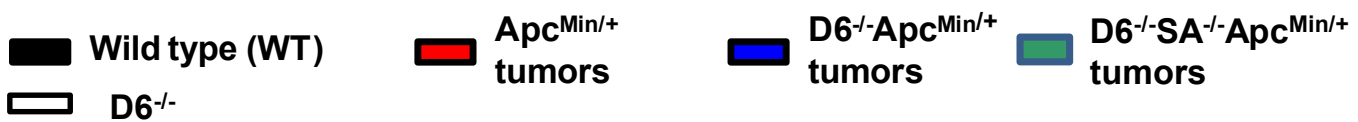

cox2

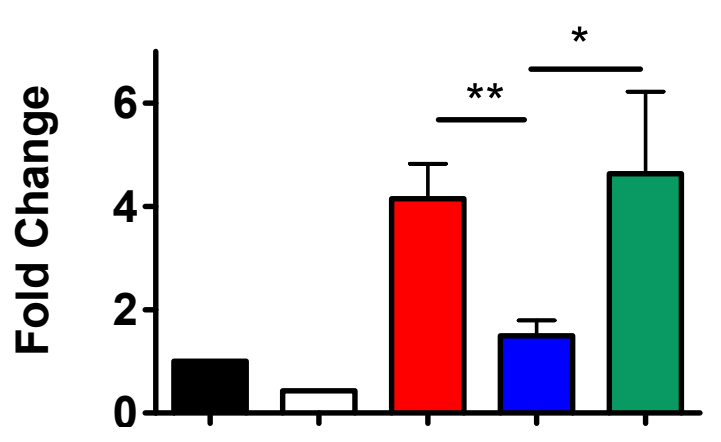

TNF- $\alpha$

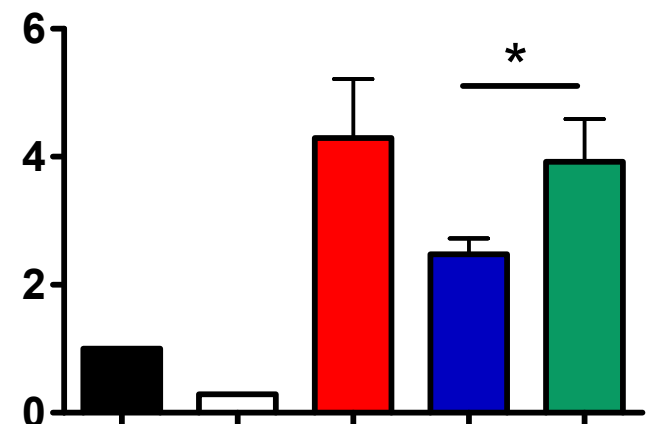

Figure 12: Increased inflammatory markers in the distal intestine tumors of $\mathrm{D6}^{-/-\mathrm{SA}^{-}}$ ${ }^{\text {I-Apc }}{ }^{\mathrm{Min} /+}$ compared to D6-Apc ${ }^{\mathrm{Min} /+}$. Relative mRNA fold changes of indicated genes in the total RNA isolated from wild-type and D6 (small intestines), $\mathrm{Apc}^{\mathrm{Min} /+}, \mathrm{D6}^{-/-} \mathrm{Apc}^{\mathrm{Min} /+}$ and $\mathrm{D6}^{--} \mathrm{SA}^{-1-} \mathrm{Apc}^{\mathrm{Min} /+}$ (small intestinal tumors) were determined using the SYBR green PCR method. The expression of each gene was normalized to $\beta$-actin and relative fold change was determined with WT as the baseline. Data are representative of tumors/tissues isolated from at least 4-5 different mice for each genotype. Statistical analysis was performed using Unpaired t test $\left(^{* *}=p<0.01,{ }^{*}=p<0.05\right)$. 
Table 1: The total number and size of the small intestinal polyps for the indicated genotypes are shown. Each value represent mean \pm SEM. The percentage of total is shown in parenthesis.

\begin{tabular}{|c|c|c|c|c|c|}
\hline Genotype & Total & $0-1 \mathrm{~mm}$ & $1-2 \mathrm{~mm}$ & 2-3 mm & $>3 \mathrm{~mm}$ \\
\hline $\begin{array}{l}\text { Apc }^{\operatorname{Min} /+} \\
(n=12)\end{array}$ & $\begin{array}{c}102 \pm 7.3 \\
(100 \%)\end{array}$ & $\begin{array}{c}25.3 \pm 3.3 \\
(25 \%)\end{array}$ & $\begin{array}{c}67.7 \pm 5.9 \\
(66 \%)\end{array}$ & $\begin{array}{c}7 \pm 1.9 \\
(7 \%)\end{array}$ & $\begin{array}{l}2 \pm 0.8 \\
(1.9 \%)\end{array}$ \\
\hline $\begin{array}{c}D 6^{-/-} \mathrm{Apc}^{\mathrm{Min} /+} \\
(\mathrm{n}=11)\end{array}$ & $\begin{array}{c}45 \pm 8.4 \\
(100 \%)\end{array}$ & $\begin{array}{c}20.2 \pm 3.8 \\
(45 \%)\end{array}$ & $\begin{array}{c}20.9 \pm 5.6 \\
(46 \%)\end{array}$ & $\begin{array}{c}2.5 \pm 0.7 \\
(6 \%)\end{array}$ & $\begin{array}{l}1.1 \pm 0.3 \\
(2.4 \%)\end{array}$ \\
\hline $\begin{array}{c}\mathrm{D} 6 \mathrm{SA}^{-/-} \mathrm{Apc} \\
(\mathrm{n}=11)\end{array}$ & $\begin{array}{c}60.1 \pm 7.9 \\
(100 \%)\end{array}$ & $\begin{array}{c}6.1 \pm 1.3 \\
(10 \%)\end{array}$ & $\begin{array}{c}37.7 \pm 6.6 \\
(63 \%)\end{array}$ & $\begin{array}{c}12.5 \pm 1.9 \\
(21 \%)\end{array}$ & $\begin{array}{c}3.8 \pm 0.7 \\
(6 \%)\end{array}$ \\
\hline $\begin{array}{l}\mathrm{SA}^{-/-} \mathrm{Apc}^{\mathrm{Min} /+} \\
(\mathrm{n}=12)\end{array}$ & $\begin{array}{c}91.17 \pm 5.7 \\
(100 \%)\end{array}$ & $\begin{array}{c}9.9 \pm 1.3 \\
(11 \%)\end{array}$ & $\begin{array}{c}53.5 \pm 3.9 \\
(59 \%)\end{array}$ & $\begin{array}{c}20.9 \pm 1.8 \\
(23 \%)\end{array}$ & $\begin{array}{c}6.8 \pm 1.1 \\
(7 \%)\end{array}$ \\
\hline
\end{tabular}




\section{DISCUSSION}

Our previous work suggested that reduced tumor burden in the $\mathrm{D6}^{-1-} \mathrm{Apc} \mathrm{Min}^{\mathrm{M}}+$ mice might be due to increased mast cell infiltration into tumors. The data presented in this chapter offers genetic evidence for this concept and suggest that mast cell infiltration into intestinal tumors might have a strong beneficial effect in intestinal tumor progression.

Previous studies showed that absence of D6 resulted in increased inflammation in a variety of models including chemical-induced cutaneous inflammation [23, 27], ovalbumin or Mycobacterium-induced lung inflammation [28, 29], lipopolysaccharide (LPS)-induced placental inflammation (abortion model) [30] and methylcholanthrene/phorbol ester (TPA)-induced skin cancers [31]. In contrast, our results presented earlier (Figures 2-3) suggest that loss of $\mathrm{D} 6$ is protective from developing intestinal tumors in $\mathrm{Apc}^{\mathrm{Min} /+}$ background mice. Since inflammation is known to promote intestinal cancer in this model, it raises the critical questions about how inflammation is altered in the intestines of $\mathrm{D6}^{-1}$ $\mathrm{Apc}^{\mathrm{Min} /+}$ and which immune cell types are mediating the observed protective effects. Our experiments with the mast cell deficient mice provided the evidence that mast cells could account, at least in part, for this phenotype. The survival

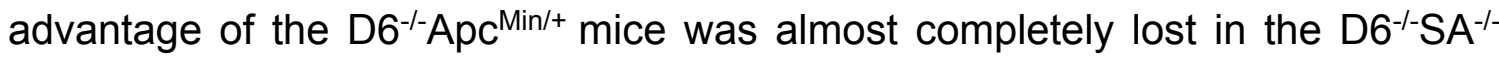
$\mathrm{Apc}^{\mathrm{Min} /+}$ and the more severe anemia further supports the idea that absence of mast cells hastens the disease process in these mice.

However, analysis of tumor burden reveals a more complex picture of intestinal tumorigenesis in the $\mathrm{Apc}^{\mathrm{Min} /+}$ mice in the $\mathrm{D6}^{-/-}$and $\mathrm{SA}^{-/-}$backgrounds. 
Further analysis of the tumor burden in these mice (Table 1) provided some answers to the observed phenotype. There are two components to analyze, tumor initiation and tumor progression. The total tumor number is indicative of initiation and the tumor size range (size) is indicative of progression/growth of tumors. Lack of D6 in Apc ${ }^{\mathrm{Min} /+}$ background decreased SI tumors (around 50\%). Absence of mast cells in $\mathrm{Apc}^{\mathrm{Min} /+}$ mice did not affect tumor numbers (tumor initiation), but significantly increased the proportion of ( $7 \%$ vs $23 \%)$ larger tumors $(2-3 \mathrm{~mm}$ tumors). Likewise, absence of $\mathrm{D} 6$ in $\mathrm{SA}^{--} \mathrm{Apc} \mathrm{Min}^{++}$background decreased overall number of tumors (102 vs 60 ) but have significantly increased tumor size (6\% vs $21 \%)$. These results suggest that mast cells are critical in controlling the size of tumors. We postulate that mast cell dependent mechanisms control the tumor progression (size), whereas mast cell independent mechanisms might control tumor initiation (numbers) in $\mathrm{D6}^{-/-} \mathrm{SA}^{-/-} \mathrm{Apc}^{\mathrm{Min} /+}$ mice. An important unresolved question from these experiments is what cellular and molecular mechanisms account for the decreased tumor incidence in the $\mathrm{D} 6^{-/-} \mathrm{Apc} \mathrm{Min}^{\mathrm{i}}$ mice. Other unpublished results from our laboratory showed that $\mathrm{D6}^{-/-} \mathrm{Apc}^{\mathrm{Min} /+}$ mice in the Rag2I- background displayed a very similar phenotype reported here for the $\mathrm{D6}^{-1-\mathrm{SA}^{-1-}}$ $\mathrm{Apc}^{\mathrm{Min} /{ }^{+}}$mice i.e., similar tumor incidence but more rapid progression of tumors. This suggests that neither mast cells nor the adaptive immune systems are likely to control tumor initiation but only play a role in tumor progression. Oncogenic transformation was proposed to initiate an inflammatory response termed the "intrinsic pathway" that could lead to inflammation that might help eliminate the transformed cells [2]. Only when the innate response fails to eliminate the 
transformed cells then tumor will form. It is possible that absence of D6 could lead to a heightened innate response (increased mast cells and possible increase chemokines due to lack of decoy function of D6) there by effective elimination of transformed cells leading to reduced tumor incidence in the $\mathrm{D6}^{-{ }^{--} \mathrm{Apc}} \mathrm{Min}^{\mathrm{+}}$ mice. Additional experiments targeting innate immune system are required to verify this hypothesis [40]. Inflammation is a well-known promoter of tumor development. In the $\mathrm{Apc}^{\mathrm{Min} /+}$ model of spontaneous intestinal carcinogenesis, loss of MyD88, a key mediator of toll-like receptor (TLR)-pathway induced inflammation, is highly protective [90]. A number of other studies also demonstrated a clear association of increased inflammation to the rapid development of intestinal tumors [90-93]. Our studies showing that inflammatory markers, such as TNF- $\alpha$ and COX2 are decreased in the small intestinal tumors of $\mathrm{D6}^{-{ }^{-}} \mathrm{Apc}^{\mathrm{Min} /+}$ compared to $\mathrm{Apc}^{\mathrm{Min} /+}$ mice and increased in $\mathrm{D}^{-1 / \mathrm{SA}^{-1-} \mathrm{Apc}} \mathrm{Min} /+^{\mathrm{m}}$ mice are also consistent with inflammation promotion of adenomas. The mechanisms behind this increase in inflammation in the $\mathrm{D}^{-1 / \mathrm{SA}^{-1-} \mathrm{Apc}}{ }^{\mathrm{Min} / \mathrm{H}}$ mice are unclear at this time.

Two other important questions on the role of mast cells in $\mathrm{D} 6 \%^{-} \mathrm{Apc} \mathrm{Min} /+^{+}$mice are 1) what are the mechanisms for their enhanced accumulation in the SI tumors and 2) what are the mechanisms by which they slow tumor growth. These questions will be addressed in chapter IV and $\mathrm{V}$, respectively. 


\section{CHAPTER IV}

\section{MECHANISMS OF MAST CELL HOMING IN D6-/-APC ${ }^{\mathrm{MIN} /+}$ MICE}

\section{INTRODUCTION}

Characterization of $\mathrm{D6}^{--\mathrm{SA}^{-/-} \mathrm{Apc}} \mathrm{Min/+}^{\mathrm{m}}$ mice showed that mast cells play a protective role in intestinal tumorigenesis. Recruitment of mast cells in to tumors is known from Ehlrich's days (reviewed by Beaven M [94]) and their role in various human and murine cancers is discussed extensively in Chapter I. The c-Kit-SCF axis plays crucial role not only in mast cell development, migration to gut mucosa, proliferation and activation but also involved in their recruitment to tumors [67, 95]. The chemokines, CCL2 (MCP-1) and CCL5 (RANTES) are also involved in mast cells recruitment to pancreatic islet tumors [48]. Murine mast cells express several chemokine receptors and their expression levels are modified under inflammatory conditions [66]. All tissue mast cells are derived from heamatopoietic stem cells that differentiate into circulating mast cell progenitors (MCPs). Development of methods to purify HSCs and selectively amplify and culture mast cell progenitors that differentiate into mature mast cells has been valuable to study mast cell functions in vitro [96]. The in vitro cultured mast cells are also routinely used in adoptive transfer experiments for in vivo functional analysis. We hypothesize that altered expression of chemokine and chemokine receptors in mast cells play 
critical role in enhancement of their tumor infiltration. To determine which of the chemokines and chemokine receptors involved in the enhanced recruitment of mast cells in $\mathrm{D6}^{--} \mathrm{Apc}^{\mathrm{Min} /+}$ tumors and to perform adoptive transfer experiments, we generated and cultured bone marrow derived mast cells (BMMCs) from C57BL/6 and $\mathrm{D6}^{-/-}$mice. 


\section{RESULTS}

\section{Phenotypic characterization of bone marrow derived mast cells (BMMCs)}

BMMCs were generated and cultured as described in the methods with the addition of stem cell factor (SCF) and IL-3. The purity of these cultures were tested by staining with mast cell specific markers CD117 and FceR1 and analyzed by flow cytometry. They become homogeneous at around four weeks of culture and confirmed by surface staining for either CD117 or FceR1 or both (Fig. 13A). The BMMCs were also identified by double Immunofluorescence staining and confocal microscopy analysis for CD117 (green) and FcER1 (Red) expression (Fig.13B). Over $95 \%$ of the cultured cells stained for both CD117 and FcER1. BMMCs grow slowly in suspension and requires sub culturing every five days. For most experiments, healthy cells cultured for 6 to 12 weeks were used.

\section{Microarray analysis of BMMCs from wild type (WT) and D6--- mice}

To identify the potential mechanisms involved in the enhanced migration of $\mathrm{D6}^{-1-}$ mast cells, we examined the global changes in gene expression patterns between the WT and $\mathrm{D6}^{-/}$mast cells by microarrays. We were particularly interested in differences in the chemokine and chemokine receptor gene expression patterns in $\mathrm{D6}^{-1-}$ mast cells in comparison with WT mast cells. In addition, we also wanted to explore differences during the in vitro development of mast cell differentiation. Therefore, total RNA was isolated from 2 week and 10 week old mast cells and analyzed on Affymetrix mouse microarray chips as described in the methods. To obtain pure mast cells from two week old culture, BMMCs were purified on MACS column using CD117 antibody. According to heat 
map analysis (Fig.14) several genes are differentially expressed between the wild type and D6--mast cells either at 2 weeks of age or at 10 weeks as well as during the mast cell development from 2 weeks to 10 weeks. Of interest to the current study, chemokine receptors CCR2 and CCR5 genes are highly up regulated in D6I- mast cells cultured for two weeks (Fig.15A) or 10 weeks (Fig.15B) compared to WT mast cells.

\section{Increased expression of CCR2 and CCR5 in D6-/- BMMCs}

Microarray data was confirmed by analyzing CCR2 and CCR5 gene expression using specific primers in RT PCR analysis. Amplification plots (Fig. 16A) showed that the CCR2 and CCR5 mRNAs (Fig. 16B) in D6--- amplified much earlier than WT, whereas the house keeping gene $\beta$-actin expression level is similar in WT and D6-- BMMCs. The CCR2 and CCR5 mRNA levels were significantly increased in D6-/- BMMCs compared to WT (Fig.16A and 16B right panels). We also examined the expression profiles of several CC, CXC chemokine receptors and leukotriene receptors BLT1, BLT2 (Fig. 17). There were no significant differences in the expression levels of any of these receptors other than CCR2 and CCR5 between the WT and D6--- mast cells. Since we observed substantial increase in CCR2 mRNA expression, we stained with CCR2 antibody to determine whether the increase in the mRNA expression correlated with increase in the surface protein expression. Flow cytometry analysis (Fig.18) shows that CCR2 expression is much higher on D6 ${ }^{-/}$mast cells whereas CCR2 staining on the WT BMMCs is comparable to isotype control antibody. 


\section{Increased migration of D6--- BMMCs towards CCL2 and CCL5}

Next, we asked the question whether these highly expressed CCR2 and CCR5 receptors are functional on D6 ${ }^{--}$mast cells. WT and D6 ${ }^{-/}$mast cells were used in a standard Transwell chamber assay of chemotaxis with increasing concentrations of ligand. The cells migrated into the bottom chamber were counted by flow cytometry. The WT and D6--- mast cells both migrated well towards SCF with peak response at $1 \mathrm{nM}$ concentration (Fig. 19 left panel). When increasing concentrations of CCL2 or CCL5 were tested, ligands for CCR2 and CCR5 respectively, only D6 ${ }^{-/-}$mast cells migrated efficiently showing the typical bell shape

curve, whereas WT mast cells did not show any chemotactic response (Fig.19 middle, right panels).

\section{Functional CCR2 and CCR5 receptors on D6-1- BMMCs}

The functionality of CCR2 and CCR5 receptors on D6-- mast cells was further tested using their corresponding ligands, CCL2 and CCL5 (which are also D6 receptor ligands) in intracellular calcium flux assay. D6--- mast cells are capable of releasing calcium in a dose dependent response to CCL2 (Fig. 20A) or CCL5 (Fig. 20B). WT BMMCs did not respond to either CCL2 or CCL5 even at the highest concentration $(60 \mathrm{nM})$ tested. The failure of WT mast cells to signal through D6 ligands prompted us to verify that they are not defective in other aspects. Thus, WT mast cells were incubated with $100 \mathrm{ng} / \mathrm{ml}$ anti DNP-lgE antibody overnight and their responsiveness to $60 \mathrm{nM} \mathrm{CCL2}$ and DNP in intracellular calcium flux assay was tested. As expected D6--- mast cells were responsive to both CCL2 and DNP signaling (Fig. 21A). The WT mast cells did not respond to CCL2 but responded 
well to DNP assuring there is no inherent defect with the WT BMMC cultures in releasing intracellular calcium upon activation (Fig. 21B).

\section{Increased CCR2 and CCR5 expression in D6 ${ }^{-/-}$mice is limited to mast cells}

We next asked whether this high expression of CCR2 and CCR5 in D6-mast cells is a common phenomenon and other leukocytes also expressed such high levels of these receptors? The T-cells and B-cells were isolated from spleen and mesenteric lymph nodes as described in methods. The total RNA was isolated from purified T and B cells and analyzed for CCR2 and CCR5 expression by real time PCR (Fig. 22). As seen in the amplification plots (Fig. 22A and 22B left panels) or relative fold changes using the WT as a baseline (Fig. 22A and 22B right panels) there is no significant difference between $\mathrm{D6}^{--}$and WT in the CCR2 and CCR5 expression. There appears to be slight increase in CCR5 expression in $\mathrm{D6}^{-1-} \mathrm{B}$ cells compared to WT B cells. The fold changes in these primary $\mathrm{T}$ and $\mathrm{B}$ cells when compared to fold changes in mast cells are not significant.

We also tested other antigen presenting cells for CCR2 and CCR5 expression in RTPCR. Bone marrow derived macrophages (BMDMs) and dendritic cells (DCs) were isolated from WT and D6---mice according to the protocols described in methods. As seen in the amplification plots (Fig. 23A and 23B left panel) or relative fold change using WT as a base (Fig. 23A and 23B right panel), we did not observe any significant difference between D6-- and WT in expression levels of CCR2 and CCR5 in BMDMs. There appears to be slight increase in CCR2 and CCR5 expression in D6-/- BMDCs from WT BMDCs. 


\section{Developmental changes in CCR2 and CCR5 expression in D6 ${ }^{-1-}$ BMMCs}

It is known that the expression of CCR2 and BLT1 changes during maturation of BMMCs [97]. Both these receptors are expressed at high levels in mast cell progenitors but mature mast cells appear to lose the expression. To examine if the $\mathrm{D6}^{-/-}$mast cells follow similar pattern of changes, we tested the mRNA levels of CCR2 and CCR5 at various time points during the development of mast cells. As shown in Fig. 24, the relative levels of CCR2 and CCR5 decreased dramatically during the development of WT mast cells but remained unchanged and somewhat elevated during the development of $\mathrm{D6}^{-/-}$mast cells.

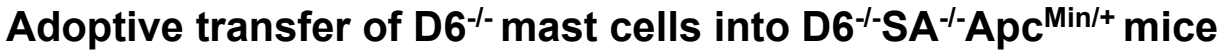

To test the efficacy of cultured mast cells to complement the in vivo deficiency of mast cells in $\mathrm{D6}^{--\mathrm{SA}^{--} \mathrm{Apc}} \mathrm{Min} /+^{+}$mice, we performed several adoptive transfer experiments. Result from a typical adoptive transfer experiment is shown in Fig.25. In this experiment, four to six weeks cultured D6-/- mast cells $\left(5 \times 10^{6}\right.$ cells/mouse) were transferred via i.p. injection into four week old D6 ${ }^{-/-S A^{-/-} \mathrm{Apc}} \mathrm{Min} /+^{-}$ mice and analyzed for tumor burden at twelve weeks of post transfer. We did not see a significant change in either the tumor numbers (Fig. 25A) or their distribution across the small intestine (Fig. 25B). We also did not observe a significant change in the size distribution of tumors (Fig. 25C). We attempted to verify the homing of the transferred mast cells by analyzing the SI tumors for MCPT-1. Consistent with the lack of phenotypic reversion we also did not see detectable mast cell infiltration into the tumors from $\mathrm{D6}^{-1-} \mathrm{SA}^{-1-} \mathrm{Apc}^{\mathrm{Min} /+}$ receiving adoptively transferred $\mathrm{D6}^{-{ }^{-}}$mast cells. 


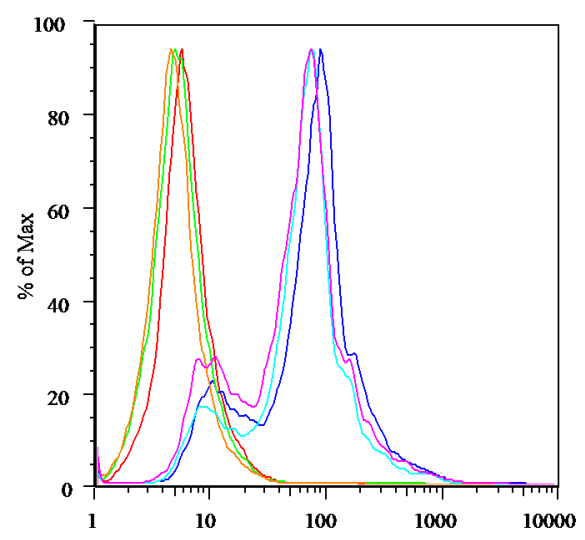

CD117(C-Kit)

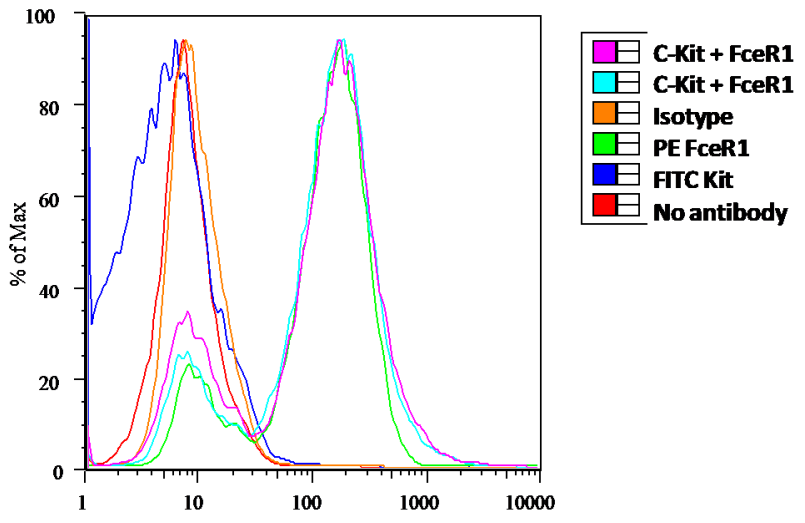

FceRI
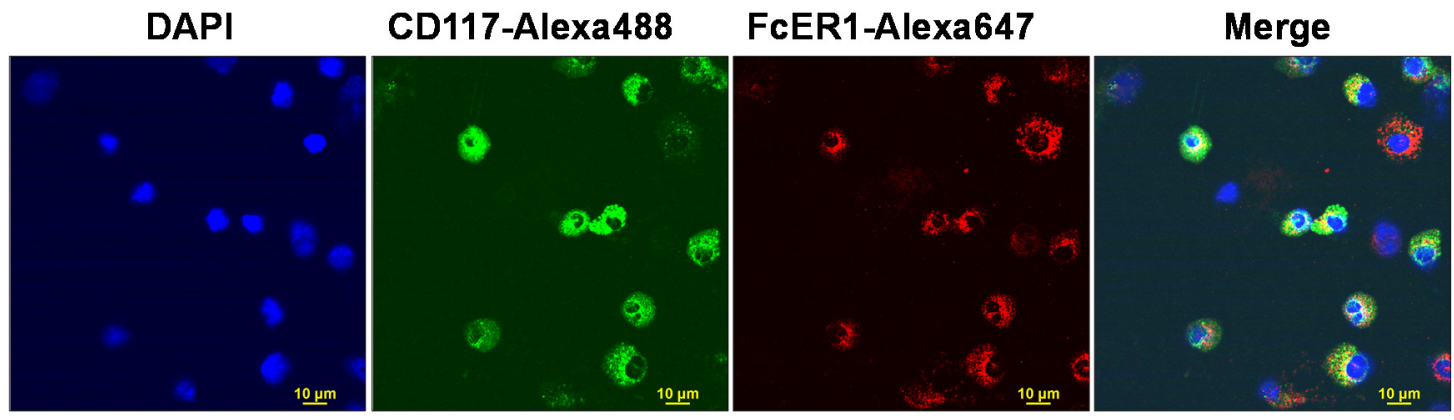

Figure 13: Characterization of bone marrow derived mast cells (BMMCs). BMMCs were cultured as described in methods. (A) Flow Cytometry Analysis of BMMCs cultured for four weeks for cell-surface expression of mast cell specific markers CD117 (C-Kit) and FceR1. BMMCs were incubated with either FITC- CD117 $(1 \mu \mathrm{g})$ or PE-FceR1 $(2 \mu \mathrm{g})$ antibody or combined (Pink lane $-1 \mu \mathrm{g}$ of CD117 $+2 \mu \mathrm{g}$ of FceR1; Cyan lane $-1 \mu \mathrm{g}$ of CD117 + $4 \mu \mathrm{g}$ of FcER1) as indicated. Isotype control antibody as reference for no staining. (B). Double Immunofluorescence staining and confocal microscopy analysis of BMMCs for CD117 and FcER1 expression. Cytospin preparations of BMMCS were stained indirectly using Rat anti CD117 and Biotin labeled anti FcER1 antibodies and visualized by Green Alexa-488 labeled anti rat antibody and Red Alexa-647 Streptavidin. Blue, DAP1; Green, CD117; Red, FcعR1. The scale bar indicates $10 \mu \mathrm{m}$. 


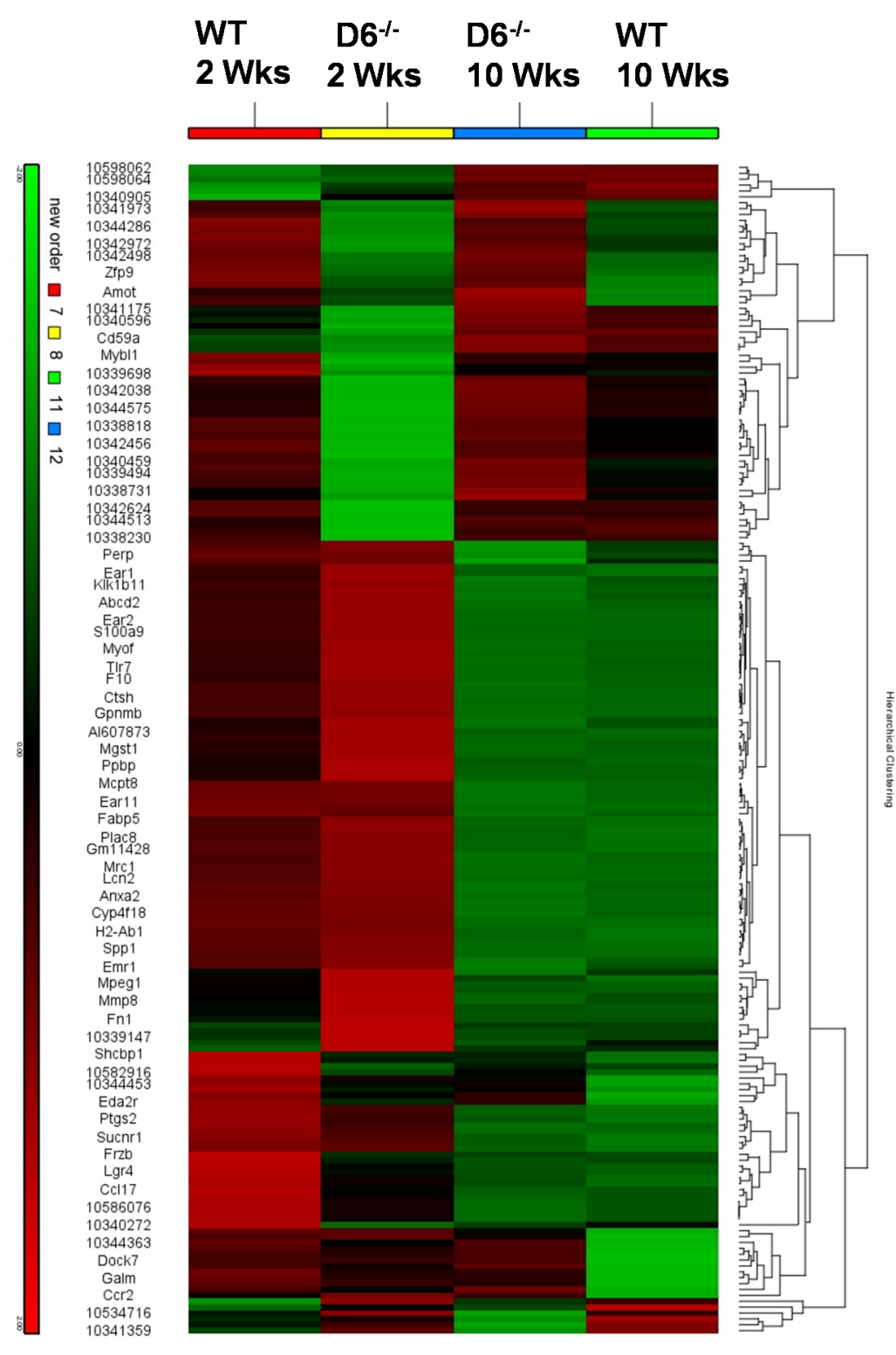

Figure 14: Microarray heat map analysis of BMMCs cultured from Wild type (WT) and D6 $^{-/-}$mice. RNA was isolated from three independent WT and D6-/- BMMC cultures collected at 2 weeks and 10 weeks of age and microarrays performed using Affymetrix GeneChip $®$ Mouse Gene 1.0 ST Array. The genes differentially expressed between wild type and D6 ${ }^{-/-}$and also the changes in the mast cell development from 2 week to 10 weeks. Red shows highest expression and green shows lowest expression. 


\section{(A) 2 Weeks}

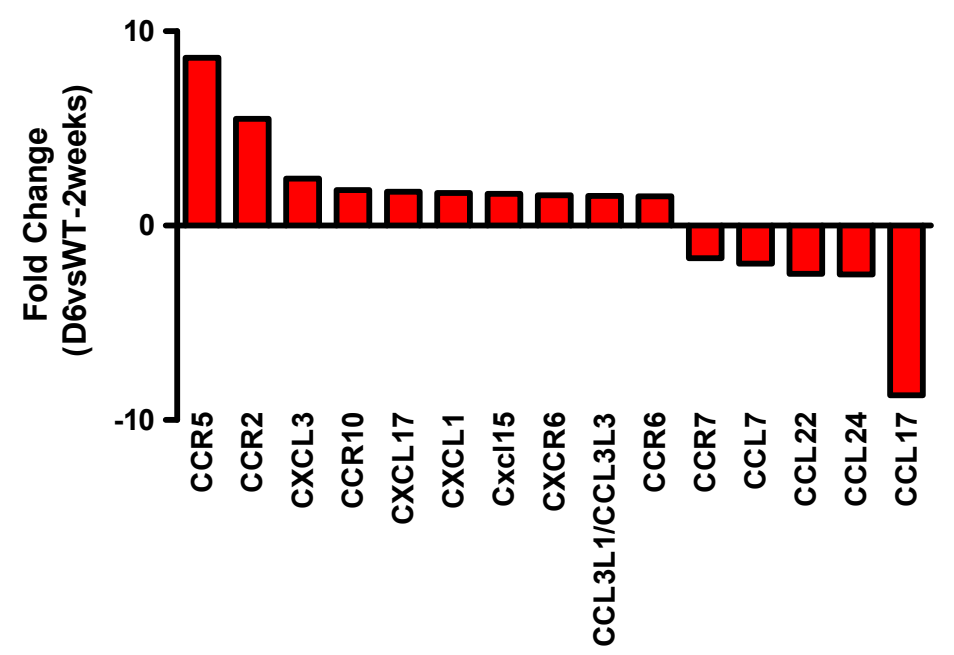

(B) 10 Weeks

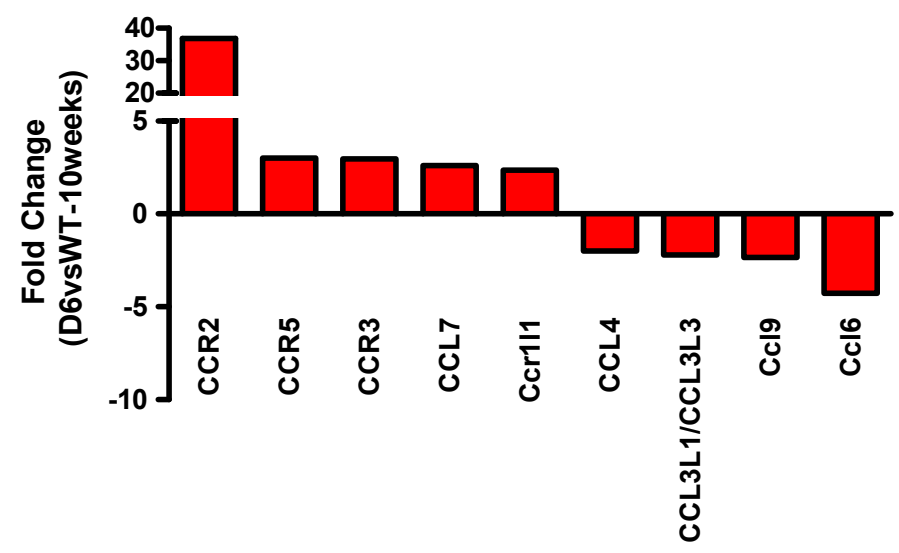

Figure 15: Expression pattern of chemokines and chemokine receptors in BMMCs. Total RNA from BMMCs cultured for two weeks (enriched for CD117 positive cells) (A) and ten weeks (B) was analyzed by microarrays as described in the methods. The fold changes of expression of the indicated genes were calculated by comparing D6-- vs WT using wild type expression as base line. Expression of those genes changed at least 2 fold with $p$ value of 0.05 was plotted. Chemokine receptors CCR2 and CCR5 were up regulated most both in 2 and 10 weeks cultured D6-/- BMMC compared to WT BMMC. 
(A) CCR2

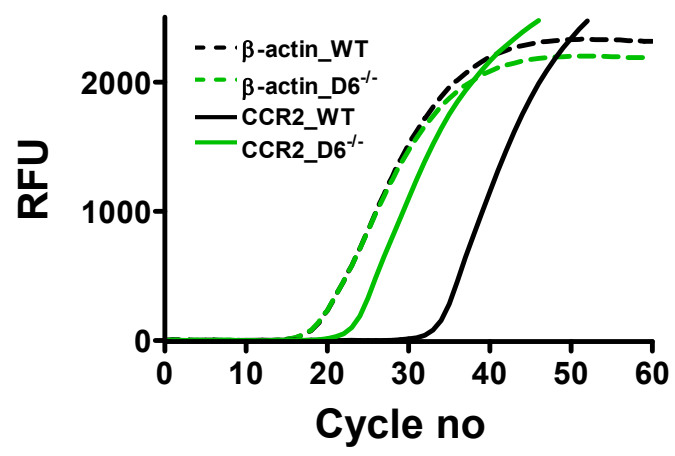

(B) CCR5

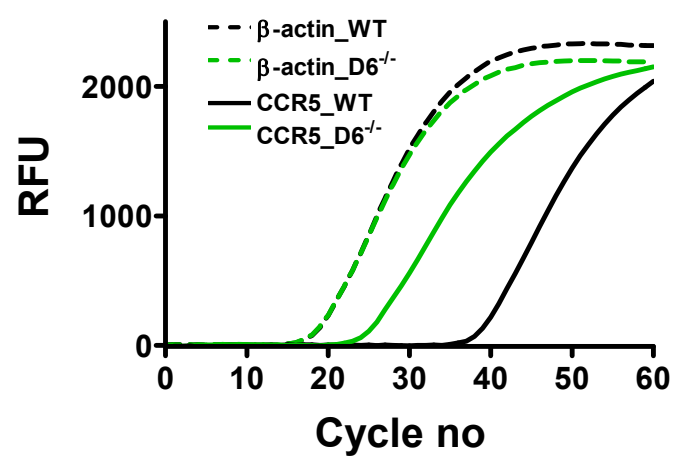

CCR2

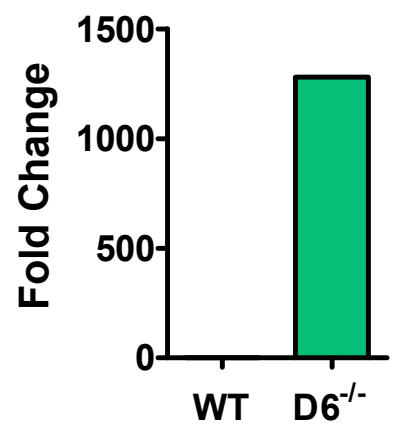

CCR5

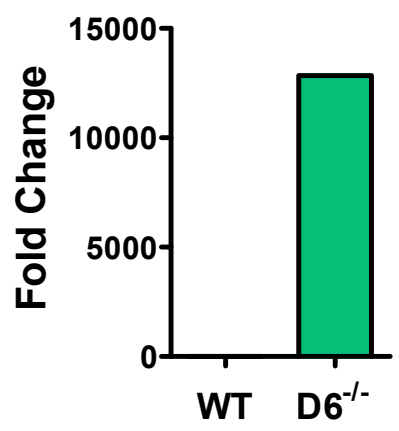

Figure 16: Increased expression of CCR2 and CCR5 mRNA levels in D6-- BMMCs. The mRNA levels of CCR2 (A) and CCR5 (B) in BMMCs (WT and D6--/) were measured using real time PCR using SyBR green as described in methods. The left panels represent the amplification plots of $\beta$-actin, CCR2 (A) and CCR5 (B). Amplification plots showing the early amplification of CCR2 and CCR5 in D6-- BMMCs compared to WT BMMCs. The $\beta$ actin expression level is similar in WT and D6-/- BMMCs. A and B (Right panels): The fold change was calculated using WT as base line and results indicate significant increase of CCR2 and CCR5 in D6--1- BMMCs. 


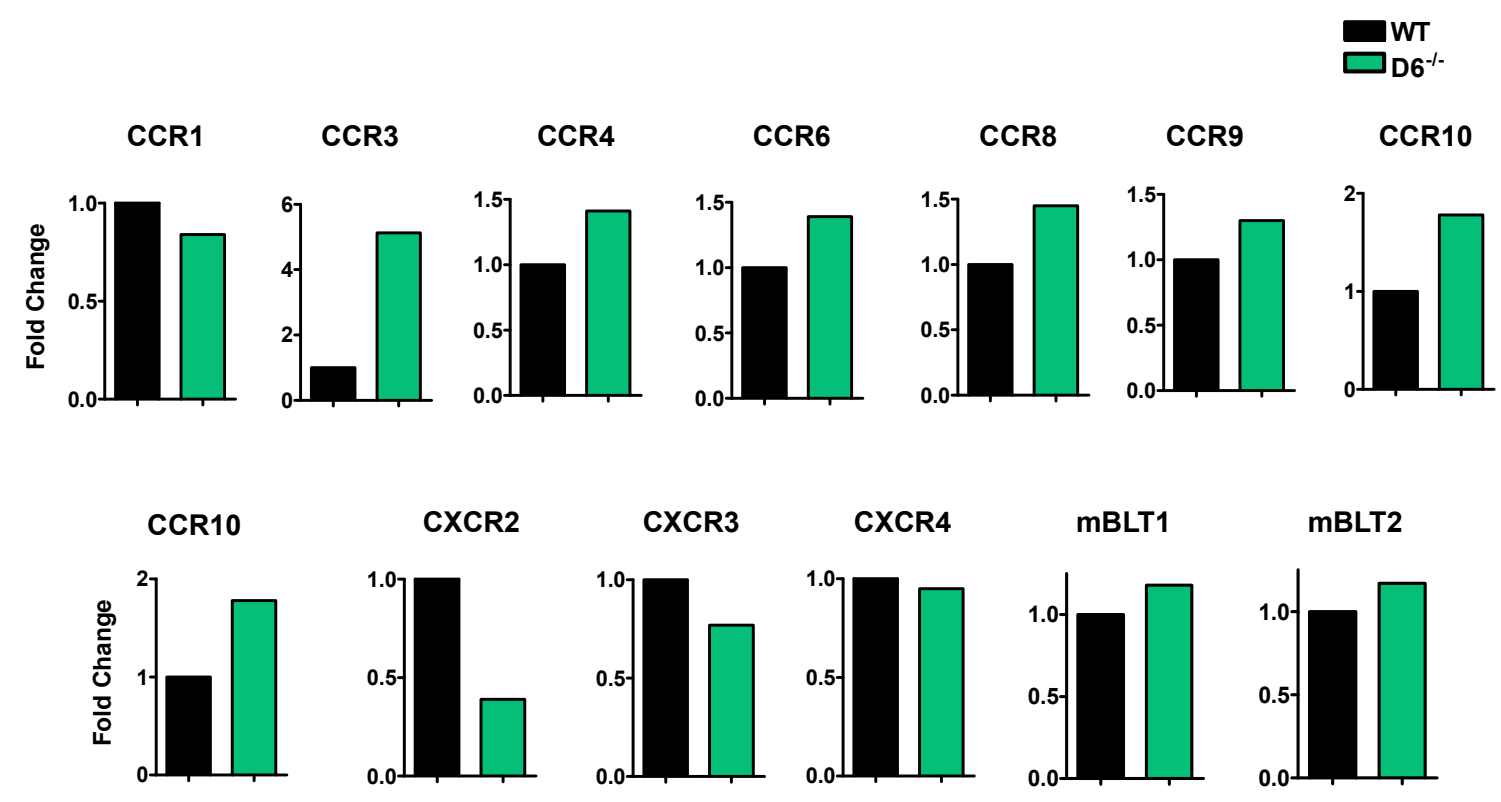

Figure 17: Expression of chemokine receptors in BMMCs. The mRNA levels of the indicated chemokine receptors were measured in total RNA isolated from ten week old cultures of BMMCs from the WT and D6-/- mice using SyBR RT PCR protocols. The level of expression of each gene was normalized to the WT as baseline. Levels of the chemokine receptors tested here are not significantly different from each other. 


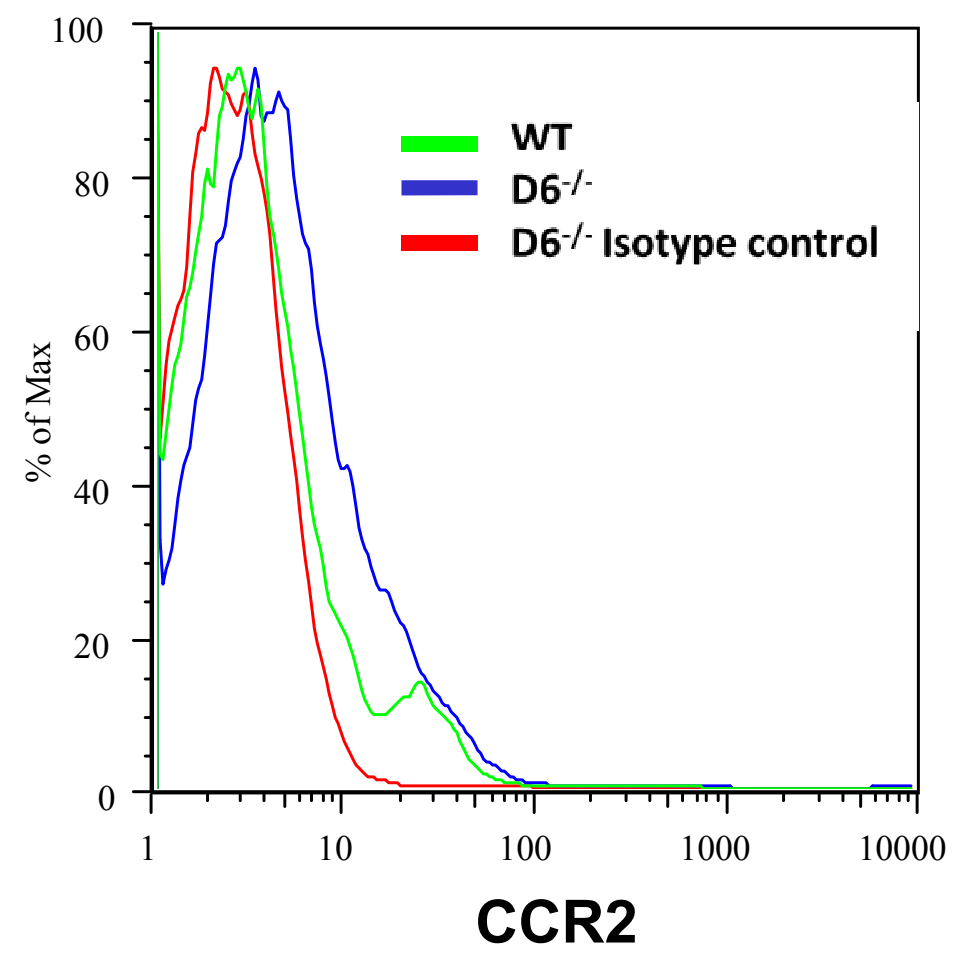

Figure 18: Increased expression of CCR2 protein in $\mathrm{D6}^{-1-} \mathrm{BMMCs}$. The cell surface expression of CCR2 was measured using Flow cytometer Analysis on WT and D6-1BMMCs. The cell-surface CCR2 expression is significantly higher on D6--1 BMMCs (Blue line), whereas CCR2 staining on the WT BMMCs is comparable to isotype control antibody. 


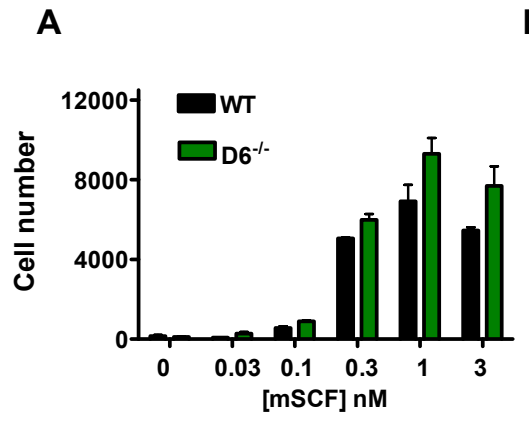

B

C
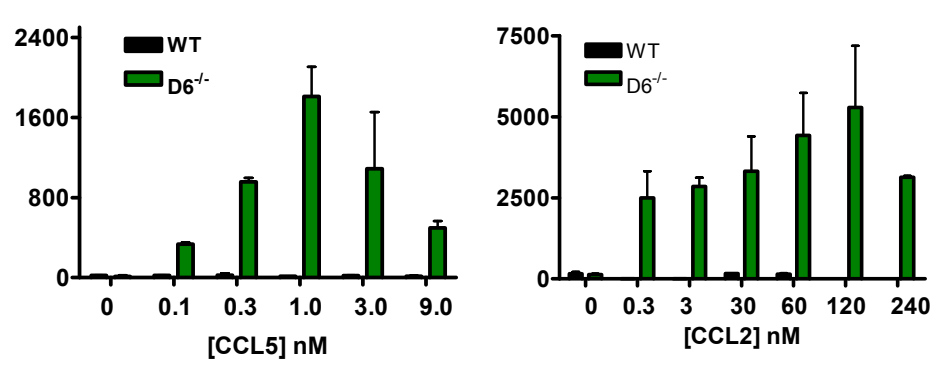

Figure 19: Increased migration of D6 ${ }^{-/}$BMMCs towards CCL2 and CCL5. Differential migration of D6-/- BMMCs to CCR2 and CCR5 ligands in chemotaxis assays. Standard Boyden chamber chemotaxis assays were performed with WT and D6--BMMCs for 3 hours with different concentrations of indicated ligands as described in methods. Cells migrated into bottom chamber were counted by flow cytometry. Both the WT and D6--BMMCs migrated at similar levels to SCF (A). When CCL5 (B) and CCL2 (C) were tested, only D6-/- BMMCS showed significant chemotaxis. WT BMMCs failed to migrate towards CCL2 and CCL5 (B and $\mathbf{C})$. 
(A)

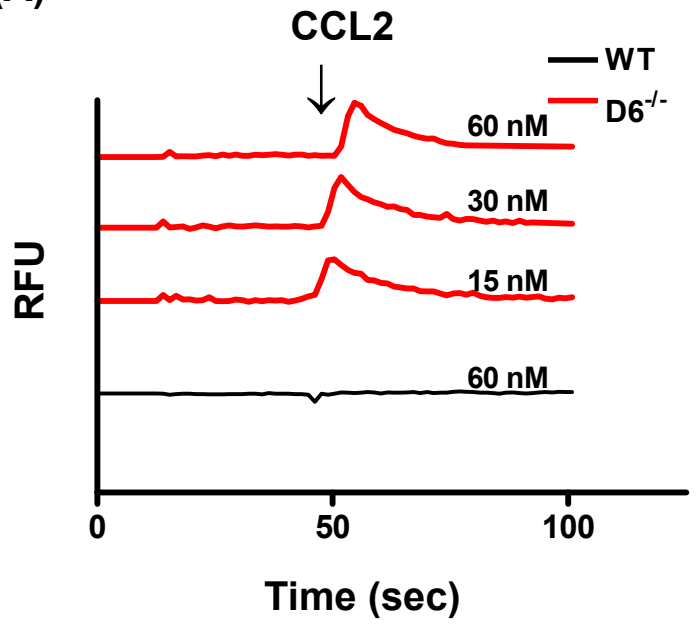

(B)

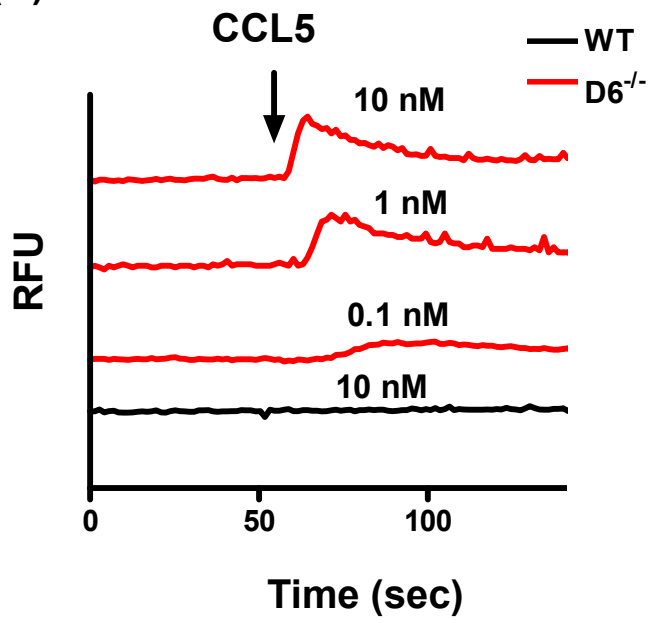

Figure 20: Functional CCR2 and CCR5 receptors on D6 ${ }^{-1-}$ BMMCs. The functional response of CCR2 and CCR5 was measured using their corresponding ligands, CCL2 and CCL5 (which are also D6 receptor ligands) using intracellular calcium release flux assay as described in Methods. Agonist mediated intracellular calcium release was measured as transient increase in fluorescence of Indo-1 loaded BMMCs. D6--/ mast cells exhibited dose response to CCL2 (A) and CCL5 (B). WT BMMC did not respond to both CCL2 and CCL5 even at high concentration (60 nM) tested. The data presented is one representative of the three independent experiments performed. 
(A)

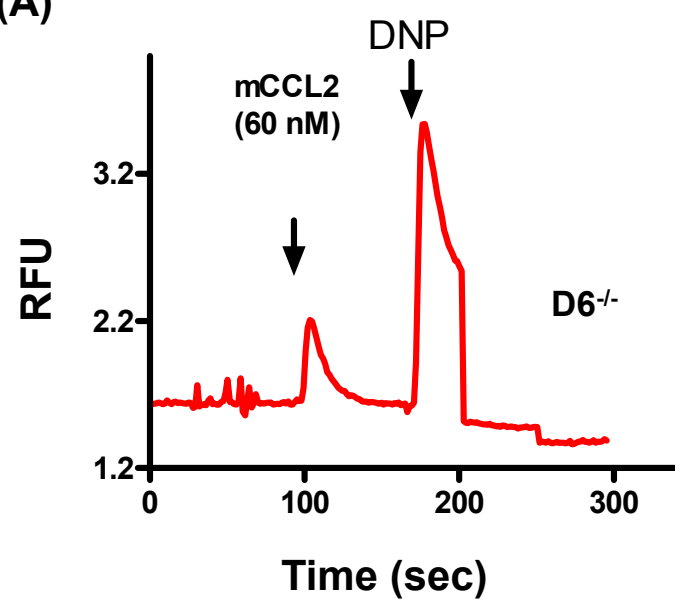

(B)

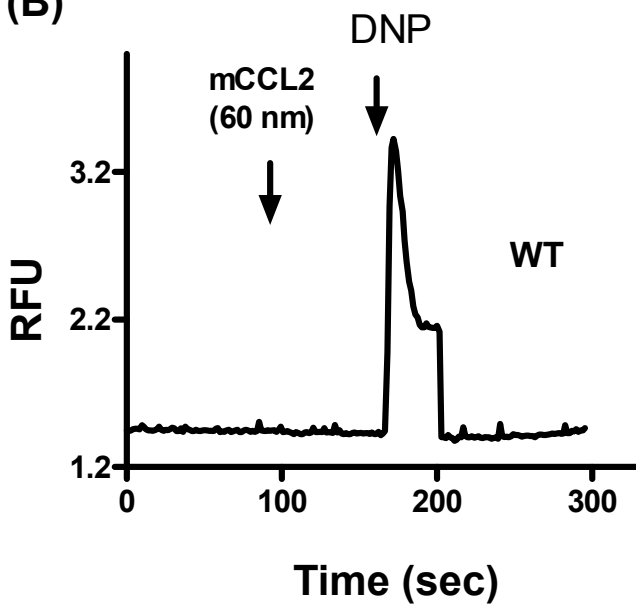

Figure 21: Functional BMMCs. Dinitrophenyl (DNP) induced calcium release. WT and D6 ${ }^{-/-}$BMMCs were sensitized overnight with Anti DNP IgE antibody $(100 \mathrm{ng} / \mathrm{ml})$ and analyzed for DNP induced calcium release in intracellular calcium flux assay. D6-- BMMCs are capable of releasing calcium upon induction with CCL2 and DNP, whereas WT BMMCs failed to respond to CCL2 but released similar levels of calcium upon induction with DNP. 
(A) T cells
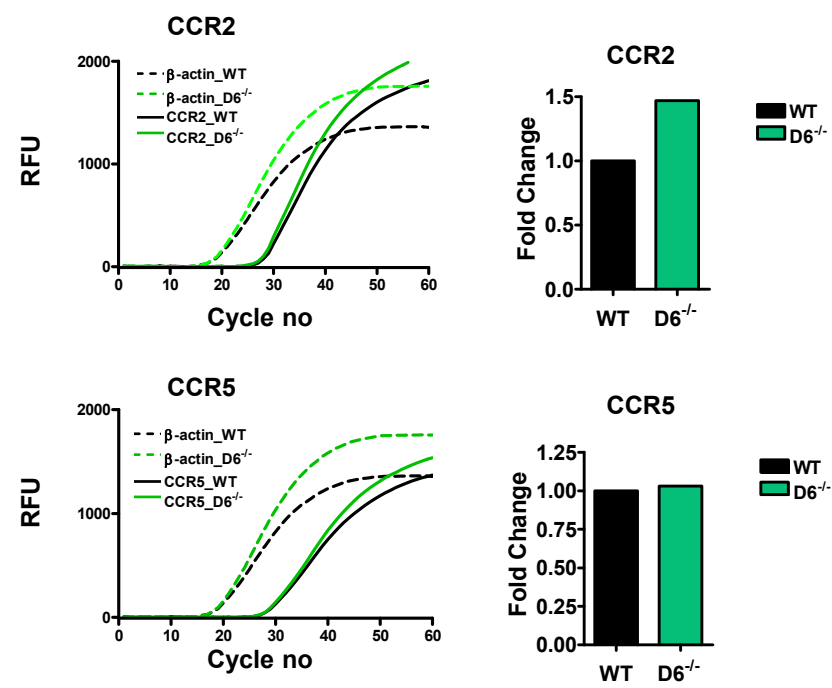

(B) B cells
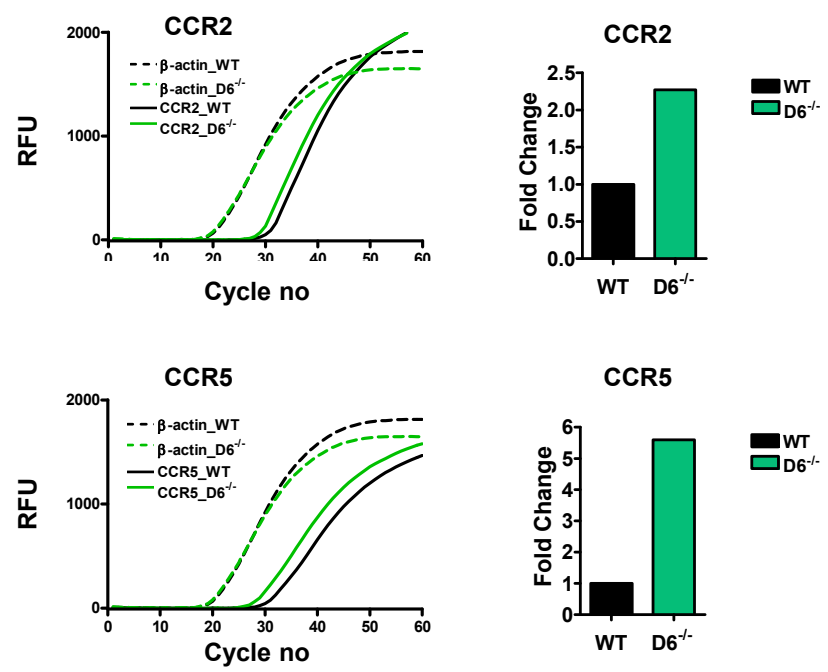

Figure 22: Expression of CCR2 and CCR5 in T and B cells. The mRNA levels of CCR2 and CCR5 in T cells (A) and B cells (B) were measured using SyBR green RT PCR protocols. The left panels represent the amplification plots of $\beta$-actin (dotted lines), CCR2 and CCR5 (solid lines). (B). The fold change in the expression of CCR2 and CCR5 was calculated using WT as base line. 
(A) BMDCs
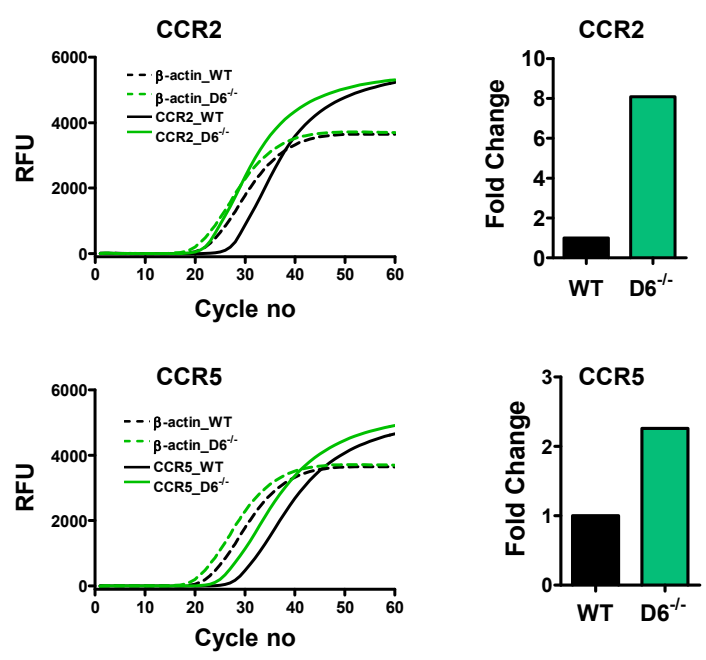

(B) BMDMs
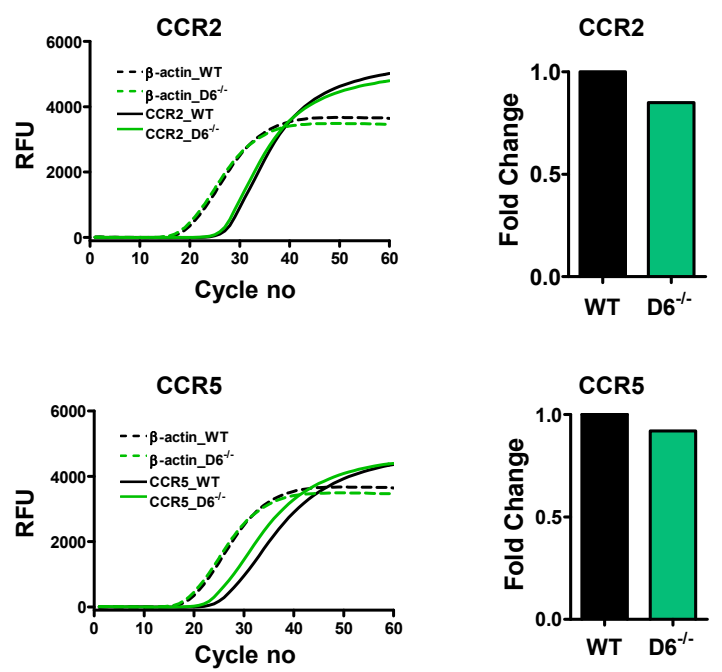

Figure 23: Expression of CCR2 and CCR5 in bone marrow derived dendritic cells (BMDCs) and bone marrow derived macrophages (BMDMs). The mRNA levels of CCR2 and CCR5 in BMDCs (A) and BMDMs (B) were measured using SyBR RT PCR protocols. The left panels represent the amplification plots of $\beta$-actin (dotted lines), CCR2 and CCR5 (solid lines). Amplification plots showing the similar amplification of CCR2 and CCR5 in both D6-/- and WT BMDCs (A) and BMDMs (B). The fold change was calculated using WT as base line. 
CCR2

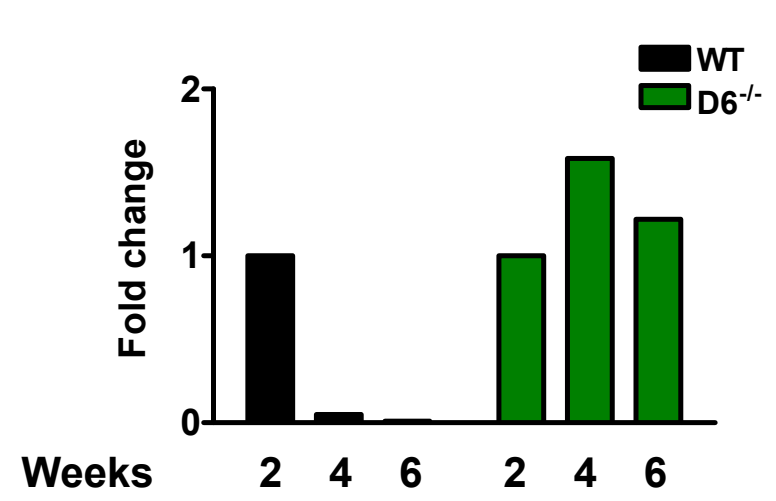

CCR5

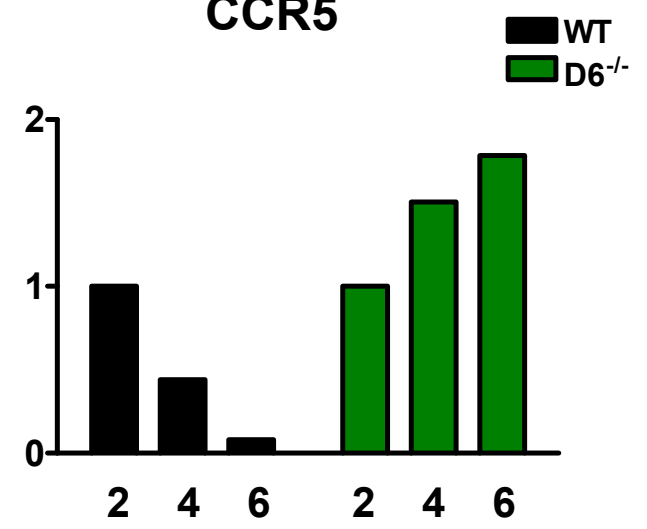

Figure 24: Expression of mRNA levels of CCR2 and CCR5 in BMMCs isolated from WT and D6-/- during maturation. RNA from BMMCs at different time intervals $(2,4,6$ weeks) was isolated and the mRNA levels of CCR2 (left panel) and CCR5 (right panel) were measured using real time PCR using SyBR green as described in methods. Two weeks BMMCs were purified on MACS column using CD117 antibody. The fold change was calculated using 2 Weeks sample as base line and results indicate down regulation of CCR2 and CCR5 in WT BMMCs and unchanged expression in D6-/- BMMCs. 
(A)

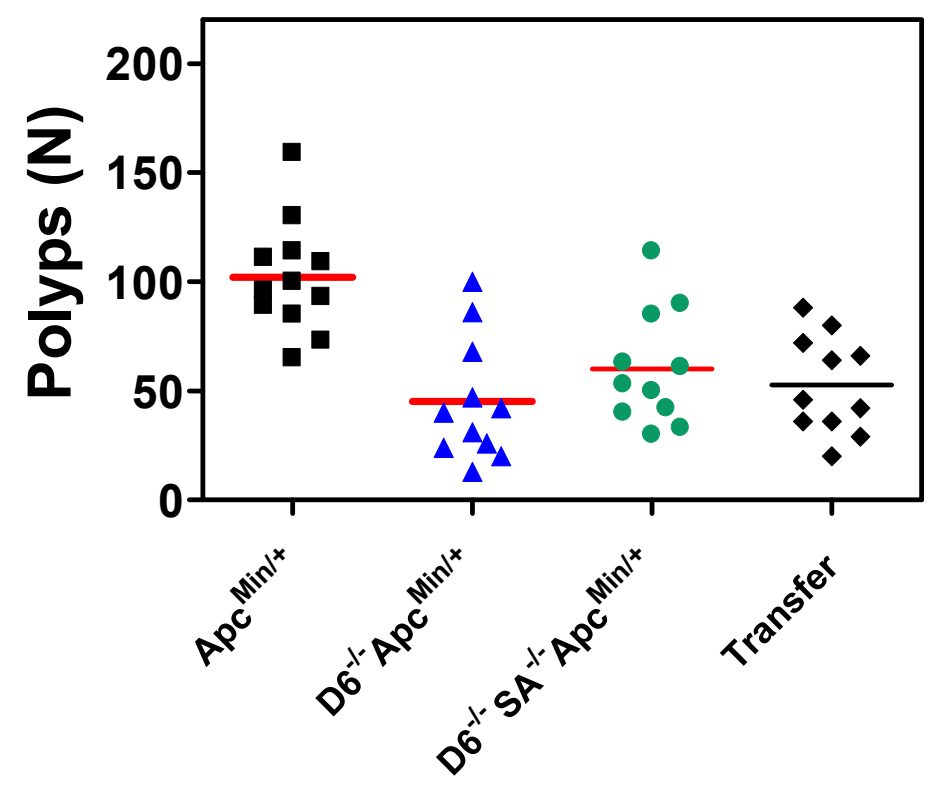

(B)

(C)
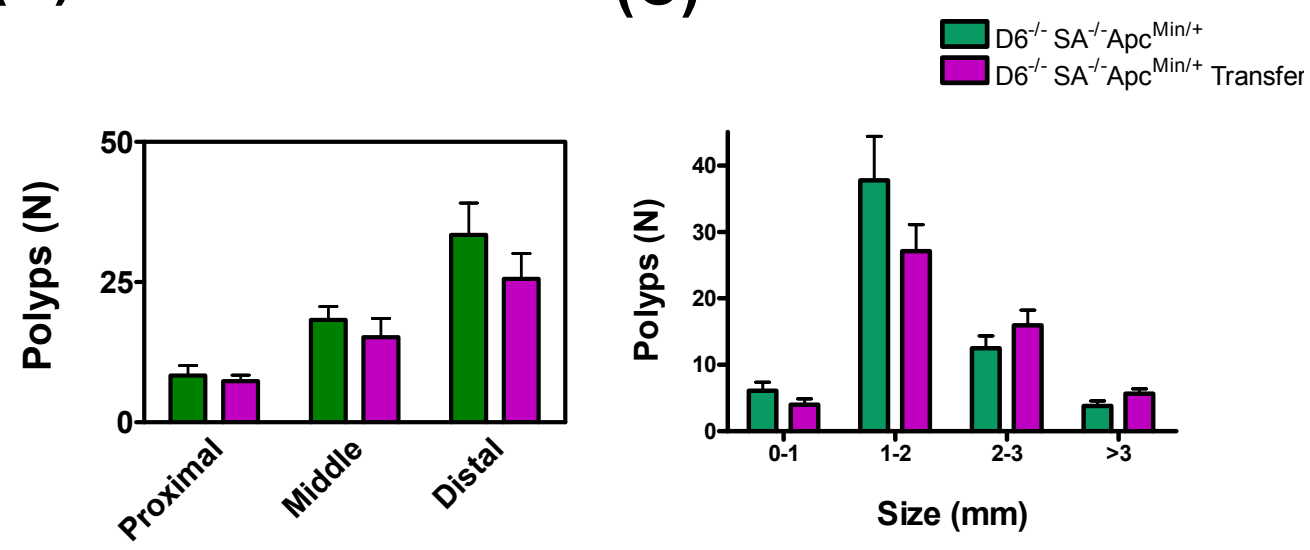

Figure 25: Adoptive transfer of BMMCs into $\mathrm{D6}^{-/-} \mathrm{SA}^{-/-} \mathrm{Apc}^{\mathrm{Min} /+}$ mice. BMMCs $\left(5 \times 10^{6}\right)$

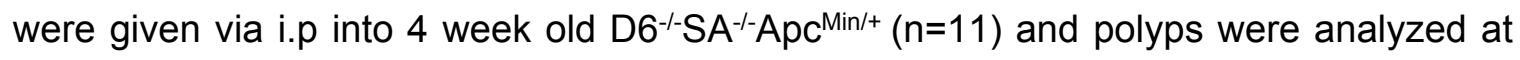
110 days age old. A. The total number of polyps in the small intestine B. Frequency of small intestinal polyps. C. Size distribution of small intestinal tumors. 


\section{DISCUSSION}

Since D6 is a well-established scavenger of inflammatory chemokines, we anticipated that the absence of D6 might lead to accumulation of some of these chemokines leading to selective recruitment of mast cells. While this indeed could be one of the mechanisms, the results presented in this chapter uncover an unexpected finding and a potential novel mechanism for enhanced migration of mast cells into $\mathrm{D6}^{--} \mathrm{Apc} \mathrm{Min}^{\mathrm{+}}$ tumors.

Phenotypic and functional characterization of bone marrow derived mast cells revealed D6-/- mast cells express functional CCR2 and CCR5 receptors. This finding is exciting because it provides a likely explanation for why more mast cells are recruited to $\mathrm{D6}^{-1-} \mathrm{Apc}^{\mathrm{Min} /+}$ tumors. Both $\mathrm{CCR} 2$ and CCR5 along with other chemokine receptors like CXCR2 and BLT1 have been implicated in mast cell homing to tissues [39]. However, mechanisms of tumor specific recruitment of mast cells are still unclear. The question why CCR2 and CCR5 receptors are up regulated on $\mathrm{D6}^{-/-}$mast cells is also puzzling. This is unlikely to be a cell culture artifact because it is not happening with the WT mast cells. However, further experiments using LY5.1 and LY 5.2 alleles as source of WT and D6-- bone marrow to co culture mast cells and distinguish their CCR2 expression levels by flow cytometry will reveal any cell autonomous mechanism for increased expression of these receptors.

There are several potential explanations for why CCR2 and CCR5 are over expressed in D6 ${ }^{-/}$mast cells. Absence of D6 might lead to alterations in bone marrow micro environment causing changes in the transcriptional programs in 
mast cell progenitors that persist in mature mast cells. A second possibility is that absence of D6 causes changes in post transcriptional processing specifically in mast cells. In this regard, it is known that the CCR2 mRNA down regulation has been demonstrated during development of B cells [98], DCs [99] and monocytes [100]. We also detected CCR2 and CCR5 mRNA expression in two week CD117 purified mast cell cultures and observed dramatic down regulation in 4 and 6 week cultures of WT mast cells (Fig 24). Collington et al [101] have reported earlier the down regulation of CCR2 mRNA in BALB/c derived BMMCs during 2 week to 6 week development of the cultures. This appears to be a mechanism to confine them into tissues preventing them from emigrating. In contrast, the expression of these transcripts persisted in $\mathrm{D6}^{-1-}$ mast cells suggesting that post transcriptional processing might be altered in the $\mathrm{D6}^{-/-}$mast cells. It would be interesting to study the mechanisms involved in the stability of CCR2 mRNA in D6-/- mice.

While dramatic up regulation of CCR2 and CCR5 is observed in cultured mast cells, their role in enhanced migration into $\mathrm{D6}^{-/-} \mathrm{Apc}^{\mathrm{Min} /+}$ tumors remains to be established. Peritoneal mast cells may be isolated from D6 ${ }^{--}$and WT mice and stained for CCR2 mRNA and protein expression. Peritoneal mast cells are connective tissue type and the relevant mucosal mast cells can only be isolated from gut under inflammatory conditions. Attempts were made to isolate mast cells from $\mathrm{D6}^{-/-} \mathrm{Apc}^{\mathrm{Min} /+}$ tumors and mesenteric lymph nodes and stain for CCR2 without much success. The percentage of mast cells very low and the CCR2 may be not expressing by all the cells. However, these experiments might be repeated by pooling tissue or cells from mesenteric lymph nodes of several mice. 
It is difficult to show CCR2-CCL2 axis involvement of mast cell migration to intestinal tumors by immune histochemical methods. This is because it was demonstrated in C57BL/6 strain that CCL2 and CCR2 staining is strong in small intestine [102] and several stromal and tumor cells also express CCL2 and CCR2. The role of CCR2-CCL2 axis in mast cell recruitment was thoroughly studied in lung mouse model of allergic inflammation using sub lethally irradiated mice and bone marrow transfers which gave inconclusive results and indicated the complexity in these interactions [101]. To more definitive identification of the role of CCL2 in the recruitment of mast cells in to tumor of $\mathrm{D6}^{-/-} \mathrm{Apc}^{\mathrm{Min} /+}$ mice requires the generation and characterization of $\mathrm{D6}^{-/-} \mathrm{Apc}^{\mathrm{Min} /+}$ in the background of $\mathrm{CCL} 2^{-/-}$ mice $\left(\mathrm{CCL}^{---} \mathrm{D6}^{--} \mathrm{Apc}^{\mathrm{Min} /+}\right)$. An alternative approach would be the generation of $\mathrm{CCR} 2^{---} \mathrm{D6}^{--} \mathrm{Apc}^{\mathrm{Min} /+}$ or $\mathrm{CCR}^{---} \mathrm{D6}^{--} \mathrm{Apc}^{\mathrm{Min} /+}$ mice. Unfortunately, making these triple knockout mice is not feasible due to their proximal location of D6 and CCR2 and CCR5 on the same chromosome.

While the adoptive transfer experiments did not provide any conclusive answers about the role of mast cells, all other data i.e. i) increased presence of mast cells in $\mathrm{D6}^{-/-} \mathrm{Apc}^{\mathrm{Min} /+}$ tumors; ii) increased tumor burden in $\mathrm{D6}^{-/-} \mathrm{SA}^{-/-} \mathrm{Apc} \mathrm{Min} /+^{-}$ mice; iii) increased chemokine receptor expression on $\mathrm{D6}^{-1-}$ mast cells all point towards a tumor protective role for mast cells in the intestine. More importantly, this data provides an explanation for large number of clinical studies that showed enhanced mast cell infiltration is strongly correlated with better prognosis. Unlike the well-established methods that exist for adoptive transfer of T- cells, mast cell adoptive transfer methods are at a very early stage of development. To this date 
not a single study on successful adoptive transfer of mast cells into a spontaneous mouse tumor model has been published. While we might continue to take an approach of transferring mast cells that are easily tractable (GFP or other markers) as well as at various stages of development success might not be a definitive outcome for this approach.

The most important finding reported in this chapter i.e. enhanced expression of CCR2 and CCR5 in mast cells could indeed be the basis for many earlier phenotypes reported in the $\mathrm{D6}^{-/-}$mice. These include skin inflammation studies $[23,103]$ and the LPS induced fetal loss [30] as well as other phenotypes reported in the context of lung inflammation [28]. This leaves us with the remaining question on the mechanisms by which mast cells control tumor growth in $\mathrm{D6}^{-/-}$ $\mathrm{Apc}^{\mathrm{Min} /+}$ mice. 


\section{CHAPTER V}

\section{MAST CELL MEDIATED T-CELL HOMING AND ACTIVATION REGULATE TUMORIGENESIS IN D6 ${ }^{-1-A P C}{ }^{\mathrm{MIN} /+}$ MICE}

\section{INTRODUCTION}

Studies described in the previous two chapters clearly outlined a protective role for mast cells in tumor development in $\mathrm{D6}^{-{ }_{-1}} \mathrm{Apc}^{\mathrm{Min} /+}$ mice. Mast cells from D6${ }^{\text {I-Apc }}{ }^{\mathrm{Min} /+}$ mice could mediate the anti-tumor immunity through a variety of mechanisms. First, a direct role for mast cells as anti-tumor effector cells was recognized long time back. Peritoneal mast cells isolated and purified from chemically induced fibrosarcoma bearing mice or normal mice showed tumor killing capability in vitro cytotoxicity assays [71]. Mast cells isolated from normal or tumor bearing mice were equally cytotoxic to mouse or rat fibrosarcomas and less effective to mouse fibroblasts suggesting this cytotoxicity is tumor specific. Second, mast cells are capable of removing aggressive cancer cells by phagocytosis $[72,104]$. Third, mast cells can phagocytize bacteria and present bacterial antigens to CD8+ T-cell hybridomas through MHC1 as efficiently as peritoneal macrophages [78]. Fourth, beyond antigen presentation, mast cells are capable of producing several soluble mediators as well as cell surface molecules 
such ICOS-L, PD-L1, PD-L2, OX40L, CD153, Fas and 4-1BB involved in costimulation of T-cell responses [105].

Mast cell produced cytokines IL-1, IL-2, IL-4, IL-10 and IFNy can modulate tumor environment to both positive and negative ways depending on the tumor setting [42]. Finally, mast cells are known to produce a diverse array of lipid mediators and chemokines that facilitate recruitment of T-cells to the right immune compartments such as tissue draining lymph nodes and potentially into tumors.

Based on the protective phenotype associated with mass cell infiltration in the $\mathrm{D6}^{--} \mathrm{Apc}^{\mathrm{Min} /+}$ mice we hypothesize that mast cell mediated T-cell homing and activation regulate tumorigenesis in $\mathrm{D6}^{-/-} \mathrm{Apc}^{\mathrm{Min} /+}$ mice. 


\section{RESULTS}

\section{Increased mast cell infiltration into $\mathrm{D6}^{-{ }^{-1}} \mathrm{Apc}^{\mathrm{Min} /+}$ tumors}

Mast cell infiltration into $\mathrm{D6}^{-/-} \mathrm{Apc}^{\mathrm{Min} /+}$ tumors was previously demonstrated by chloroesterase staining on paraffin sections. To co-stain for multiple immune cell markers that are not amenable for staining on paraffin sections, we began using OCT frozen tissue sections for immunofluorescence studies as an alternate approach. Washed distal intestines from the 110 days old mice were frozen in OCT and sections were prepared and stained for mast cell protease using rat anti mouse MCPT-1 antibody as described in methods. The mast cell infiltration into $\mathrm{Apc}^{\mathrm{Min} /+}, \mathrm{D6}^{--} \mathrm{Apc}^{\mathrm{Min} /+}$ and $\mathrm{D6}^{--} \mathrm{SA}^{--} \mathrm{Apc}^{\mathrm{Min} /+}$ tumors is shown in Fig.26A. Mast cell staining appears diffused as reported earlier in the literature. The tumors from the control mast cell deficient $\mathrm{D6}^{---} \mathrm{SA}^{-/-} \mathrm{Apc}^{\mathrm{Min} /+}$ mice did not stain for MCPT-1 (Fig. 26A). Tumor regions were outlined at higher magnification. For each strain, at least six different tumors originating from three different mice outlined and the green fluorescence intensities with in the tumor outlined regions were measured using Nikon Elements software. The relative fluorescence units were plotted (Fig. 26B). The $\mathrm{D6}^{--} \mathrm{Apc}^{\mathrm{Min} /+}$ tumors displayed significantly higher MCPT-1 expression compared to $\mathrm{Apc}^{\mathrm{Min} /+}$.

\section{Mast cell mediated enhanced infiltration of $\mathrm{CD}^{+} \mathrm{T}$ cells into tumors}

According to our hypothesis mast cells in tumors are capable of recruiting $\mathrm{CD}^{+} \mathrm{T}$ cells to tumors and therefore mast cell enriched $\mathrm{D6}^{--} \mathrm{Apc}^{\mathrm{Min} /+}$ tumors will have higher number $\mathrm{CD}^{+} \mathrm{T}$ cells. To verify this, distal intestine frozen sections 
from 110 day old mice were stained with $\mathrm{CD} 8^{+}$antibody specific to alpha subunit. The immunofluorescence confocal images of $\mathrm{CD}^{+}{ }^{+} \mathrm{T}$-cell infiltration into $\mathrm{Apc}^{\mathrm{Min} /+}$, $\mathrm{D6}^{--} \mathrm{Apc}^{\mathrm{Min} /+}$ and $\mathrm{D6}^{--} \mathrm{SA}^{---} \mathrm{Apc}^{\mathrm{Min} /+}$ tumors are displayed in Fig. 27A. The tumor infiltrating $\mathrm{CD}^{+}$positive T cells were counted and calculated per $100 \mathrm{~mm}^{2}$ area and plotted (Fig. 27B). We have counted at least six tumors in each genotype (three different mice per genotype). The infiltrated $\mathrm{CD} 8^{+} \mathrm{T}$ cell numbers in $\mathrm{D6}^{-/}$ $\mathrm{Apc}^{\mathrm{Min} /+}$ mice was significantly higher than $\mathrm{Apc}^{\mathrm{Min} /+}$ and $\mathrm{D6}^{-/-} \mathrm{SA}^{-/-} \mathrm{Apc}^{\mathrm{Min} /+}$ mice.

\section{$\mathrm{T}$-cell independent mast cell recruitment into $\mathrm{D6}^{-1-} \mathrm{Apc}^{\mathrm{Min} /+}$ tumors}

It is evident from the above results that increased tumor infiltration of mast cells and $\mathrm{CD} 8^{+} \mathrm{T}$-cells in $\mathrm{D6}^{-1-} \mathrm{Apc}^{\mathrm{Min} /+}$. The data suggests that enhanced T-cell recruitment in $\mathrm{D6}^{-1-} \mathrm{Apc}^{\mathrm{Min} /+}$ is mast cell dependent as there was a significant reduction in T-cell infiltration in $\mathrm{D6}^{--} \mathrm{SA}^{-1-} \mathrm{Apc} \mathrm{Min} /+^{-}$tumors. How does absence of Tcells effect mast cell recruitment? This question was addressed using Rag2 ${ }^{-/-}$D6 $^{-/-}$ $\mathrm{Apc}^{\mathrm{Min} /+}$ mice. The mRNA was isolated from distal intestine tumors of Rag2 ${ }^{-1-\mathrm{D} 6^{-/-}}$ $\mathrm{Apc}^{\mathrm{Min} /+}$ mice and analyzed for Mcpt-1 and Mcpt-2 expression by RTPCR. Both mast cell specific genes are increased in $\mathrm{D6}^{-/-} \mathrm{Apc}^{\mathrm{Min}}$ and $\mathrm{Rag}^{-/-} \mathrm{D6}^{-/-} \mathrm{Apc}^{\mathrm{Min} /+}$ mice relative to $\mathrm{Apc}^{\mathrm{Min} /+}$ mice (Fig. 28A). The cell lysates prepared from the distal intestine tumors of $\mathrm{Rag2}^{-/-} \mathrm{D6}^{-/-} \mathrm{Apc}^{\mathrm{Min} /+}$ mice were analyzed for Mcpt-1 protein expression in Western blots (Fig. 28B Left) and quantified (Fig.28B Right). Rag2${ }^{\text {I-D6 }}{ }^{-1-} \mathrm{Apc}^{\mathrm{Min} /+}$ mice tumors showed similar expression of Mcpt-1 as $\mathrm{D6}^{-1-} \mathrm{Apc}^{\mathrm{Min} /+}$ tumors. These results provide direct genetic evidence for T-cell independent mast cell recruitment to Min tumors. 


\section{Uptake and presentation of exogenous peptide antigens by BMMCs}

While mast cells are recognized as effectors in many settings they are also known to be capable of taking up exogenous peptides, present them to $\mathrm{CD} 8^{+} \mathrm{T}$ cells through MHC-1 and activate $\mathrm{CD} 8^{+} \mathrm{T}$ cell proliferation and IFN- $\gamma$ release [106]. To ensure mast cells from D6 ${ }^{-/}$mice are also as effective as WT mast cells in mediating T- cell functions, we performed co-culture experiments using bone marrow derived mast cells (BMMCs) and ovalbumin specific $C D 8^{+} \mathrm{T}$ cells from OT1 TCR transgenic mice. First, we tested the BMMCs for their capacity to take up and present exogenous peptide antigens on their surface through MHC-1. Mast cells were cultured with or without 1 or $4 \mu \mathrm{M}$ OVA derived peptide SIINFEKEL for 3 hours and washed to remove unbound peptide followed by staining with the antibody capable of binding to peptide and MHC-1 only in complex and analyzed by flow cytometry (Fig. 29). The WT and D6 $6^{-/-}$mast cells stained equally well with this antibody indicating that $\mathrm{D6}^{-/-}$mast cells can take up the peptide and present the same on their surface through MHC-1.

We next asked whether BMMCs could present antigens to $\mathrm{CD} 8^{+} \mathrm{T}$ cells and activate them. WT and D6 ${ }^{-/}$BMMCs were pulsed with $4 \mu \mathrm{M}$ SIINFEKEL, washed and added at different ratios as indicated to $1 \times 10^{6} / \mathrm{ml}$ MACS purified CD8 ${ }^{+} \mathrm{T}$ cells from OT-1 transgenic mice. After 48 hour co-culture, T cell blasts were visible under microscope and representative T cell blasts were captured (Fig.30). After co-culture, cells were stained for $\mathrm{CD}^{+} \mathrm{T}$ cell activation markers CD69, CD44 and CD25 and analyzed by flow cytometry. Both the WT and D6 $6^{-/-}$BMMCs pulsed with peptide exhibited CD69, CD44 and CD25 maximum upregulation at higher mast 
cell ratio (1:2) and unpulsed BMMCs at the same concentration did not show this response (Fig. 31). These results show D6--- mast cells can capture and present peptide antigens to $\mathrm{CD} 8^{+} \mathrm{T}$ cells leading to their activation.

\section{Activation of $\mathrm{CD}^{+} \mathrm{T}$ cells proliferation by BMMCs}

We further investigated the potential of $\mathrm{D6}^{-{ }^{-}}$mast cells to induce $\mathrm{CD} 8^{+} \mathrm{T}$ cell proliferation by CFSE dilution. BMMCs were pulsed with $4 \mu \mathrm{M}$ SIINFEKEL, washed and added at different ratios as indicated to $1 \times 10^{6} / \mathrm{ml}$ MACS purified, CFSE labeled OT- $1 \mathrm{CD}^{+} \mathrm{T}$ cells. After 72 hour co-culture, CD8+ $\mathrm{T}$ cells were analyzed for CFSE dilution by flow cytometry. The mast cell dose dependent increase in proliferation of $\mathrm{CD}^{+} \mathrm{T}$ cells was observed where maximum proliferation occurred at highest mast cell number to $\mathrm{CD} 8^{+} \mathrm{T}$ cell ratio for both the WT and D6-- BMMCs (Fig. 32). The inset in the 1:2 ratio is a control showing the addition of the same number of mast cells without the peptide on their surface. The addition of unpulsed BMMCS even at these high concentrations resulted in only a partial single division, whereas cultures with peptide pulsed mast cells showed up to five cycles of division. These results show $\mathrm{D6}^{-/-}$mast cells can activate $\mathrm{T}$ cell proliferation in an antigen specific manner.

\section{Mast cell mediated cytotoxic potential of $\mathrm{CD}^{+} \mathrm{T}$ cells}

Activated $\mathrm{CD}^{+} \mathrm{T}$ cells reduce the tumor burden by producing the intracellular cytokine IFN- $\gamma$. We explored the effector functions of $\mathrm{CD}^{+} \mathrm{T}$ cells induced by $\mathrm{D6}^{-/-}$mast cells by staining $\mathrm{CD}^{+} \mathrm{T}$ cells for intracellular IFN- $\mathrm{F}$ production after antigen specific activation. BMMCs were pulsed with $4 \mu \mathrm{M}$ SIINFEKEL, washed and added to MACS purified OT-1 CD8 ${ }^{+}$T cells at 1:2 ratio. 
After 48 hour co culture and 5 hour stimulation, CD8 ${ }^{+} T$ cells were analyzed for intracellular IFN- $\gamma$ levels by flow cytometry. The $\mathrm{CD} 8^{+} \mathrm{T}$ cells activated by pulsed $\mathrm{D6}^{-/-}$mast cells produced IFN- $\gamma$ to the same extent as $\mathrm{CD} 8^{+} \mathrm{T}$ cells activated by pulsed WT mast cells (Fig. 33). Control unpulsed mast cells did not result in any significant IFN-y production from $\mathrm{CD} 8^{+} \mathrm{T}$ cells. 


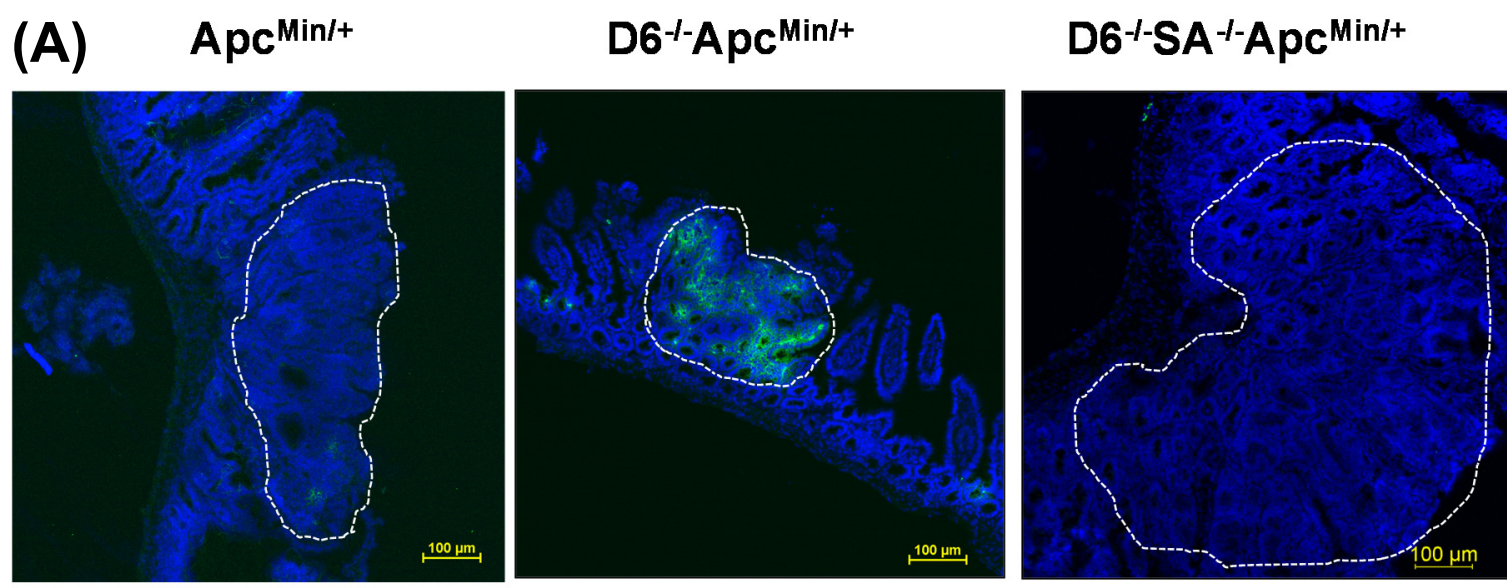

(B)

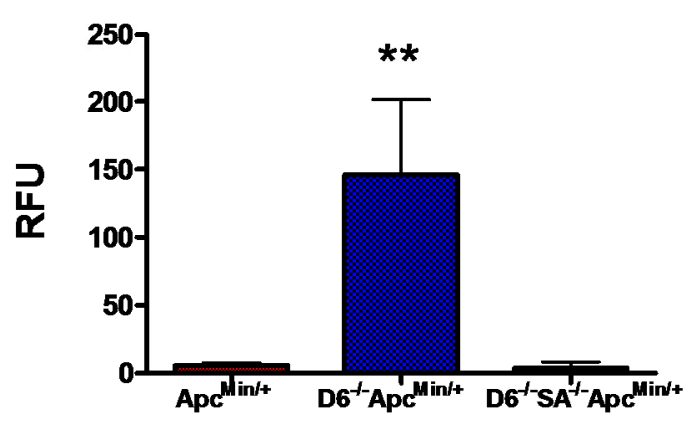

Figure 26: Increased mast cell infiltration into $\mathrm{D6}^{-{ }_{-1}} \mathrm{Apc}^{\mathrm{Min} /+}$ tumors. Representative images of mast cell infiltration into adenomas are shown. The immunofluorescence staining for mast cell specific protease, MCPT-1 was performed. The frozen distal intestine (110 days old) sections were stained with Rat anti mouse MCPT-1 antibody and visualized by Alexa 488 labeled anti rat antibody. Tumor regions marked with white line, Blue, DAP1; Green, MCPT-1. The images were captured using Nikon A1R confocal microscope at 200 x magnification. The scale bar indicates $100 \mu \mathrm{m}$. Quantification of mast cells: From each strain six different tumors were outlined and the green fluorescent intensities with in the tumors were measured using Nikon Elements software The relative fluorescence units were plotted. The $\mathrm{D6}^{-{ }^{-} \mathrm{Apc}} \mathrm{Min} /+^{+}$mice tumors displayed higher MCPT-1 expression

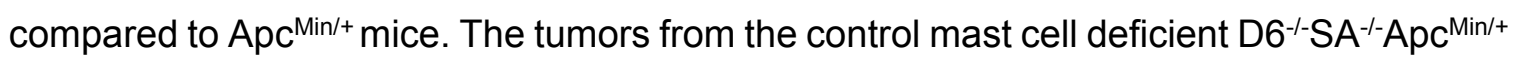
mice did not stain for MCPT-1. 
(A)
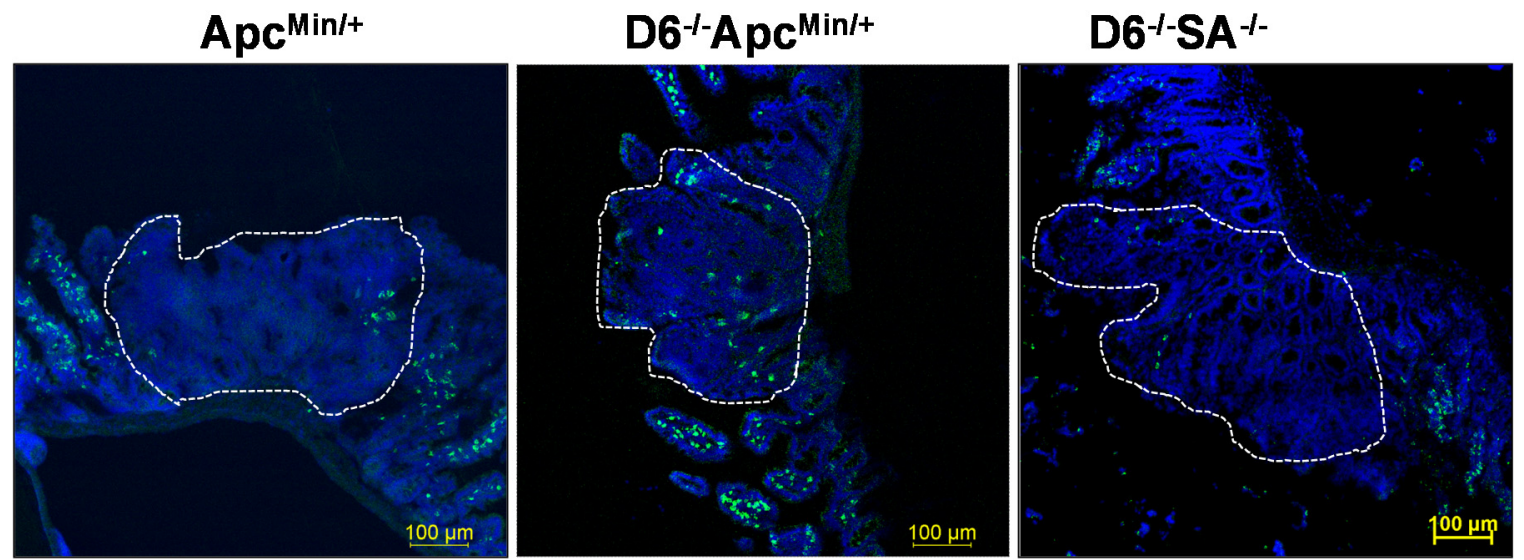

(B)

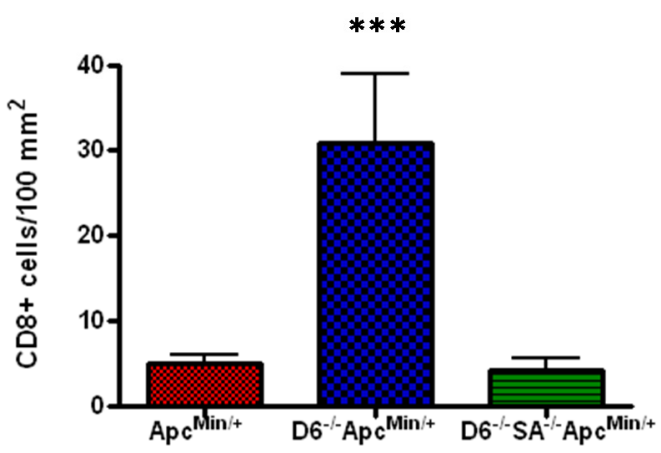

Figure 27: Mast cell mediated enhanced infiltration of $C D 8^{+} \mathrm{T}$ cells into tumors. (A) Representative images of immunofluorescence staining of $\mathrm{CD}^{+} \mathrm{T}$ cell infiltration into adenomas. The frozen sections of the distal intestines of the indicated mice (110 day old) were cut and stained with Rat anti mouse $\mathrm{CD}^{+}$antibody and visualized by Alexa 488 labeled anti rat antibody. Tumor regions marked with white line. Blue, DAP1; Green, CD8. The images were captured using Nikon A1R confocal microscope at 200 x magnification. The scale bar indicates $100 \mu \mathrm{m}$. (B) Quantification of $C D 8^{+} T$ cells: The tumor infiltrating $\mathrm{CD}^{+}$positive T cells were counted and calculated per $100 \mathrm{~mm}^{2}$ area and plotted. We have counted at least 6 tumors in each genotype (3 different mice per genotype). The infiltrated $\mathrm{CD}^{+} \mathrm{T}$ cells number in $\mathrm{D6} 6^{-/-} \mathrm{Apc}^{\mathrm{Min} /+}$ mice was significantly higher than $\mathrm{Apc}^{\mathrm{Min}}$ and $\mathrm{D6}^{-/-} \mathrm{SA}^{-}$

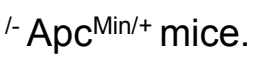


(A)

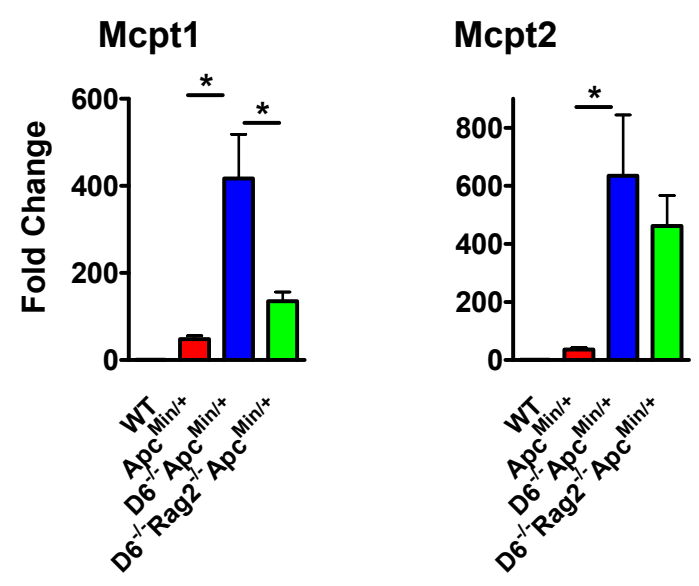

(B)

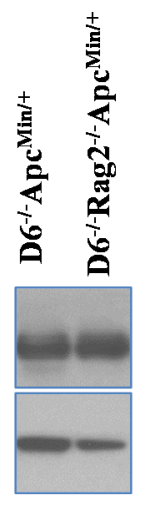

MCPT1

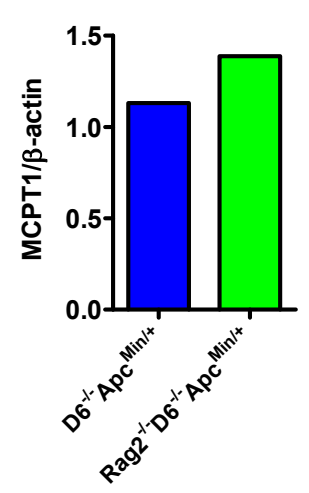

Figure 28: T-cell independent Mast cell recruitment into $\mathrm{D6}^{-/-} \mathrm{Apc}^{\mathrm{Min} /+}$ tumors. (A) mRNA levels of Mcpt1 and Mcpt2 were measured using RT-PCR. There is a significant increase in MCPT1 and MCPT2 levels in D6 ${ }^{-/-} \mathrm{Apc}^{\mathrm{Min} /+}$ and D6--/-Rag2 ${ }^{-1-} \mathrm{Apc}^{\mathrm{Min} /+}$ compared

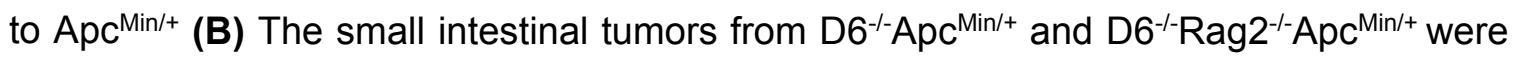
dissected and the protein lysates were prepared using RIPA plus buffer. The tumors lysates $(30 \mu \mathrm{g})$ were subject SDS-PAGE and Western blots prepared. The blots were probed for MCPT-1. The blot was stripped and probed again for $\beta$-actin. The quantification of blots was performed using the Metamorph software. The protein levels of MCPT1 were similar in both $\mathrm{D6}^{-/-} \mathrm{Apc}^{\mathrm{Min} /+}$ and D6 ${ }^{-/-} \mathrm{Rag}^{-/-} \mathrm{Apc} \mathrm{Min}^{\mathrm{H}}$. 


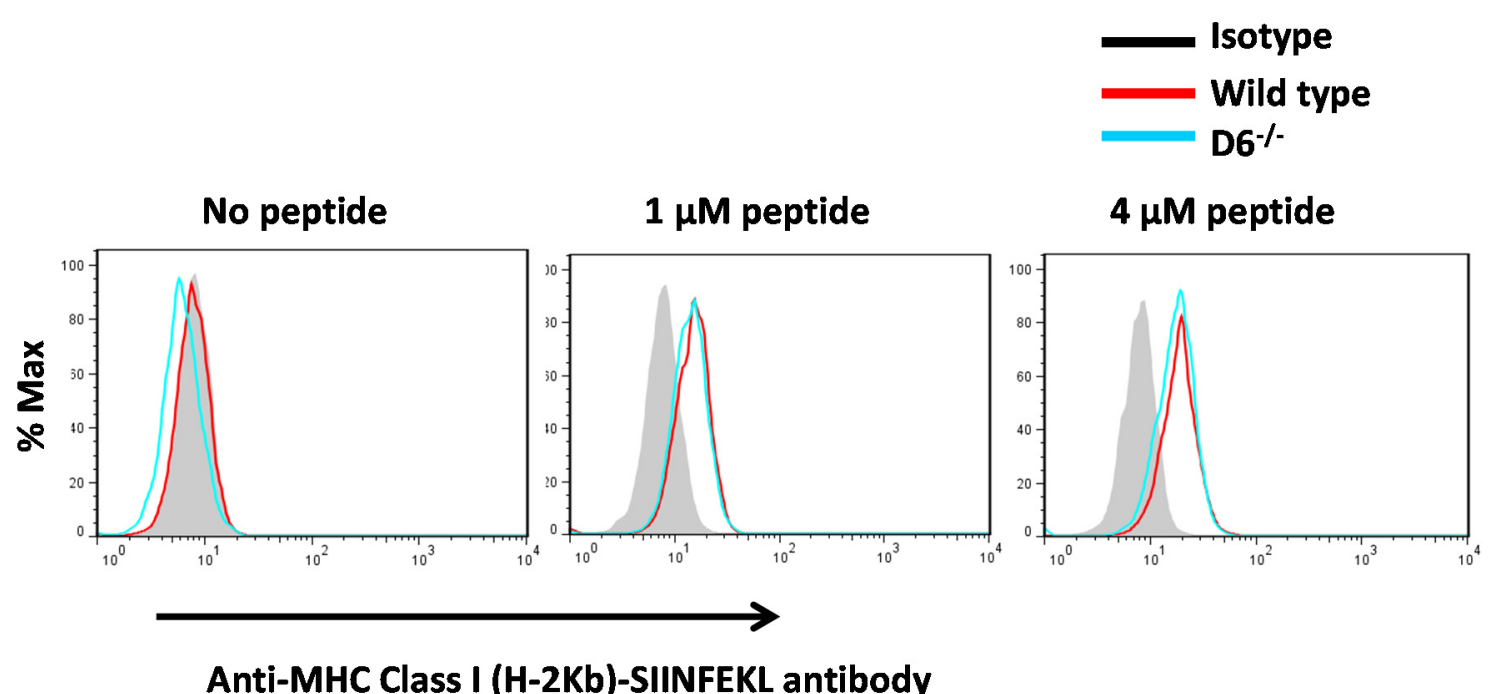

Figure 29: Uptake and presentation of exogenous peptide antigens by BMMCs. Mast cells were cultured with or without 1 or 4 uM peptide SIINFEKEL for 3hours followed by staining with the antibody specific to $\mathrm{MHC}-1$ coupled peptide and analyzed by flow cytometry. Both the wildtype and $\mathrm{D6}^{-/-}$mastcells stained equally well with this antibody indicating D6-/- mast cells can take up the peptide and present the same on their surface as well. 


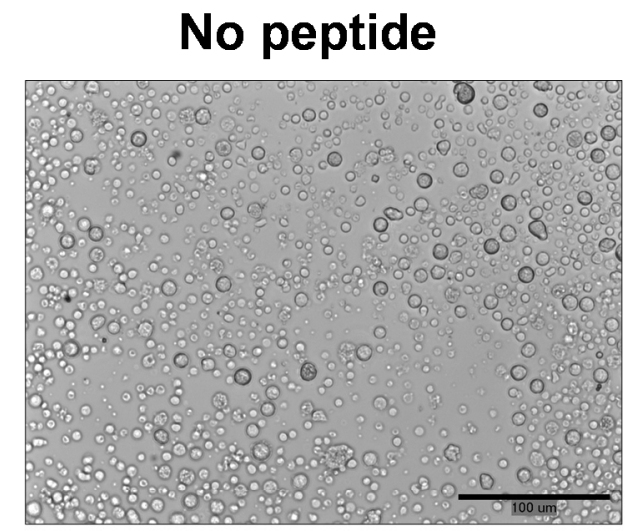

\section{SIINFEKL activated}
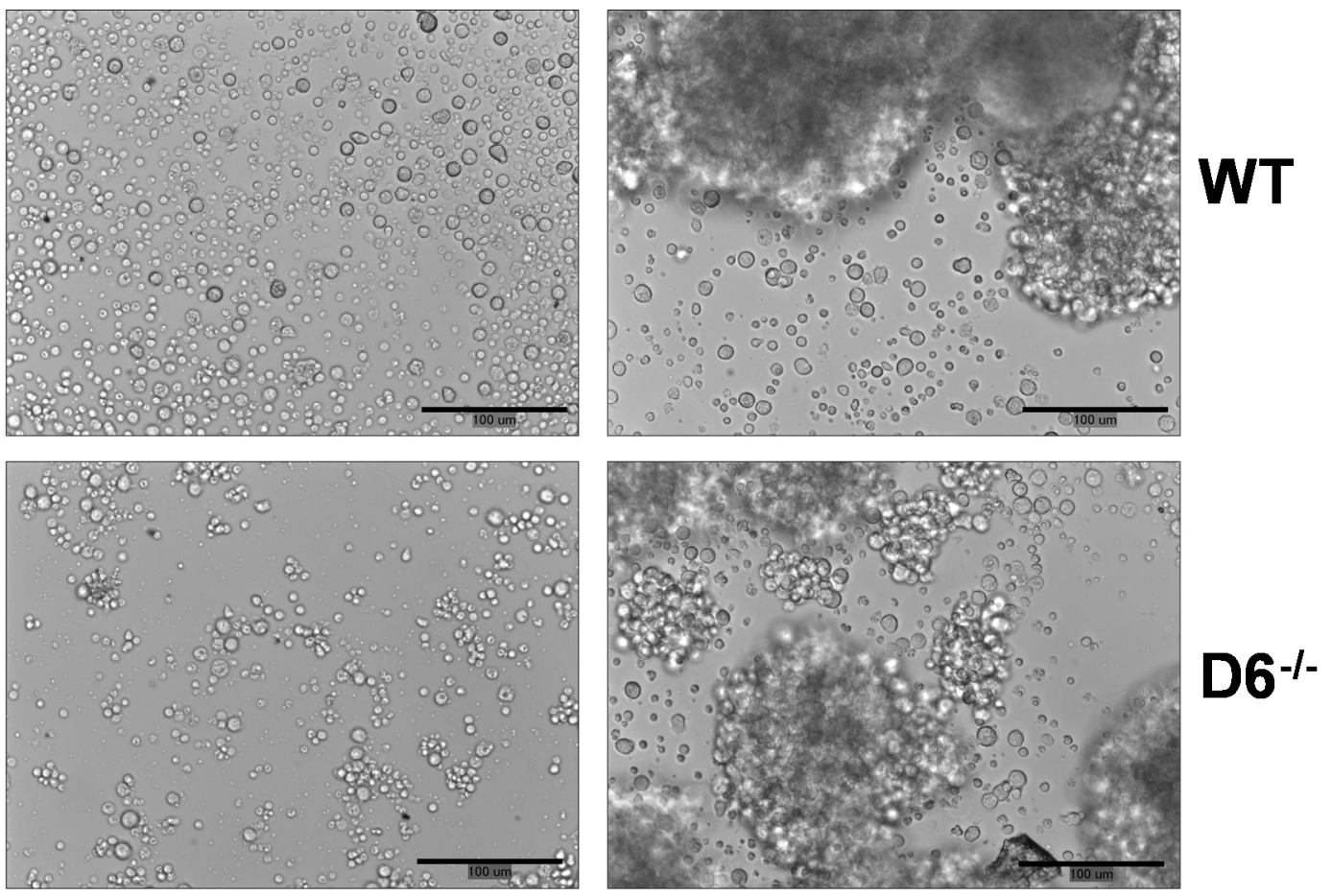

Figure 30: Induction of $\mathrm{CD}^{+} \mathrm{T}$ cell blasts by peptide pulsed BMMCs. The representative images of $\mathrm{CD}^{+} \mathrm{T}$ cell blasts after co-culturing with mast cells for $48 \mathrm{hrs}$ were captured using Nikon T300 microscope. BMMCs were pulsed with $4 \mu \mathrm{M}$ SIINFEKEL, washed and added to MACS purified OT-1 CD8 ${ }^{+} \mathrm{T}$ cells at 1:2 ratio. After 48 hour coculture, clusters of proliferated CD8 ${ }^{+} \mathrm{T}$ cell were visible in SIINFEKEL activated wells (right panel). The scale bar indicates $100 \mu \mathrm{m}$. 
(A)
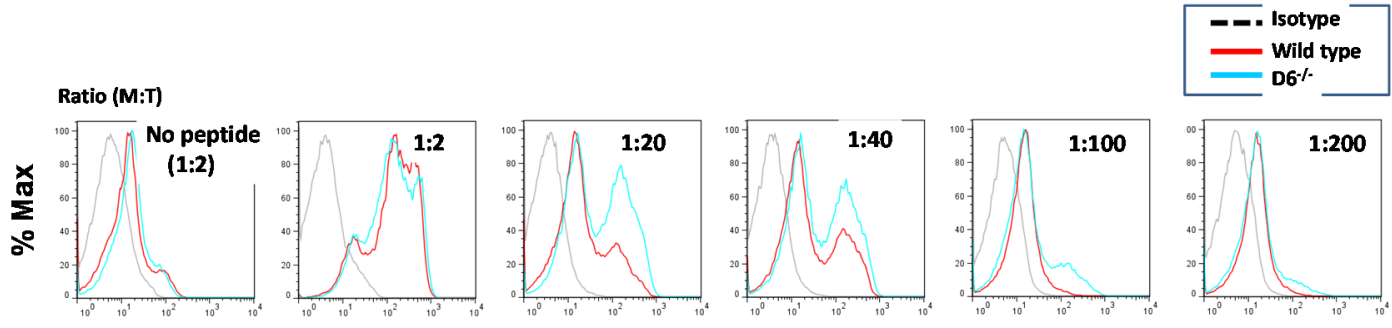

\section{CD69}

(B)
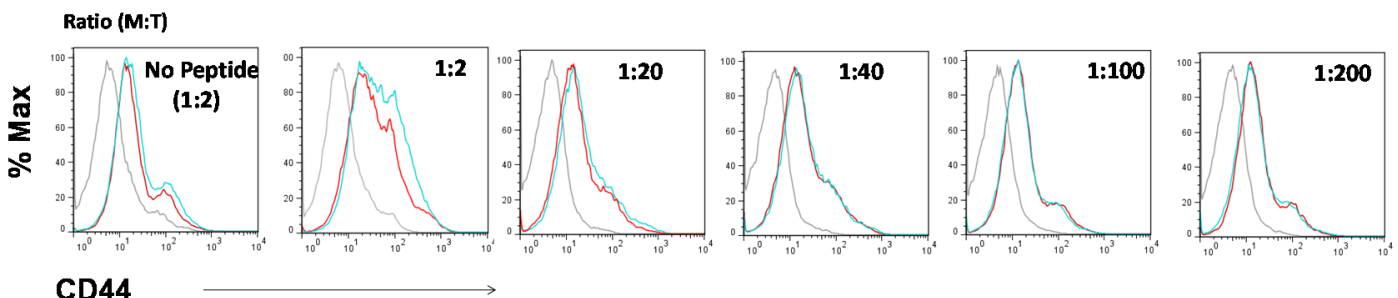

(C)
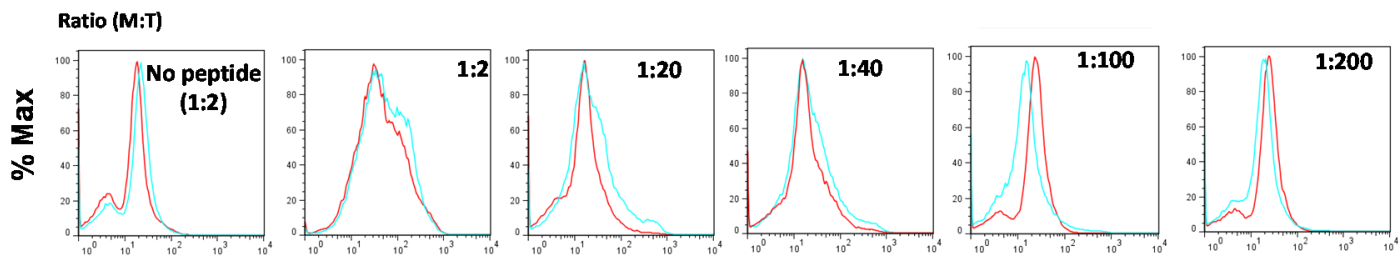

CD25

Figure 31: Antigen specific activation of $C D 8^{+} T$ cells by BMMCs. BMMCs were pulsed with $4 \mu \mathrm{M}$ SIINFEKEL, washed and added to MACS purified OT-1 CD8 ${ }^{+}$T cells at different ratios as indicated. After 48 hour co-culture, the cell-surface expression of CD69, CD44 and CD25 on CD8 ${ }^{+}$T cells was analyzed by flow cytometry. Both the WT and D6-- BMMCs mediated $\mathrm{CD}^{+} \mathrm{T}$ cell activation upon SIINFEKEL treatment. 


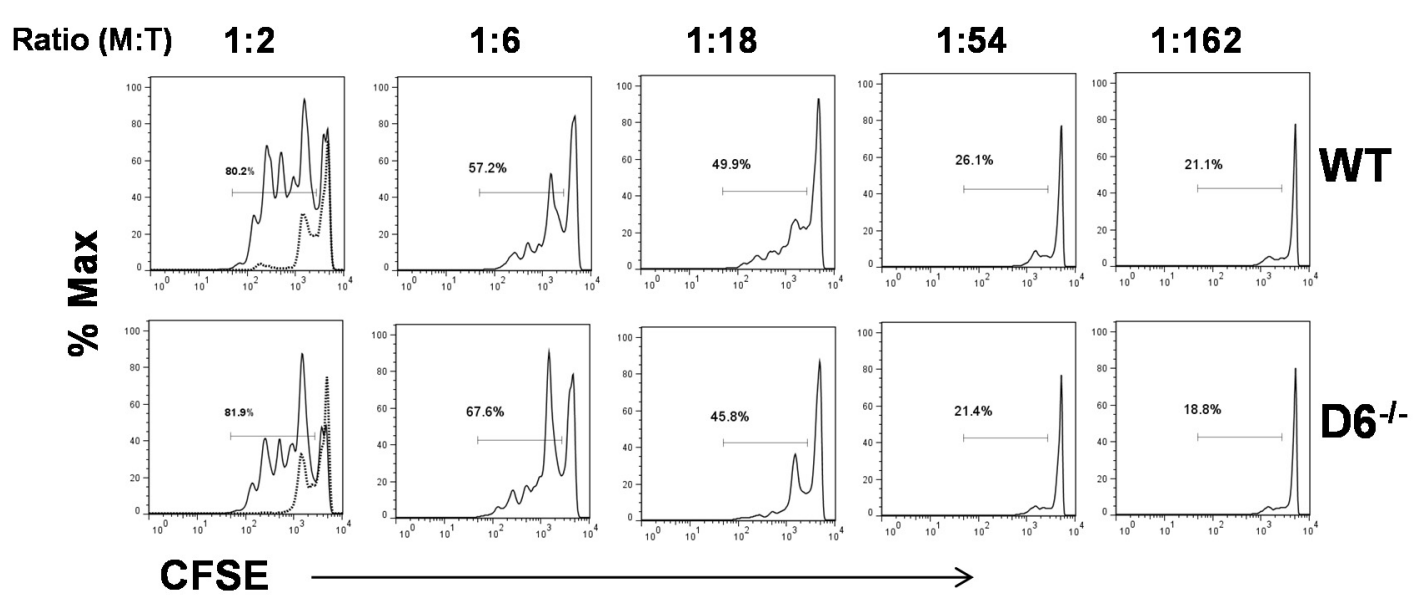

Figure 32: Activation of $\mathrm{CD}^{+} \mathrm{T}$ cells proliferation by BMMCs. BMMCs were pulsed with $4 \mu \mathrm{M}$ SIINFEKEL, washed and added to MACS purified, CFSE-labeled OT-1 CD8 ${ }^{+}$ T cells at different ratios as indicated with the CD8+ T-cell numbers fixed at I $\times 10^{6}$ per assay. After 72 hour co-culture, CD8 ${ }^{+} \mathrm{T}$ cells were analyzed for CFSE dilution by flow cytometry. The proliferation of $\mathrm{CD}^{+} \mathrm{T}$ cells was maximum at highest mast cell number to $\mathrm{CD}^{+} \mathrm{T}$ cell ratio for both the WT and D6-- BMMCs. The inset in the 1:2 ratio of shows the addition of the same number of mast cells without the peptide on their surface. 

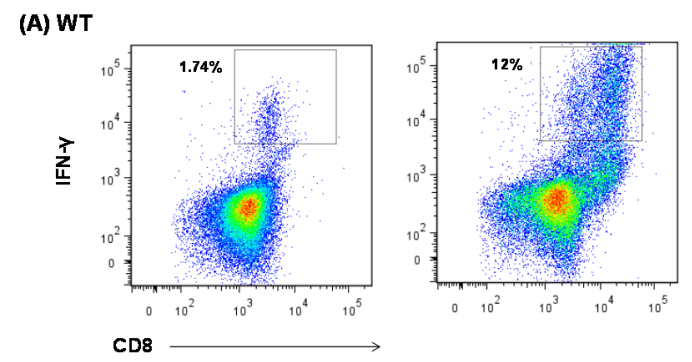

(B) D6-
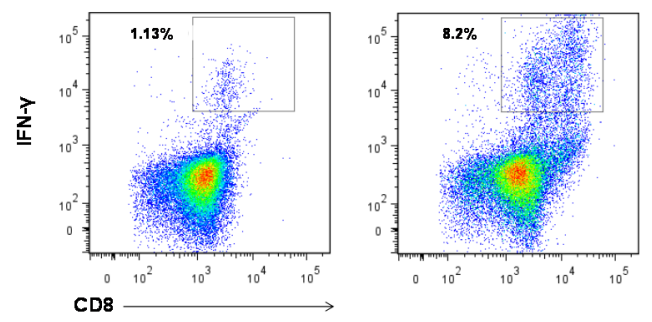

Figure 33: Intracellular staining of $\mathrm{CD8}^{+} \mathrm{T}$ cells for IFN-Y. BMMCS were pulsed with 4 uM SIINFEKEL,washed, and added to MACS purified OT-1 CD8 T $^{+}$cells at 1:2 ratio. After 48 hour co culture, cells were stimulated with PMA/ionomycin cocktail for 5 hours and analyzed for intracellular IFN-y levels by flow cytometry. The WT and D6-- BMMCs mediated IFN-y release from $\mathrm{CD}^{+} \mathrm{T}$ cells upon SIINFEKEL treatment. 


\section{DISCUSSION}

The results presented here showed that enhanced mast cell infiltration into tumors is intimately linked to facilitated T-cell recruitment into tumors in the D6 ${ }^{-/-}$ $\mathrm{Apc}^{\mathrm{Min} /+}$ mice. Moreover, these results place mast cells clearly acting upstream of the cytotoxic T-cells. T- Cell recruitment to tumors is dependent on the presence of mast cells $\left(\mathrm{D6}^{-1-} \mathrm{SA}^{-1-} \mathrm{Apc}^{\mathrm{Min} /+}\right)$ whereas the enhanced mast cell recruitment is completely independent of the T-cell function (D6 ${ }^{-/}$Rag $^{--}{ }^{--} \mathrm{Apc}^{\mathrm{Min} /+}$ ). According to our hypothesis, activated $\mathrm{CD} 8^{+} \mathrm{T}$ cells remove tumors by immune surveillance and mast cells facilitate this process by directly presenting tumor antigens to $\mathrm{CD} 8^{+} \mathrm{T}$ cells as well as facilitating their recruitment into tumors.

Under most inflammatory and infection conditions tissue associated mast cell number increases. For example, mast cell numbers in nasal mucosa increases during pollen season. The increase in mast cell numbers and induction of mast cell proteases 1 (MCPT-1) in intestinal mucosal epithelium during infection by helminthes is T-cell mediated $[107,108]$. The accumulation of mast cells in a Tcell independent manner was also noticed in $\mathrm{Rag}^{-1-} \mathrm{Apc}^{\mathrm{Min} /+}$ mice adenomas [63].

Gounaris et al suggested that deficiency of mast cells in $\mathrm{Apc}^{\triangle 468}$ epithelium is unfit to propagate and progress in to full tumors [63]. Gournaris et al showed the requirement of mast cells in tumorigenesis by using bone marrow transfers of WT, $\mathrm{Kit}{ }^{\mathrm{W}-\mathrm{sh} / \mathrm{W}-\mathrm{sh}}, \mathrm{Cd} 34^{---} \mathrm{Cd} 43^{-/-}$into lethally irradiated $\mathrm{Apc}^{\Delta 468}$ mice. They observed only $25 \%$ reduction in polyp number (60 to 45$)$ with $\mathrm{Kit}{ }^{\mathrm{W}-\mathrm{sh} / \mathrm{W}-\mathrm{sh}} \mathrm{BM}$. However, irradiation and bone marrow transfers into Apc mice have their limitations and consequences in obtaining consist phenotype in spontaneous intestinal cancer models. 
Therefore, we choose genetic approaches to examine the precise role for mast cell requirement in tumorigenesis. The intestinal adenomas of $\mathrm{Apc}^{\mathrm{Min} /+}$ and $\mathrm{D6}^{-/-}$ $\mathrm{Apc}^{\mathrm{Min} /+}$ mice are infiltrated with mast cells but the vastly increased mast cell infiltration in $\mathrm{D6}^{-/-} \mathrm{Apc}^{\mathrm{Min} /+}$ mice relative to $\mathrm{Apc}^{\mathrm{Min} /+}$ is tumor protective. We believe our data presented here outlines a simpler explanation of reduced immune

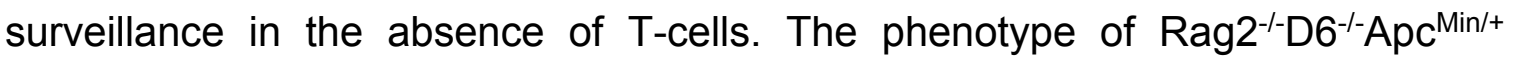

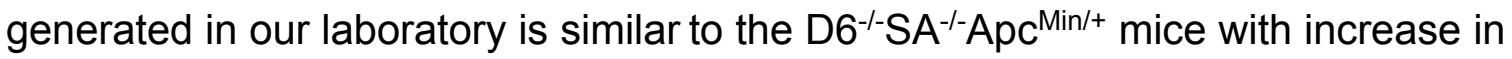
overall tumor burden as described in chapter III of this dissertation. It is possible that in the absence of T-cells and mast cells might even be tumor promoting but certainly do not mediate any direct anti-tumor activities.

Several studies pointed out the significance of the tumor infiltrating lymphocytes (TIL) within the core of the tumor or at invasive margin as a good prognosis factor in colorectal cancer $[109,110]$. A recent review highlights most of the research in this area [111] not only in colon cancer but also in other cancers providing the link between TILS and tumor prognosis. TILS consist of CD4+ helper cells or $\mathrm{CD} 8^{+}$cytotoxic cells or both. There are three types of $\mathrm{CD} 4^{+} \mathrm{T}$-cell in tumors including $\mathrm{CD} 4^{+}$helper, T-regs and Th17 cells. The balance between $\mathrm{CD} 4^{+}$helper cells enhancing $\mathrm{CD}^{+} \mathrm{CTL}$ function or opposing Tregs mediated immune suppression will dictate the tumor outcome. A large influx of CD8+ CTLs in the D6${ }^{\text {-Apc }}{ }^{\mathrm{Min} /+}$ mice (Fig. 27) described here clearly points to the overall enhancement of immune surveillance function by the absence of D6. While further studies are clearly needed to dissect the role and contribution of different $\mathrm{CD}^{+}$subsets including T-regs, the use of $\mathrm{SA}^{-/-}$and Rag2 $2^{-/-}$compound mice outlines the critical 
importance of mast cell mediated T-cell responses in the initiation of tumor protective responses in the Min mice.

The data presented here also suggests that $\mathrm{D6}^{-/}$mast cells can present peptide antigens as effectively as WT mast cells. Upon antigen presentation by the mast cells, $\mathrm{CD} 8^{+}$cells differentiate into CTLs producing perforin, granzymeB and activating the caspases in tumor cells leading to apoptosis. The increased apoptosis seen in the D6 ${ }^{--} \mathrm{Apc}^{\mathrm{Min} /+}$ tumors (Fig. 3) suggests that this indeed could be the mechanism mediating tumor protection in these mice. Homeostatic migration of effector $\mathrm{CD} 8^{+} \mathrm{T}$-cells do not need $\mathrm{CD} 4^{+}$help whereas differentiated $\mathrm{CD}^{+} \mathrm{T}$ cells need $\mathrm{CD} 4^{+}$help to migrate to viral infection site [112]. $\mathrm{CD} 4^{+}$cells secrete IFNy to help epithelial cells produce CXCL-9 and CXCL-10 for CXCR3 mediated $\mathrm{CD}^{+} \mathrm{T}$-cell recruitment. In our system, the mast cell mediated production of $\mathrm{LTB}_{4}$ could also be an important mediator of CTL recruitment into tumors.

Over all the results presented in this thesis outline an important immune regulatory function for mast cells, an aspect long suspected from a wide range of clinical studies but has not been formally proven. These studies provide a clear demonstration of the antitumor potential of mast cells and delineated the mechanisms underlying this important function paving the way for development of clinical applications based on these principles. 


\section{CONCLUSIONS AND SIGNIFICANCE OF THIS STUDY}

Cancer is one of the leading causes of deaths worldwide and especially in developed countries like the United States. Over the last decade the importance of immune system in controlling the development of cancer in both positive and negative ways is being appreciated. This research is focused on understanding the role of mast cells in controlling intestinal cancer development and the role of chemokines in the recruitment of appropriate cells involved in generating effective anti-tumor immunity. A mouse model of intestinal cancer, $\mathrm{Apc}^{\mathrm{Min} /+}$ was studied in combination with a variety genetic models that lack chemokine decoy receptor D6 and/or mast cells. The objective of this study was to reveal the mechanisms underlying the observation that absence of D6 led to decreased inflammation and reduced tumor development in this model.

In summary, our results suggest that i) mast cells play a critical role in immune surveillance of small intestinal tumors. ii) D6 ligands (CCL2 and CCL5) recruit mast cells via enhanced expression of CCR2 and CCR5 in D6--Apc ${ }^{\mathrm{Min} /+}$ iii) increased accumulation of mast cells facilitate recruitment of $\mathrm{CD}^{+} \mathrm{T}$-cells in intestinal tumors of $\mathrm{D6}^{---} \mathrm{Apc}^{\mathrm{Min}+}$ iv) $\mathrm{D6}^{-1-}$ mast cells can efficiently induce $\mathrm{CD} 8^{+} \mathrm{T}$ cell activation and proliferation v) mast cells are recruited into tumors even in the absence of T-cells indicating mast cells act upstream of $\mathrm{CD}^{+} \mathrm{T}$-cells in mediating anti-tumor immunity. 
An important observation from our study is the elevated expression of CCR2 and CCR5 in cultured mast cells from the D6 ${ }^{-/-}$mice relative to WT mice. While we have not yet formally demonstrated that this increase in CCR2 or CCR5 is responsible for the enhanced migration of mast cells into $\mathrm{D6}^{-1-} \mathrm{Apc} \mathrm{Min} /+^{+}$tumors, we believe this is the most likely explanation. Further studies showing elevated expression of CCR2 on in vivo mast cells either from tumors or draining lymph nodes are essential. Demonstration of CCL2 or CCL5 dependent enhanced mast cell recruitment in an in vivo model such as skin inflammation or implantable tumor models would provide further support to the idea that CCR2 is the cause of enhanced mast cell trafficking.

The most significant contribution of the current study is the demonstration that the mast cells directly contribute to enhanced immune surveillance of intestinal cancers. Our genetic studies clearly identified the importance of mast cells in slowing the tumor progression in the $\mathrm{D6}^{--} \mathrm{Apc}^{\mathrm{Min} /+}$ mice. While the presence of mast cells in tumors has been known since the days of Ehrlich, their contribution to the tumor promotion or tumor elimination has been a matter of continued investigation and debate. Our studies presented here strongly point to a protective role for mast cells in this intestinal tumor model.

Although the chemokine scavenging role of D6 has been known for a decade the exact mechanisms through which it regulates inflammation in vivo are only beginning to be appreciated. Recent work from theGraham laboratory showed that the D6 function at lymphatic surfaces, distinct from the normal role in clearance of inflammation. The number of Ly6 $\mathrm{C}^{\text {high }}$ monocytes increased in D6--- 
mice spleen and blood in CCR2 dependent manner and exhibited enhanced immune suppressive activity. Bone marrow transfer experiments showed that the absence of D6 expression on lymphatic vessels and not on hematopoietic cells is important for the monocyte recruitment [113] . During LPS induced inflammation, increased levels of CCL2 accumulation in $6^{-/-}$mice draining lymph nodes recruited high CCR2 expressing CD11 $\mathrm{b}^{+} \mathrm{Gr} 1^{\text {high }}$ cells [114]. Blocking CCR2 inhibited the migration of other cellular flow and restored the migration of antigen presenting DCs. This indicate the plausible role of D6 is to prevent accumulation of inflammatory chemokines on lymphatic endothelium so that APC can efficiently present the antigens. Graham and colleagues suggest that the draining lymph node area becomes like a clogged sink in the absence D6 preventing the normal flow of leukocytes. However, our results showed a significantly different outcome i.e. a more efficient anti-tumor immune response in the absence of D6. While, we have not measured the presence and abundance of immature DCs and monocytes at the draining lymph nodes, earlier studies from our laboratory noted the presence of more mast cells in the draining lymph nodes of $\mathrm{Apc}^{\mathrm{Min} /+}$ and $\mathrm{D6}^{-/-} \mathrm{Apc}^{\mathrm{Min} /+}$ mice. Indeed, in the context of generating immunity to the altered self-antigens this clogged sink is what might be needed for unconventional antigen presentation by APCs such as mast cells. Clearly further work is needed to explore this possibility.

Mast cells could orchestrate antitumor immunity at several levels. These include direct cytotoxicity and phagocytosis, efficient tumor antigen presentation and/or effective CTL recruitment to the tumors. The data from $\mathrm{D6}^{-/} \mathrm{Rag2}^{-{ }^{-}} \mathrm{Apc}^{\mathrm{Min} /+}$ clearly shows mast cells alone are not sufficient to reduce the tumor burden and 
$\mathrm{CD}^{+} \mathrm{T}$-cell mediated immune response is essential. Hence, we do not think direct cytotoxicity or phagocytic capabilities of mast cells are the mechanism for the D6${ }^{\text {I-Apc }}{ }^{\mathrm{Min} /+}$ phenotype.

Our co-culture experiments using bone marrow derived mast cells (BMMCs) and OT-1 CD8 ${ }^{+} \mathrm{T}$ cells showed $\mathrm{D6}^{--}$mast cells are capable of efficient antigen presentation to mediate $\mathrm{CD}^{+} \mathrm{T}$ cell activation and proliferation. We also showed the effector function of $\mathrm{CD}^{+} \mathrm{T}$ cells by measuring their IFN-y levels upon antigen specific activation by $\mathrm{D6}^{--}$mast cells. While, we have not directly demonstrated tumor antigen uptake and presentation by $\mathrm{D6}^{-{ }^{-}}$mast cells, there is evidence in autoimmunity models for mast cells processing protein antigens and efficiently presenting to $\mathrm{CD}^{+} \mathrm{T}$ cells [79]. We believe mast cells in $\mathrm{D6}^{--} \mathrm{Apc} \mathrm{Min}^{++}$tumors are involved in priming and activating naïve $\mathrm{CD} 8^{+} \mathrm{T}$ cells by taking up tumor antigens and present them in draining lymph node. In addition, recent data suggests that naïve T-cells can also be primed directly within the tumors [115]. Mast cells in D6${ }^{\text {-Apc }}{ }^{\mathrm{Min} /+}$ tumors may also be involved in secondary priming and proliferation of memory $\mathrm{CD}^{+} \mathrm{T}$ cells for sustained response. We do not know at this time involvement of other cell types or whether $\mathrm{CD} 4^{+} \mathrm{T}$-cell help is needed. It is also unclear the extent or relative contributions of the conventional DCs and/or mast cells in initial priming.

There are reported instances of tumor reactive CTLs not being efficiently recruited to tumors and staying at the periphery in draining lymph nodes failing to initiate anti-tumor immune response. We think one of the reasons for effective immune surveillance in $\mathrm{D6}^{-/-} \mathrm{Apc} \mathrm{Min} /+^{+}$tumors is the ability of mast cells to produce 
several T-cell chemoattractants such as LTB 4, CCL5, XCL1 and CXCL10 upon activation. It is well known that $\mathrm{LTB}_{4}$ produced by mast cells plays a central role in recruiting effector $\mathrm{CD}^{+} \mathrm{T}$ cells. An important observation in this regard is that when $\mathrm{BLT1}^{-/-}$mice were crossed onto the $\mathrm{D6}^{-/-} \mathrm{Apc}^{\mathrm{Min} /+}$ background, not only the survival advantage of the $\mathrm{D6}^{-/-} \mathrm{Apc}^{\mathrm{Min} /+}$ mice was lost but the $\mathrm{BLT} 1^{---} \mathrm{D6}^{-{ }^{-} \mathrm{Apc}} \mathrm{cin}^{\mathrm{Mi} /}$ mice displayed highly accelerated disease. Further studies on mast cell and T-cell recruitment into these tumors will provide a more direct evidence for the mast cell mediated $\mathrm{LTB}_{4}$ dependent $\mathrm{CTL}$ recruitment into the $\mathrm{D6}^{-/-} \mathrm{Apc}^{\mathrm{Min} /+}$ small intestinal tumors. A model summarizing our findings on the role of mast cell mediated immune surveillance in the $\mathrm{D6}^{-1-} \mathrm{Apc} \mathrm{Min} /+^{-}$mice is shown in Figure 34.

Over all the studies reported in this dissertation highlight the role of mast cells in immune surveillance of intestinal cancers. What is the relevance of these findings to human cancers? The importance of the immune system in controlling tumor growth has been recognized to the extent that the recent update of hall marks of cancer by Hanahan and Weinberg now includes "avoiding immune destruction" as an emerging hallmark of cancer [116]. This joins the previously established hallmark of tumor-promoting inflammation [116] and thus recognizing the pivotal role of immune system both in tumor suppression and tumor promotion. The importance of the distinct immune cell types as guides for determining the prognosis was elegantly reviewed by Galon and colleagues [117]. They mentioned mast cells also part of this immune contexture along with Macrophages, MDSCs, and B cells but they analyzed clinical outcome using only T cell populations. It is very clear from this analysis that $97 \%$ of the published papers showed that large 
infiltration of high density of cytotoxic and memory $\mathrm{T}$ cells $\mathrm{CD} 8^{+} / \mathrm{CD} 45 \mathrm{R} 0$ in the center and invasive margin of colorectal tumors is correlated with good prognosis.

Many clinical studies outlined in the chapter I, examined the clinical outcome of mast cell infiltration into tumors. While many studies reporting mast cell presence correlated with good prognosis there are other studies that highlight tumor promoting effects of mast cells. Independent of the mechanism of their recruitment, the results presented here clearly outline a protective role for mast cells in intestinal cancers especially when correlated with $\mathrm{CD} 8^{+} \mathrm{T}$ cells.

Tumors are normally classified using tumor burden $(T)$, presence cancer cells in the lymph node $(\mathrm{N})$ and evidence of metastasis $(\mathrm{M})$ called TNM staging. Recently it was suggested by several groups to include immune scoring as a new prognostic factor and include immune score as part of new tumor classification method [118]. The results presented in this dissertation supports the potential need to include the presence of mast cells in immune scoring along with $C D 8^{+} \mathrm{T}$ cells as a positive prognostic factor in intestinal cancers. Thus, approaches to enhance mast cell infiltration into tumors might be a strategy to develop immunotherapy protocols for colon cancer. 


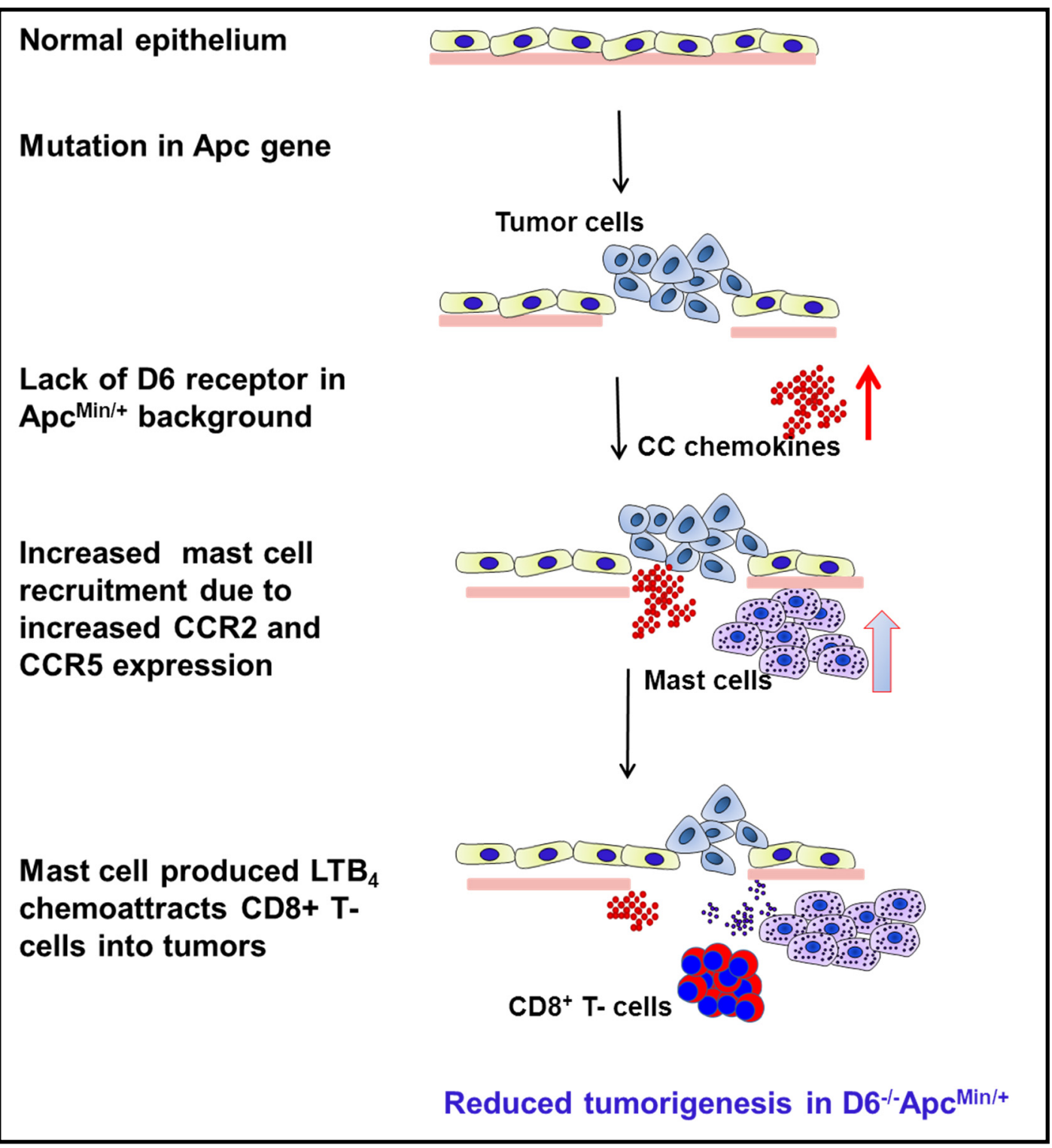

Figure 34: A model for reduced tumorigenesis in the $\mathrm{D6}^{-1-} \mathrm{Apc}^{\mathrm{Min} /+}$ mice. In $\mathrm{Apc} \mathrm{Min} /+^{\mathrm{N}}$ mice loss of heterozygosity initiates intestinal tumors. Absence of D6 in this background resulted in increased mast cell infiltration into tumors. This is likely due to the increased chemokines in $\mathrm{D6}^{-1-} \mathrm{Apc}^{\mathrm{Min} /+}$ tumors as well as enhanced CCR2 and CCR5 expression on mast cells. Mast cell produced chemokines and $\mathrm{LTB}_{4}$ chemoattract cytotoxic lymphocytes into the tumors leading to effective immune surveillance and reduced tumor burden in D6${ }^{1}-\mathrm{Apc}^{\mathrm{Min} /+}$ mice. 


\section{REFERENCES}

1. Grivennikov, S.I., F.R. Greten, and M. Karin, Immunity, Inflammation, and Cancer. Cell. 140(6): p. 883-899.

2. Mantovani, A., et al., Cancer-related inflammation. Nature, 2008. 454(7203): p. 436-44.

3. Greten, F.R., et al., IKK[beta] Links Inflammation and Tumorigenesis in a Mouse Model of Colitis-Associated Cancer. Cell, 2004. 118(3): p. 285-296.

4. DiDonato, J.A., F. Mercurio, and M. Karin, NF-kappaB and the link between inflammation and cancer. Immunol Rev, 2012. 246(1): p. 379-400.

5. Yu, H., M. Kortylewski, and D. Pardoll, Crosstalk between cancer and immune cells: role of STAT3 in the tumour microenvironment. Nat Rev Immunol, 2007. 7(1): p. 41-51.

6. Mantovani, A., et al., Role of tumor-associated macrophages in tumor progression and invasion. Cancer Metastasis Rev, 2006. 25(3): p. 315-22.

7. Schreiber, R.D., L.J. Old, and M.J. Smyth, Cancer immunoediting: integrating immunity's roles in cancer suppression and promotion. Science, 2011. 331(6024): p. 1565-70.

8. Dunn, G.P., et al., Cancer immunoediting: from immunosurveillance to tumor escape. Nat Immunol, 2002. 3(11): p. 991-8.

9. Dunn, G.P., L.J. Old, and R.D. Schreiber, The three Es of cancer immunoediting. Annu Rev Immunol, 2004. 22: p. 329-60. 
10. Koebel, C.M., et al., Adaptive immunity maintains occult cancer in an equilibrium state. Nature, 2007. 450(7171): p. 903-7.

11. Matsushita, H., et al., Cancer exome analysis reveals a T-cell-dependent mechanism of cancer immunoediting. Nature, 2012. 482(7385): p. 400-4.

12. Murdoch, C., et al., The role of myeloid cells in the promotion of tumour angiogenesis. Nat Rev Cancer, 2008. 8(8): p. 618-31.

13. Galon, J., et al., Type, Density, and Location of Immune Cells Within Human Colorectal Tumors Predict Clinical Outcome. Science Building the Body from Genes, 2006. 313(5795): p. 1960-1964.

14. Ono, S.J., et al., Chemokines: roles in leukocyte development, trafficking, and effector function. J Allergy Clin Immunol, 2003. 111(6): p. 1185-99; quiz 1200.

15. White, G.E., A.J. Iqbal, and D.R. Greaves, CC chemokine receptors and chronic inflammation--therapeutic opportunities and pharmacological challenges. Pharmacol Rev, 2013. 65(1): p. 47-89.

16. Bonecchi, R., et al., Chemokines and chemokine receptors: an overview. Front Biosci, 2009. 14: p. 540-51.

17. Kelvin, D.J., et al., Chemokines and serpentines: the molecular biology of chemokine receptors. J Leukoc Biol, 1993. 54(6): p. 604-12.

18. Murphy, P.M., The molecular biology of leukocyte chemoattractant receptors. Annu Rev Immunol, 1994. 12: p. 593-633.

19. Zlotnik, A. and O. Yoshie, The chemokine superfamily revisited. Immunity, 2012. 36(5): p. 705-16. 
20. Rot, A. and U.H. von Andrian, Chemokines in innate and adaptive host defense: basic chemokinese grammar for immune cells. Annu Rev Immunol, 2004. 22: p. 891-928.

21. Locati, M., et al., Silent chemoattractant receptors: D6 as a decoy and scavenger receptor for inflammatory CC chemokines. Cytokine Growth Factor Rev, 2005. 16(6): p. 679-86.

22. Galliera, E., et al., beta-Arrestin-dependent constitutive internalization of the human chemokine decoy receptor D6. J Biol Chem, 2004. 279(24): p. 25590-7.

23. Jamieson, T., et al., The chemokine receptor D6 limits the inflammatory response in vivo. Nat Immunol, 2005. 6(4): p. 403-11.

24. Nibbs, R.J., et al., The beta-chemokine receptor D6 is expressed by lymphatic endothelium and a subset of vascular tumors. Am J Pathol, 2001. 158(3): p. 867-77.

25. McKimmie, C.S., et al., Hemopoietic Cell Expression of the Chemokine Decoy Receptor D6 Is Dynamic and Regulated by GATA1. J Immunol, 2008. 181(5): p. 3353-3363.

26. Wu, F.Y., et al., Chemokine decoy receptor d6 plays a negative role in human breast cancer. Mol Cancer Res, 2008. 6(8): p. 1276-88.

27. Martinez de la Torre, Y., et al., Increased inflammation in mice deficient for the chemokine decoy receptor D6. Eur J Immunol, 2005. 35(5): p. 1342-6.

28. Di Liberto, D., et al., Role of the chemokine decoy receptor D6 in balancing inflammation, immune activation, and antimicrobial resistance in 
Mycobacterium tuberculosis infection. J Exp Med, 2008. 205(9): p. 207584.

29. Whitehead, G.S., et al., The chemokine receptor D6 has opposing effects on allergic inflammation and airway reactivity. Am J Respir Crit Care Med, 2007. 175(3): p. 243-9.

30. Martinez de la Torre, Y., et al., Protection against inflammation- and autoantibody-caused fetal loss by the chemokine decoy receptor D6. Proc Natl Acad Sci U S A, 2007. 104(7): p. 2319-24.

31. Nibbs, R.J., et al., The atypical chemokine receptor D6 suppresses the development of chemically induced skin tumors. J Clin Invest, 2007. 117(7): p. 1884-92.

32. Su, L.K., et al., Multiple intestinal neoplasia caused by a mutation in the murine homolog of the APC gene. Science, 1992. 256(5057): p. 668-70.

33. Moser, A.R., H.C. Pitot, and W.F. Dove, A dominant mutation that predisposes to multiple intestinal neoplasia in the mouse. Science, 1990. 247(4940): p. 322-4.

34. Heib, V., et al., Advances in the understanding of mast cell function. $\mathrm{Br} \mathrm{J}$ Haematol, 2008. 142(5): p. 683-94.

35. Austen, K.F. and J.A. Boyce, Mast cell lineage development and phenotypic regulation. Leuk Res, 2001. 25(7): p. 511-8.

36. Wright, S.H., et al., Transforming growth factor-beta1 mediates coexpression of the integrin subunit alphaE and the chymase mouse mast 
cell protease-1 during the early differentiation of bone marrow-derived mucosal mast cell homologues. Clin Exp Allergy, 2002. 32(2): p. 315-24.

37. McLachlan, J.B., et al., Mast cell-derived tumor necrosis factor induces hypertrophy of draining lymph nodes during infection. Nat Immunol, 2003. 4(12): p. 1199-205.

38. Galli, S.J., S. Nakae, and M. Tsai, Mast cells in the development of adaptive immune responses. Nat Immunol, 2005. 6(2): p. 135-42.

39. Ott, V.L., et al., Mast cell-dependent migration of effector CD8+ $T$ cells through production of leukotriene B4. Nat Immunol, 2003. 4(10): p. 974-81.

40. Galli, S.J., M. Grimbaldeston, and M. Tsai, Immunomodulatory mast cells: negative, as well as positive, regulators of immunity. Nat Rev Immunol, 2008. 8(6): p. 478-86.

41. Vyas, H. and G. Krishnaswamy, Paul Ehrlich's "Mastzellen"--from aniline dyes to DNA chip arrays: a historical review of developments in mast cell research. Methods Mol Biol, 2006. 315: p. 3-11.

42. Theoharides, T.C. and P. Conti, Mast cells: the Jekyll and Hyde of tumor growth. Trends Immunol, 2004. 25(5): p. 235-41.

43. Kankkunen, J.P., I.T. Harvima, and A. Naukkarinen, Quantitative analysis of tryptase and chymase containing mast cells in benign and malignant breast lesions. Int J Cancer, 1997. 72(3): p. 385-8.

44. Ju, M.J., et al., Combination of peritumoral mast cells and T-regulatory cells predicts prognosis of hepatocellular carcinoma. Cancer Sci, 2009. 100(7): p. $1267-74$. 
45. Bellone, G., et al., KIT/stem cell factor expression in premalignant and malignant lesions of the colon mucosa in relationship to disease progression and outcomes. Int J Oncol, 2006. 29(4): p. 851-9.

46. Wu, X., et al., Tumor-infiltrating mast cells in colorectal cancer as a poor prognostic factor. Int J Surg Pathol, 2013. 21(2): p. 111-20.

47. Coussens, L.M., et al., Inflammatory mast cells up-regulate angiogenesis during squamous epithelial carcinogenesis. Genes Dev, 1999. 13(11): p. $1382-97$.

48. Soucek, L., et al., Mast cells are required for angiogenesis and macroscopic expansion of Myc-induced pancreatic islet tumors. Nat Med, 2007. 13(10): p. 1211-8.

49. Aaltomaa, S., et al., Mast cells in breast cancer. Anticancer Res, 1993. 13(3): p. 785-8.

50. Dabiri, S., et al., The presence of stromal mast cells identifies a subset of invasive breast cancers with a favorable prognosis. Mod Pathol, 2004. 17(6): p. 690-5.

51. Amini, R.M., et al., Mast cells and eosinophils in invasive breast carcinoma. BMC Cancer, 2007. 7: p. 165.

52. Alkhabuli, J.O., Significance of neo-angiogenesis and immuno-surveillance cells in squamous cell carcinoma of the tongue. Libyan J Med, 2007. 2(1): p. $30-9$.

53. Hedstrom, G., et al., Mast cell infiltration is a favourable prognostic factor in diffuse large B-cell lymphoma. Br J Haematol, 2007. 138(1): p. 68-71. 
54. Chan, J.K., et al., Mast cell density, angiogenesis, blood clotting, and prognosis in women with advanced ovarian cancer. Gynecol Oncol, 2005. 99(1): p. 20-5.

55. Fleischmann, A., et al., Immunological microenvironment in prostate cancer: high mast cell densities are associated with favorable tumor characteristics and good prognosis. Prostate, 2009. 69(9): p. 976-81.

56. Johansson, A., et al., Mast cells are novel independent prognostic markers in prostate cancer and represent a target for therapy. Am J Pathol, 2010. 177(2): p. 1031-41.

57. Mukherjee, S., et al., Evaluation of endoscopic biopsy in gastric lesions with a special reference to the significance of mast cell density. Indian J Pathol Microbiol, 2009. 52(1): p. 20-4.

58. Nielsen, H.J., et al., Independent prognostic value of eosinophil and mast cell infiltration in colorectal cancer tissue. J Pathol, 1999. 189(4): p. 487-95.

59. Heijmans, J., et al., Role of mast cells in colorectal cancer development, the jury is still out. Biochim Biophys Acta, 2012. 1822(1): p. 9-13.

60. Massague, J., TGFbeta in Cancer. Cell, 2008. 134(2): p. 215-30.

61. Xia, Q., et al., No relationship between the distribution of mast cells and the survival of stage IIIB colon cancer patients. J Transl Med, 2011. 9: p. 88.

62. Tanaka, T. and H. Ishikawa, Mast cells and inflammation-associated colorectal carcinogenesis. Semin Immunopathol, 2013. 35(2): p. 245-54. 
63. Gounaris, E., et al., Mast cells are an essential hematopoietic component for polyp development. Proc Natl Acad Sci U S A, 2007. 104(50): p. 1997782.

64. Sinnamon, M.J., et al., A protective role of mast cells in intestinal tumorigenesis. Carcinogenesis, 2008. 29(4): p. 880-6.

65. Conti, P., et al., Impact of Rantes and MCP-1 chemokines on in vivo basophilic cell recruitment in rat skin injection model and their role in modifying the protein and mRNA levels for histidine decarboxylase. Blood, 1997. 89(11): p. 4120-7.

66. Juremalm, M. and G. Nilsson, Chemokine receptor expression by mast cells. Chem Immunol Allergy, 2005. 87: p. 130-44.

67. Huang, B., et al., SCF-mediated mast cell infiltration and activation exacerbate the inflammation and immunosuppression in tumor microenvironment. Blood, 2008. 112(4): p. 1269-79.

68. Theoharides, T.C., et al., Mast cells and inflammation. Biochim Biophys Acta, 2012. 1822(1): p. 21-33.

69. Pittoni, P. and M.P. Colombo, The dark side of mast cell-targeted therapy in prostate cancer. Cancer Res, 2012. 72(4): p. 831-5.

70. Liu, J., et al., Mast cell: insight into remodeling a tumor microenvironment. Cancer Metastasis Rev, 2011. 30(2): p. 177-84.

71. Farram, E. and D.S. Nelson, Mouse mast cells as anti-tumor effector cells. Cell Immunol, 1980. 55(2): p. 294-301. 
72. Della Rovere, F., et al., Phagocytosis of cancer cells by mast cells in breast cancer. Anticancer Res, 2009. 29(8): p. 3157-61.

73. Ch'ng, S., et al., Mast cells dysregulate apoptotic and cell cycle genes in mucosal squamous cell carcinoma. Cancer Cell Int, 2006. 6: p. 28.

74. Samoszuk, M., E. Kanakubo, and J.K. Chan, Degranulating mast cells in fibrotic regions of human tumors and evidence that mast cell heparin interferes with the growth of tumor cells through a mechanism involving fibroblasts. BMC Cancer, 2005. 5: p. 121.

75. Samoszuk, M. and M.A. Corwin, Acceleration of tumor growth and peritumoral blood clotting by imatinib mesylate (Gleevec). Int J Cancer, 2003. 106(5): p. 647-52.

76. Gri, G., et al., Mast cell: an emerging partner in immune interaction. Front Immunol, 2012. 3: p. 120.

77. Hershko, A.Y. and J. Rivera, Mast cell and $T$ cell communication; amplification and control of adaptive immunity. Immunol Lett, 2010. 128(2): p. $98-104$.

78. Malaviya, R., et al., Mast cells process bacterial Ags through a phagocytic route for class I MHC presentation to T cells. J Immunol, 1996. 156(4): p. $1490-6$.

79. Stelekati, E., et al., Mast cell-mediated antigen presentation regulates CD8+ $T$ cell effector functions. Immunity, 2009. 31(4): p. 665-76. 
80. Piconese, S., et al., Mast cells counteract regulatory T-cell suppression through interleukin-6 and OX40/OX40L axis toward Th17-cell differentiation. Blood, 2009. 114(13): p. 2639-48.

81. Kashiwakura, J., et al., $T$ cell proliferation by direct cross-talk between OX40 ligand on human mast cells and OX40 on human T cells: comparison of gene expression profiles between human tonsillar and lung-cultured mast cells. J Immunol, 2004. 173(8): p. 5247-57.

82. Gri, G., et al., $C D 4+C D 25+$ regulatory $T$ cells suppress mast cell degranulation and allergic responses through OX40-OX40L interaction. Immunity, 2008. 29(5): p. 771-81.

83. Jala, V.R., W.H. Shao, and B. Haribabu, Phosphorylation-independent beta-arrestin translocation and internalization of leukotriene $B 4$ receptors. $\mathrm{J}$ Biol Chem, 2005. 280(6): p. 4880-7.

84. Basu, S., et al., Critical role for polar residues in coupling leukotriene B4 binding to signal transduction in BLT1. J Biol Chem, 2007. 282(13): p. 10005-17.

85. Dahl, A., et al., Quantitative PCR based expression analysis on a nanoliter scale using polymer nano-well chips. Biomed Microdevices, 2007. 9(3): p. $307-14$.

86. Tan, S.Y., et al., Prognostic significance of cell infiltrations of immunosurveillance in colorectal cancer. World J Gastroenterol, 2005. 11(8): p. $1210-4$. 
87. Rajput, A.B., et al., Stromal mast cells in invasive breast cancer are a marker of favourable prognosis: a study of 4,444 cases. Breast Cancer Res Treat, 2008. 107(2): p. 249-57.

88. Gounaris, E., et al., Mast cells are an essential hematopoietic component for polyp development. Proceedings of the National Academy of Sciences, 2007. 104(50): p. 19977-19982.

89. Nautiyal, K.M., et al., Brain mast cells link the immune system to anxietylike behavior. Proc Natl Acad Sci U S A, 2008. 105(46): p. 18053-7.

90. Rakoff-Nahoum, S. and R. Medzhitov, Regulation of spontaneous intestinal tumorigenesis through the adaptor protein MyD88. Science, 2007. 317(5834): p. 124-7.

91. Karin, M. and F.R. Greten, NF-kappaB: linking inflammation and immunity to cancer development and progression. Nat Rev Immunol, 2005. 5(10): p. $749-59$.

92. Coussens, L.M. and Z. Werb, Inflammation and cancer. Nature, 2002. 420(6917): p. 860-7.

93. Greten, F.R., et al., IKKbeta links inflammation and tumorigenesis in a mouse model of colitis-associated cancer. Cell, 2004. 118(3): p. 285-96.

94. Beaven, M.A., Our perception of the mast cell from Paul Ehrlich to now. Eur J Immunol, 2009. 39(1): p. 11-25.

95. Pittoni, P., et al., Tumor-intrinsic and -extrinsic roles of c-Kit: mast cells as the primary off-target of tyrosine kinase inhibitors. Oncogene, 2011. 30(7): p. $757-69$. 
96. Gurish, M.F., et al., Intestinal mast cell progenitors require CD49dbeta7 (alpha4beta7 integrin) for tissue-specific homing. J Exp Med, 2001. 194(9): p. $1243-52$.

97. Weller, C.L., et al., Leukotriene B4, an activation product of mast cells, is a chemoattractant for their progenitors. J Exp Med, 2005. 201(12): p. 196171.

98. Flaishon, L., et al., Expression of the chemokine receptor CCR2 on immature $B$ cells negatively regulates their cytoskeletal rearrangement and migration. Blood, 2004. 104(4): p. 933-41.

99. Sozzani, S., et al., Cutting Edge: Differential Regulation of Chemokine Receptors During Dendritic Cell Maturation: A Model for Their Trafficking Properties. The Journal of Immunology, 1998. 161(3): p. 1083-1086.

100. Phillips, R.J., M. Lutz, and B. Premack, Differential signaling mechanisms regulate expression of CC chemokine receptor-2 during monocyte maturation. J Inflamm (Lond), 2005. 2: p. 14.

101. Collington, S.J., et al., The role of the CCL2/CCR2 axis in mouse mast cell migration in vitro and in vivo. J Immunol, 2010. 184(11): p. 6114-23.

102. Rodriguez-Sanabria, F., et al., Tissue distribution and expression of paraoxonases and chemokines in mouse: the ubiquitous and joint localisation suggest a systemic and coordinated role. J Mol Histol, 2010. 41(6): p. 379-86. 
103. Singh, M.D., et al., Elevated expression of the chemokine-scavenging receptor D6 is associated with impaired lesion development in psoriasis. Am J Pathol, 2012. 181(4): p. 1158-64.

104. Malaviya, R., et al., Mast cell phagocytosis of FimH-expressing enterobacteria. J Immunol, 1994. 152(4): p. 1907-14.

105. Nakae, S., et al., Mast cells enhance $T$ cell activation: importance of mast cell costimulatory molecules and secreted TNF. J Immunol, 2006. 176(4): p. $2238-48$.

106. Mekori, Y.A. and D.D. Metcalfe, Mast cell-T cell interactions. J Allergy Clin Immunol, 1999. 104(3 Pt 1): p. 517-23.

107. Stevens, R.L., et al., Strain-specific and tissue-specific expression of mouse mast cell secretory granule proteases. Proc Natl Acad Sci U S A, 1994. 91(1): p. 128-32.

108. Friend, D.S., et al., Mast cells that reside at different locations in the jejunum of mice infected with Trichinella spiralis exhibit sequential changes in their granule ultrastructure and chymase phenotype. J Cell Biol, 1996. 135(1): p. 279-90.

109. Pages, F., et al., Effector memory $T$ cells, early metastasis, and survival in colorectal cancer. N Engl J Med, 2005. 353(25): p. 2654-66.

110. Galon, J., et al., Type, density, and location of immune cells within human colorectal tumors predict clinical outcome. Science, 2006. 313(5795): p. $1960-4$. 
111. Jochems, C. and J. Schlom, Tumor-infiltrating immune cells and prognosis: the potential link between conventional cancer therapy and immunity. Exp Biol Med (Maywood), 2011. 236(5): p. 567-79.

112. Nakanishi, Y., et al., CD8(+) $T$ lymphocyte mobilization to virus-infected tissue requires CD4(+) T-cell help. Nature, 2009. 462(7272): p. 510-3.

113. Savino, B., et al., Control of murine Ly6C(high) monocyte traffic and immunosuppressive activities by atypical chemokine receptor D6. Blood, 2012. 119(22): p. 5250-60.

114. McKimmie, C.S., et al., An analysis of the function and expression of D6 on lymphatic endothelial cells. Blood, 2013. 121(18): p. 3768-77.

115. Thompson, E.D., et al., Tumor masses support naive $T$ cell infiltration, activation, and differentiation into effectors. J Exp Med, 2010. 207(8): p. 1791-804.

116. Hanahan, D. and R.A. Weinberg, Hallmarks of cancer: the next generation. Cell, 2011. 144(5): p. 646-74.

117. Fridman, W.H., et al., The immune contexture in human tumours: impact on clinical outcome. Nat Rev Cancer, 2012. 12(4): p. 298-306.

118. Galon, J., et al., The immune score as a new possible approach for the classification of cancer. J Transl Med, 2012. 10: p. 1. 


\title{
CURRICULUM VITAE
}

\author{
SOBHA R BODDULURI \\ 4024 Whiteblossom Estates Court \\ Louisville, KY 40241 \\ Home: (502) 425-7835 \\ Email: soboddu1@gmail.com
}

\section{ACADEMIC QUALIFICATIONS}

$\begin{array}{llll}\text { University of Louisville } & \text { Ph.D. candidate } & \text { 2008-present } & \text { Microbiology \& Immunology } \\ \text { University of Louisville } & \text { M.S } & 2008-2011 & \text { Microbiology \& Immunology } \\ \text { Hunter College, CUNY } & \text { M.Phil. } & 1994 & \begin{array}{r}\text { Biology (Molecular, Cellular \& } \\ \text { Developmental Biology) }\end{array} \\ \text { Allahabad University } & \text { M.S. } & 1978 & \text { Agricultural Biochemistry } \\ \text { Andhra University } & \text { B.S. } & 1976 & \text { Chemistry \& Biology }\end{array}$

\section{PROFESSIONAL EXPERIENCE}

\section{Research Manager Jan 2001-July2001}

James Graham Brown Cancer Center, U of L, Louisville, KY

- Characterized the expression of HIV gp120 protein in QT6 cells and developed a purification procedure for structural studies.

\section{Laboratory Research Analyst III Feb. 1999-Sep 2000}

Department of Medicine, Duke University Medical Center, Durham, NC.

- Cloning, expression and purification of novel and known chemokines and testing their biological function. Mapping of chemokine genes in mice.

\section{Laboratory Research Analyst III Dec. 1996-Feb 1999}

Department of Cell Biology, Duke University Medical Center, Durham, NC. 
- Study of endocytic pathways of $G$ protein-coupled receptors, operation of a bioreactor for large-scale Sf9 cell culture and expression of receptors, Cloning and expression of GST-fusion proteins.

\section{Laboratory Research Analyst II Sep. 1994- Nov 1996}

Department of Biochemistry, Duke University Medical Center, Durham, NC.

- Developed a procedure for large-scale expression of protein farnesyl transferase in Sf9 cells and scaled up the protein purification for crystallization, laboratory management.

Graduate Student Sep. 1987- Dec. 1992

Department of Biological Sciences, Hunter College, CUNY, New York.

- Characterization of the DNA-Protein Interactions in a cAMP Regulated Gene of Dictyostelium discoideum, isolated complete cDNA clones for Protein Phosphatase 2A.

\section{Senior Laboratory Technician Oct. 1984- July 1987}

Department of Pediatrics and Medicine, The Johns Hopkins School of Medicine, Baltimore, MD.

- Purification of mitochondrial creatine kinase from chicken hearts, Purification of apolipoprotein-E from VLDL, measuring the effect of hyperoxia on endothelial cell proliferation.

Junior Research Fellow Jan. 1982- Dec. 1983

Department of Microbiology and Cell Biology, Indian Institute of Science, Bangalore, India.

- Propagation of Eucalyptus and Sandalwood by tissue culture.

\section{TEACHING EXPERIENCE:}

Fall 1989 Molecular biology laboratory course, Hunter College, CUNY. 


\section{RESEARCH EXPERIENCE}

Over the years my research projects involved use of a variety of cell and molecular biology techniques as well as protein expression, purification, biochemical characterization and crystallization for structural studies. Some specific projects are outlined below.

One project involved cloning and expression of novel chemokine genes to identify their biological functions and for making antibodies.

Previously I worked in a Howard Hughes lab focused on elucidating the mechanisms in mediating internalization of G-protein coupled receptors. I tested the role of various dominant negative endocytic mutants in agonist mediated sequestration of multiple receptors using mammalian cell transfections, flow cytometry and confocal microscopy (PNAS. USA. 95: 7157-7162 (1998).

During my stay in x-ray crystallography lab, I had an opportunity to work as team in collaboration with protein biochemistry group to develop a procedure to produce milligram quantities of protein farnesyl transferase. I was responsible for setting up and operation of a 16-L bioreactor for Sf9 cell growth and protein production. I have purified protein farnesyl transferase by scaling up the DEAE-sephacel, Q-sepharose, phenyl sepharose column chromatography procedures leading to crystal structure of 2.25-angstrom resolution (Science. 275: 1800-1804 (1997). Later I have used this experience to setup a 36-L bioreactor to produce G-protein coupled receptors.

My M.Phil work is on the DNA-Protein interactions in a cAMP Regulated Gene of Dictyostelium discoideum. These studies identified two major DNA-protein complexes $\mathrm{C} 2$ and $\mathrm{C} 3$, resulting from proteins binding to the AT rich region (BASAL) of a developmentally regulated gene were detected using gel mobility shift assays. The BASAL binding factor (BBF1) involved in forming the C3 complex, was further purified to near homogeneity. BBF1 was identified as a $60-\mathrm{kDa}$ protein by glycerol gradient analysis of the native protein and by SDS gel electrophoresis of the protein UV cross-linked to its target DNA. The protein involved in the formation of the C2 complex was purified and identified as a 34-43 kDa protein (BBF2) by glycerol gradient analysis and UV cross-linking. Mutational analysis shows that BBFI binds in the $5^{\prime}$ half of the BASAL region and BBF2 binds in the 3' half.

PhD Dissertation Project: Chronic inflammation in known to promote cancer of various organs and recent studies also point to a critical role for inflammation in immunosurveillance of cancer. Chemokines are key mediators of inflammation and therefore are likely to play an important role in promoting chronic inflammation and/or tumor-eradicating immunosurveillance mechanisms. D6 is a chemokine decoy receptor that scavenges many chemokines to regulate tissue inflammation. My project is to identify the immune mechanisms involved in the reduction of tumor burden in $\mathrm{D6}^{-1-} \mathrm{Apc}^{\mathrm{Min} /+}$ mice and initial experiments lead to the hypothesis that mast cells play a protective role in intestinal tumorogenesis. Details of this research are the subject matter of the current dissertation. 


\section{PUBLICATIONS}

Zhang, J., Ferguson, S.S.G., Barak, L.S., Bodduluri, S.R., Laporte, S.A., Law, P-Y. and Caron M.G. Role for G-Protein Coupled Receptor Kinase in agonist-Specific Regulation of u-Opoid Receptor Responsiveness. Proc. Natl. Acad. Sci. USA. 95: 7157-7162 (1998)

Park. H-W., Boduluri, S.R., Moomaw, J.F., Casey, P. J., and Beese. L.S. Crystal Structure of Protein Farnesyltransferase at 2.25 Angstrom Resolution. Science. 275: 1800-1804 (1997)

Haribabu, B., Pavlovic, J., Bodduluri, S.R., Doody, J.F., Ortiz, B.D., Mullings, S., Moon, B and Dottin, R.P. Signal Transduction Pathways Involved in the Expression of the UDP Glucose pyrophosphorylase gene of Dictyostelium discoideum. Dev. Gen. 12: 35-44, (1991).

Dottin, R.P., Bodduluri, S.R., Doody, J.F. and Haribabu, B. Signal Transduction and Gene Expression in Dictyostelium discoideum. Dev. Gen. 12: 2-5, (1991).

Lakshmi Sita, G. Sobha Rani, B. and Shankara Rao, K. Propagation of Eucalyptus grandis by Tissue Culture. Eucalyptus in India. (Eds) Sharma, J.K, Nair C.T.S, Kedarnath S \& Kondas, S. 1986.

Lakshmi Sita, G. and Sobha Rani, B. In Vitro Propagation of Eucalyptus grandis. Plant Cell Reports. Vol 4: 63-65, 1985.

Lakshmi Sita, G. and Sobha Rani, B . Preliminary studies on isolation and culture of protoplasts from Sandalwood (Santalum Album). 6th International Protoplast Symposium, Basel, Aug 12-16 1983, Experientia suplimentum, Vol 45: 4-5, 1983.

\section{Manuscripts:}

Jala VR, Maturu P, Krishnan E, Mathis S, Bodduluri SR, Wang, M, Jenson B, Procter M, Knight $R$ and Haribabu B. Host Dependent Reshaping of Gut Microbiome Controls Colon Cancer Development in Mice to be submitted 2013.

Bodduluri SR, Mathis S, Maturu P, Krishnan E, Satpathy, S, Smith ME, Chilton P, Mitchell T, Lira, S, Locati M, Mantovani A, and Haribabu B and V R Jala. Mast cell-T cell Interactions Regulate Inflammatory Chemokine Mediated Immune Surveillance of Intestinal Cancer to be submitted 2013.

Bodduluri SR, Jala, VR and Haribabu, B. Absence of the Chemokine Decoy Receptor D6 Accelerates Dextran Sodium Sulphate Promoted Colon Cancer in the APC ${ }^{\mathrm{Min} /+}$ mice. To be submitted 2013. 